Construção semi-automática de taxonomias para generalização de regras de associação 



\title{
Construção semi-automática de taxonomias para generalização de regras de associação
}

\author{
Camila Delefrate Martins
}

Orientadora: Profa. Dra. Solange Oliveira Rezende

Dissertação apresentada ao Instituto de Ciências Matemáticas e de Computação - ICMC-USP, como parte dos requisitos necessários para obtenção do título de Mestre em Ciências de Computação e Matemática Computacional.

\section{"VERSÃO REVISADA APÓS DEFESA"}

Data da Defesa: 14/07/2006

Visto do Orientador:

USP - São Carlos

Setembro/2006 



\section{Dedicatória}

Aos meus pais

Homero e Célia, ao meu irmão Guilherme e ao meu amor, Leandro. 



\section{Agradecimentos}

Aos meus pais, Homero e Célia que, além de me darem as oportunidades para mais essa conquista, deram também amor, carinho, educação, broncas, incentivo e confiança. Ao meu irmão Guilherme, pelo carinho e pelas diversas discussões sobre computação, que a mãe não entende.

Ao meu amor Leandro, por aguentar os momentos difíceis e pelo incentivo, mesmo quando resolvi ir para bem longe. Também por todo amor e por me ajudar a enxergar meu potencial nos rompantes de insegurança.

À minha orientadora Solange Rezende, por ter me dado o primeiro voto de confiança. Foi assim que tudo começou e à ela também devo essa conquista. Obrigada por participar da minha vida pessoal e profissional, com toda a sua sabedoria e carinho. Você é uma inspiração para todas as mulheres que desejam sucesso profissional.

À professora Maria Carolina Monard, pelo incentivo desde a época da graduação, pelo carinho e atenção de sempre. Também pela maravilhosa oportunidade de ir para a Espanha.

À toda a minha família, incluindo a agregada, pelo amor e boas conversas. Meus avós, meus tios e tias, meus primos e primas, meus sogros, meus cunhados e cunhadas, minha con-cunhada, que também sempre me incentivaram e ajudaram à sua maneira. Em especial à Barbara, por ajudar na avaliação da taxonomia.

Ao Anand, por passar noites corrigindo artigos em inglês e pela revisão do abstract.

Aos alunos e ex-alunos da professora Solange, Edson Melanda, Jaqueline Pugliesi, Marcos Domingues, Marcos Paula, Maria Fernanda Moura e Walter Nagai pela ajuda e pelas ótimas festinhas na casa da Solange. Às amigas Magaly Fujimoto, Marina Pivato, Roberta Sinoara e Veronica Carvalho pelas discussões que trouxeram conhecimento e muitas constribuições para este trabalho. À Giselle Cantador pela disposição e paciência na procura constante pela nossa orientadora.

À todos do LABIC, por fazerem o ambiente do nosso laboratório tão especial. Aos colegas Edson, Jean, Richardson e Ronaldo por sempre estarem dispostos a ajudar e pelas sugestões. Ao professor Alneu de Andrade Lopes, pelo interesse e idéias para este trabalho.

Às minhas amigas de toda a vida, Carolina Alves, Carolina Codá, Flávia Küll e Marília Bueno pelo carinho de tantos anos, pelos conselhos e por entenderem a minha ausência nos últimos tempos.

Aos meus amigos de graduação, que me proporcionaram tantos momentos inesquecíveis durante os 4 anos em que estudamos juntos. 
Aos meus amigos da pós-graduação, por tantos momentos de descontração e por aguentarem minhas palavras trocadas no final do mestrado. Às minhas grandes amigas, Débora Medeiros e Paula Herculano pelo carinho, dedicação e por aguentarem uma amiga "workaholic".

Às minhas "compañeras de piso", Lauren e Sarah pela amizade, apoio e cumplicidade conquistados em poucos meses morando juntas. Em um país tão diferente, o carinho de vocês me fortaleceu e me ajudou a concluir meu trabalho na nossa Espanha.

Aos funcinários do ICMC, pela atenção, respeito e dedicação.

À Universidade de São Paulo, pela oportunidade e pela qualidade do ensino e pesquisa.

Ao CNPq, pelo apoio financeiro que permitiu a realização deste trabalho. 


\section{Resumo}

$\mathcal{P}$

ara o sucesso do processo de mineração de dados é importante que o conhecimento extraído seja compreensível e interessante para que o usuário final possa utilizá-lo em um sistema inteligente ou em processos de tomada de decisão. Um grande problema, porém, é identificado quando a tarefa de mineração de dados denominada associação é utilizada: a geração de um grande volume de regras. Taxonomias podem ser utilizadas para facilitar a análise e interpretação das regras de associação, uma vez que as mesmas provêm uma visão de como os itens podem ser hierarquicamente classificados. Em função dessa hierarquia é possível obter regras mais gerais que representem um conjunto de itens. Dentro desse contexto, neste trabalho é apresentada uma metodologia para construção semi-automática de taxonomias, que inclui procedimentos automáticos e interativos para a realização dessa tarefa. Essa combinação possibilita a utilização do conhecimento do especialista e também o auxilia na identificação de grupos. Entre os principais resultados deste trabalho, pode-se destacar a proposta e implementação do algoritmo SACT (Semi-automatic Construction of Taxonomies - Construção Semi-automática de Taxonomias), que provê a utilização da metodologia proposta. Para viabilizar a utilização do algoritmo, foi desenvolvido o módulo computacional RuLEESACT. Com o objetivo de viabilizar e analisar a qualidade da metodologia proposta e do módulo desenvolvido, foi realizado um estudo de caso no qual foram construídas taxonomias para duas bases de dados utilizando o RuLEE-SACT. Uma das taxonomias foi analisada e validada por uma especialista do domínio. Posteriormente, as taxonomias e as bases de transações foram fornecidas para dois algoritmos de generalização de regras de associação a fim de analisar a aplicação das taxonomias geradas. 



\section{Abstract}

$I$ $\mathrm{n}$ the data mining process it is important that the extracted knowledge is understandable and interesting to the final user, so it can be used to support in the decision making. However, the data mining task named association has one problem: it generates a big volume of rules. Taxonomies can be used to facilitate the analysis and interpretation of association rules, because they provide an hierarchical vision of the items. This hierarchy enables the obtainment of more general rules, which represent a set of items. In this context, a methodology to semi-automatically construct taxonomies is proposed in this work. This methodology includes automatic and interactives procedures in order to construct the taxonomies, using the specialist's knowledge and also assisting in the identification of groups. One of the main results of this work is the proposal and implementation of the SACT (Semi-automatic Construction of Taxonomies) algorithm, which provides the use of the proposed methodology. In order to facilitate the use of this algorithm, a computational module named RuLEE-SACT was developed. Aiming to analyze the viability and quality of the proposed methodology and the developed module, a case study was done. In this case study, taxonomies of two databases were constructed using the RULEE-SACT. One of them was analyzed and validated by a domain specialist. Then the taxonomies and the databases were supplied to two algorithms which generalize association rules, aiming to analyze the use of the generated taxonomies. 



\section{Sumário}

Sumário

xiii

Lista de Figuras

xvii

Lista de Tabelas $\quad$ xix

$\begin{array}{ll}\text { Lista de Siglas } & \text { xxi }\end{array}$

1 Introdução 1

1.1 Hipótese . . . . . . . . . . . . . . . . . . . . . . . . . . 3

1.2 Objetivos Gerais . . . . . . . . . . . . . . . 3

1.3 Objetivos Específicos . . . . . . . . . . . . . . . 3

1.4 Organização . . . . . . . . . . . . . . . . . . . . 4

2 Mineração de Dados e Associação 5

2.1 Mineração de Dados . . . . . . . . . . . . . . . . . . . . . . . 5

2.1.1 Conceitos e Definições . . . . . . . . . . . . . . . 6

2.1.2 O Processo de Mineração de Dados . . . . . . . . . . . . . . . . 6

2.1.3 Considerações sobre Mineração de Dados . . . . . . . . . . . . . . . 10

2.2 Associação . . . . . . . . . . . . . . . . . . . . . . 11

2.2.1 Conceitos e Definições . . . . . . . . . . . . . . . . . . . . 11

2.2.2 Geração de itemsets freqüentes . . . . . . . . . . . . . . . . . . . . 13

2.2.3 Desafios da Aplicação de Associação . . . . . . . . . . . . . . . . . 17

2.3 Considerações Finais . . . . . . . . . . . . . . . . . . . . . . 17

3 Taxonomias para Generalização de Regras de Associação e Trabalhos $\begin{array}{lr}\text { Relacionados } & 19\end{array}$

3.1 Taxonomias . . . . . . . . . . . . . . . . . . . . . . . . . . 19

3.1 .1 Conceitos e Definições . . . . . . . . . . . . . . . . . . 21

3.1.2 Uso de Taxonomias na Generalização de Regras de Associação . . 22 
3.1.3 Importância da Construção Semi-automática de Taxonomias . . . . 26

3.2 Trabalhos Relacionados Desenvolvidos no LABIC . . . . . . . . . . . . . 26

3.2.1 Ambiente RulEE . . . . . . . . . . . . . . . . . . 27

3.2 .2 Módulo RulEE-GAR . . . . . . . . . . . . . . . . . . . . . 29

3.2.3 Generalização de Regras de Associação Usando Taxonomias . . . . 32

3.3 Considerações Finais . . . . . . . . . . . . . . . . . . . . . . . . . . . . . . 33

4 Metodologia para Construção Semi-automática de Taxonomias para Generalização de Regras de Associação 35

4.1 Metodologia Proposta . . . . . . . . . . . . . . 36

4.2 Considerações sobre a Metodologia . . . . . . . . . . . . . . . . 40

4.3 Módulo de Construção Semi-automática de Taxonomias para Generalização de Regras de Associação - RulEE-SACT . . . . . . . . . . . . . . . . . . 41

4.3 .1 Requisitos . . . . . . . . . . . . . . . . . . 42

4.3 .2 Repositório . . . . . . . . . . . . . . . . . . . 42

4.3 .3 Classes . . . . . . . . . . . . . . . . . . . . . 44

4.3.4 Definição e Tratamento dos Dados de Entrada . . . . . . . . . . . . 44

4.3 .5 Visão Geral do Algoritmo $S A C T$. . . . . . . . . . . . . . . . . . 44

4.3.6 Descrição do Processo de Construção Semi-automática de Taxonomias no Módulo RulEE-SACT . . . . . . . . . . . . . . . . . . 47

4.4 Considerações Finais . . . . . . . . . . . . . . . . . . . . . . 54

5 Estudo de Caso $\quad 57$

5.1 Primeira Fase: Análise dos Dados . . . . . . . . . . . . . . . . . . . 58

5.1 .1 Descrição das Bases de Dados . . . . . . . . . . . . . . . . . . 58

5.1 .2 Preparação dos Dados para o Módulo RulEE-SACT . . . . . . . . 59

5.2 Segunda Fase: Construção das Taxonomias . . . . . . . . . . . . . . . . . . 60

5.2.1 Utilização do RulEE-SACT . . . . . . . . . . . . . . . . . . 61

5.2 .2 Taxonomias Geradas . . . . . . . . . . . . . . . . . . 64

5.3 Terceira Fase: Análise dos Resultados . . . . . . . . . . . . . . . . 65

5.4 Considerações Finais . . . . . . . . . . . . . . . . . . . . . . . . 67

6 Conclusões e Trabalhos Futuros 69

$\begin{array}{ll}\text { Referências Bibliográficas } & 73\end{array}$

$\begin{array}{ll}\text { A Documento de Requisitos do RulEE-SACT } & 79\end{array}$

A.1 Introdução . . . . . . . . . . . . . . . . . . . . . . . . . . . . . 79

A.1.1 Escopo . . . . . . . . . . . . . . . . . . . . . 79

A.1.2 Definições, Acrônimos e Abreviações do Documento de Requisitos . 80

A.2 Descrição Geral do RulEE-SACT . . . . . . . . . . . . . . . . . . . 81 
A.2.1 Funções do Módulo . . . . . . . . . . . . . . . . . . . . . . . . . . . 81

A.2.2 Características dos Usuários . . . . . . . . . . . . . . . . . . 81

A.2.3 Suposições e Dependências . . . . . . . . . . . . . . . . . . . . . . 82

A.3 Requisitos Específicos . . . . . . . . . . . . . . . . . . . . . 82

A.3.1 Requisitos Funcionais . . . . . . . . . . . . . . . . 82

A.3.2 Requisitos de Desempenho . . . . . . . . . . . . . . . . 85

A.4 Consideraçõs Finais . . . . . . . . . . . . . . . . . . . . . . . 85 



\section{Lista de Figuras}

2.1 Etapas do processo de mineração de dados . . . . . . . . . . . . . . . . . . 7

2.2 Espaço de busca para o conjunto de itens $A=\{a, b, c, d, e\} \ldots$. . . . . 14

2.3 Separação de itemsets freqüentes e não-freqüentes no espaço de busca de $A=\{a, b, c, d, e\} \ldots \ldots \ldots \ldots \ldots$

3.1 Parte de uma ontologia para o diagnóstico de câncer de mama . . . . . . . 20

3.2 Exemplo de uma taxonomia para vestuário . . . . . . . . . . . . . . . . 22

3.3 Arquitetura geral do ambiente RulEE . . . . . . . . . . . . . . . 28

3.4 Contextualização e funcionalidades do módulo computacional RuLEE-GAR no protótipo do ambiente RulEE . . . . . . . . . . . . . . . . 30

3.5 Processo para generalização de regras de associação no algoritmo GART . 31

3.6 Exemplo de uma listagem de contribuição dos itens . . . . . . . . . . . . . . 33

4.1 Metodologia para construção semi-automática de taxonomias para generalização de regras de associação . . . . . . . . . . . . . . . . . . . . . . . . . . 37

4.2 Parte do diagrama físico da base de dados do RulEE . . . . . . . . . . . . . 43

4.3 Exemplo de um arquivo texto de entrada do módulo RULEE-SACT para um domínio de supermercado . . . . . . . . . . . . . . . . . . . . . . . 44

4.4 Criação de um processo de construção semi-automática de taxonomias no RULEE-

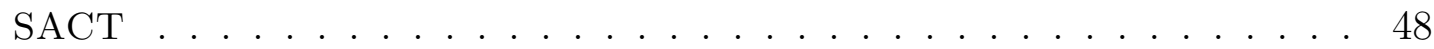

4.5 Seleção dos itens freqüentes no RulEE-SACT . . . . . . . . . . . . . . . . . 49

4.6 Visualização dos elementos e seus atributos no RulEE-SACT . . . . . . . . 49

4.7 Geração da taxonomia inicial no RulEE-SACT . . . . . . . . . . . . . . . . 50

4.8 Geração da taxonomia inicial, visualização da taxonomia e obtenção do arquivo com a taxonomia no formato padrão do RULEE-SACT . . . . . . . . . . . . . 51

4.9 Deslocamento de um item RulEE-SACT . . . . . . . . . . . . . . . . . . . . . . 51

4.10 Reagrupamento de acordo com um atributo no RULEE-SACT . . . . . . . . . 52

4.11 Inserção de nova informação (atributo) no RULEE-SACT . . . . . . . . . . 53

4.12 Criação de um novo item da taxonomia no RULEE-SACT . . . . . . . . . . . 53 
4.13 Visualização da taxonomia com o novo item criado no RULEE-SACT . . . . . 54

5.1 Parte da taxonomia gerada utilizando o módulo RULEE-SACT para a base de dados do supermercado . . . . . . . . . . . . . . . . . . 65

5.2 Parte da taxonomia gerada utilizando o módulo RuLEE-SACT para a base de dados da mercearia . . . . . . . . . . . . . . . . . 65 


\section{Lista de Tabelas}

2.1 Relação de itens comprados por transação do Exemplo 1 . . . . . . . . . . 15

2.2 Itemsets freqüentes do Exemplo $1 \ldots \ldots$. . . . . . . . . . . . . 16

2.3 Regras geradas no Exemplo $1 \ldots \ldots$. . . . . . . . . . . . . 16

2.4 Problema do volume de regras de associação . . . . . . . . . . . . . . . 17

3.1 Relação de itens comprados por transação do Exemplo 2 . . . . . . . . . . 24

4.1 Descrição das tabelas criadas para o RULEE-SACT . . . . . . . . . . . . . . . 43

4.2 Descrição dos principais métodos da classe SACT . . . . . . . . . . . . . . . 45

5.1 Parte do conjunto de dados resultante, com dois atributos, da base de dados do supermercado . . . . . . . . . . . . . . . . . . . 59

5.2 Parte do conjunto de dados resultante da base de dados da mercearia . . . . . . 60 



\section{Lista de Siglas}

LABIC Laboratório de inteligência computacional

RulEE

Ambiente para exploração de regras (Rule Exploration Environment)

RulEE-GAR Módulo de generalização de regras de associação usando taxonomias ( $G e$ -

$\mathcal{A R I n E}$ neralization of Association Rules using Taxonomies)

$\begin{array}{ll}\text { ment for Association Rules Interactive Exploration) } \\ \text { RulEE-SACT } & \text { Módulo de construção semi-automática de taxonomias (Semi-automatic }\end{array}$ Construction of Taxonomies)

RulEE-SEAR Exploração subjetiva de regras de associação (Subjective Exploration of Association Rules)

GART Algoritmo de generalização de regras de associação usando taxonomias (Generalization of Association Rules using Taxonomy)

SACT Algoritmo de construção semi-automática de taxonomias (Semiautomatic Construction of Taxonomies) 



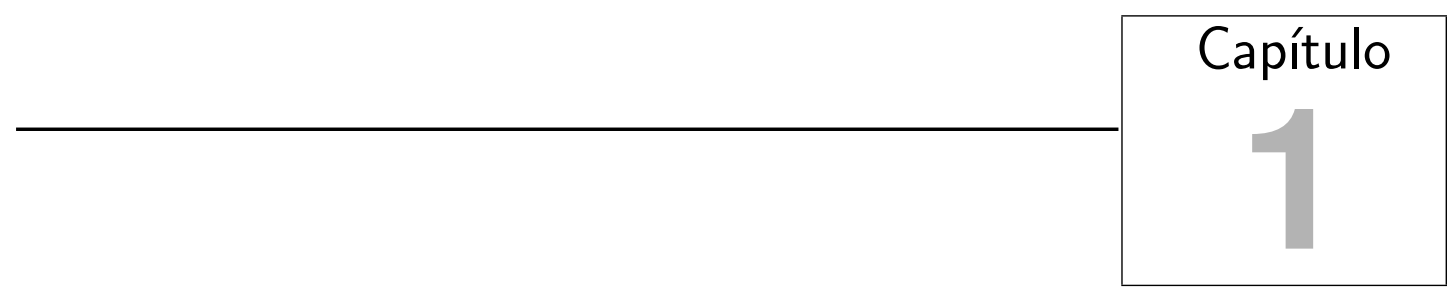

\section{Introdução}

objetivo do processo de mineração de dados é encontrar conhecimento a partir de um conjunto de dados para ser utilizado em um processo de tomada de decisão ou em um sistema inteligente. Portanto, é importante que esse conhecimento descoberto seja compreensível e interessante para os usuários finais, a fim de fornecer suporte no processo de tomada de decisão (Rezende, Pugliesi, Melanda, \& Paula, 2003). Entretanto um dos problemas encontrados no processo de mineração de dados é que, muitas vezes, os modelos extraídos são muito complexos ou não fazem sentido para os usuários especialistas do domínio em que o processo de mineração de dados está sendo aplicado (Pazzani, 2000). A fim de facilitar a compreensão dos modelos é comum a utilização de regras como linguagem para representação do conhecimento.

No caso da utilização de regras, tem sido identificado um outro problema. Muitos dos algoritmos de extração geram uma enorme quantidade de padrões, dos quais, em geral, poucos são realmente interessantes para o usuário (Padmanabhan \& Tuzhilin, 2000). Esse problema se apresenta com freqüência quando é aplicada a tarefa de mineração de dados denominada associação. Essa tarefa tem como objetivo descobrir o quanto um conjunto de itens presentes em um registro de uma base de dados implica na presença de algum outro conjunto distinto de itens no mesmo registro (Agrawal \& Srikant, 1994). Com a extração de regras de associação é possível descobrir todas as associações existentes nas transações de uma base de dados, o que pode levar à geração de um grande número de regras, sobrecarregando os usuários finais e dificultando a identificação de conhecimento interessante.

Com o objetivo de facilitar a interpretação das regras de associação, taxonomias podem ser utilizadas. As taxonomias refletem uma caracterização coletiva ou individual de como os itens (ou seja, os elementos do domínio de uma aplicação) podem ser hierarquicamente 
classificados. Em função dessa hierarquia é possível obter regras mais gerais que representem um conjunto de itens (por exemplo, o conjunto formado por todas as marcas de café).

Nesse contexto, foi desenvolvido no Laboratório de Inteligência Computacional (LA$\mathrm{BIC}^{1}$ ) do Instituto de Ciências Matemáticas e de Computação da Universidade de São Paulo (ICMC-USP ${ }^{2}$ ) o algoritmo GART (Generalization of Association Rules using Taxonomies - Generalização de Regras de Associação Usando Taxonomias), que utiliza taxonomias para generalizar regras de associação na etapa de pós-processamento do conhecimento com o intuito de eliminar regras não interessantes e/ou redundantes. Dessa maneira, o grande volume de conhecimento gerado é reduzido (Domingues, 2004). Nesse trabalho também foi desenvolvido o módulo RULEE-GAR para prover a utilização desse algoritmo, além de fornecer funcionalidades para análise de regras generalizadas.

Atualmente, está em desenvolvimento um trabalho que visa explorar o uso de taxonomias para generalizar regras de associação nas três etapas do ciclo principal do processo de mineração de dados (Carvalho, 2004): pré-processamento, extração de padrões e pósprocessamento. Para que a generalização das regras seja realizada utilizando os trabalhos citados, o usuário deve fornecer as taxonomias. A construção manual das mesmas representa um alto custo, uma vez que consome muito tempo e exige profundo conhecimento do domínio da aplicação. Por outro lado, uma construção completamente automática pode não ser uma solução interessante, uma vez que a intervenção do especialista é interessante para analisar os grupos encontrados e guiar .

Dessa maneira, é proposta neste trabalho uma metodologia para construção semiautomática de taxonomias a partir de bases de dados, a qual foi implementada no algoritmo SACT (Semi-automatic Construction of Taxonomies - Construção Semi-automática de Taxonomias). A metodologia inclui procedimentos automáticos e interativos, utilizando o conhecimento do especialista e também auxiliando a construção das taxonomias. Assim, o conhecimento e esforço necessários para a realização dessa tarefa são reduzidos, provendo rapidez e a obtenção de boas taxonomias. Também é apresentado o módulo RULEE-SACT, desenvolvido com o objetivo de viabilizar a utilização do algoritmo $S A C T$, além de fornecer funcionalidades para análise e exploração das taxonomias geradas. O RulEE-SACT é um dos módulos de pós-processamento do ambiente RulEE (Rule Exploration Environment - Ambiente para Exploração de Regras). Esse ambiente é utilizado para exploração de regras de classificação, regressão e associação, cujo projeto e protótipo também foram desenvolvidos por pesquisadores do LABIC (Paula, 2003).

A hipótese que guiou o desenvolvimento deste trabalho é apresentada a seguir. Em seguida, são apresentados os objetivos gerais e específicos e a organização desta dissertação.

\footnotetext{
${ }^{1}$ http://labic.icmc.usp.br

${ }^{2}$ http://www.icmc.usp.br
} 


\subsection{Hipótese}

A motivação para o desenvolvimento deste trabalho foi baseada na hipótese de que é possível construir taxonomias a partir de bases de dados, combinando métodos automáticos e interativos de maneira que sejam obtidas taxonomias novas e de boa qualidade que possam ser utilizadas no processo de generalização de regras de associação. Essa construção semi-automática também pode reduzir o tempo e a necessidade do conhecimento do especialista durante a identificação de taxonomias de um domínio, provendo rapidez durante a realização dessa tarefa e melhorando a compreensão do conhecimento extraído.

\subsection{Objetivos Gerais}

O trabalho descrito nesta dissertação tem os seguintes objetivos gerais:

- Verificar os benefícios da construção semi-automática de taxonomias na identificação de taxonomias novas e de boa qualidade para a generalização de regras de associação;

- Reduzir o tempo gasto e a necessidade do conhecimento do especialista na identificação de taxonomias;

- Disponibilizar uma nova funcionalidade para o ambiente RULEE.

\subsection{Objetivos Específicos}

Os objetivos específicos deste trabalho são:

- Propor uma metodologia para construção de taxonomias a partir de bases de dados que combine métodos automáticos e interativos;

- Desenvolver um módulo computacional, integrado ao RuLEE, para apoiar a utilização da metodologia proposta e fornecer funcionalidades para análise das taxonomias geradas;

- Realizar um estudo de caso completo utilizando o módulo desenvolvido para gerar taxonomias e utilizá-las para generalizar regras de associação, a fim de verificar a aplicação da metodologia proposta para esse problema.

- Fornecer ao RulEE uma interface para construção de taxonomias e para o compartilhamento de conhecimento entre usuários de um mesmo projeto. 


\subsection{Organização}

Esta dissertação está dividida em 6 capítulos. Nesse primeiro capítulo foi apresentado o contexto em que se insere este trabalho, bem como a hipótese que guiou seu desenvolvimento e seus objetivos.

No Capítulo 2 é descrito o processo de mineração de dados, sendo apresentados suas etapas e os usuários que participam desse processo. A associação, uma das tarefas da mineração de dados, também é descrita nesse capítulo, visto que é o foco deste trabalho. Além disso, são discutidos os desafios da aplicação do processo de mineração de dados e da associação em bases de dados reais.

No Capítulo 3 são abordados os conceitos e definições de taxonomias, sua utilização em regras de associação e uma discussão sobre a importância da construção semi-automática de taxonomias na generalização de regras de associação. Também são apresentados nesse capítulo os trabalhos desenvolvidos no LABIC que estão relacionados com o uso de taxonomias para generalizar regras de associação.

No Capítulo 4 é descrita a metodologia para construção semi-automática de taxonomias proposta neste trabalho, bem como o módulo computacional RULEE-SACT desenvolvido para viabilizar a utilização dessa metodologia.

No Capítulo 5 é apresentado um estudo de caso desenvolvido com o objetivo de validar a metodologia proposta e mostrar sua utilização no problema de generalização de regras de associação. Esse estudo de caso foi realizado com base de dados reais e, após a identificação das taxonomias desses domínios, as mesmas foram utilizadas para generalizar regras de associação com o objetivo de avaliar a metodologia.

No Capítulo 6 são apresentadas as conclusões deste trabalho e propostas para trabalhos futuros. 


-

\section{Mineração de Dados e Associação}

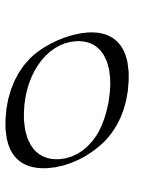

uso de métodos manuais para análise e obtenção de conhecimento a partir de dados torna essa tarefa dispendiosa (em termos financeiros e de tempo), totalmente subjetiva e inviável quando aplicada a grandes bases de dados. Nesse contexto, técnicas especializadas de extração automática de conhecimento têm sido desenvolvidas sob o nome de extração de conhecimento de bases de dados, geralmente referenciado na literatura como knowledge discovery in database (KDD), data mining (DM) ou mineração de dados (MD).

Neste capítulo é apresentada uma visão geral do processo de mineração de dados e de uma de suas tarefas, a associação. Essa tarefa é foco deste trabalho e tem recebido grande atenção, seja na área acadêmica ou em aplicações práticas, em função de sua aplicabilidade a problemas de negócio (Antonie \& Zaane, 2004; Oliveira, Zaane, \& Saygin, 2004; Besemann, Denton, Yekkirala, Hutchison, \& Anderson, 2004; Aggelis, 2004; Hipp, Güntzer, \& Nakhaeizadeh, 2002).

\subsection{Mineração de Dados}

A mineração de dados é uma área multidisciplinar que incorpora técnicas utilizadas em diversas áreas como Inteligência Artificial (especialmente Aprendizado de Máquina), Base de Dados e Estatística. Por isso, as técnicas utilizadas em mineração de dados não devem ser vistas como substitutas de outras formas de análises (por exemplo, data warehousing e online analytical processing), mas como práticas para melhorar os resultados das explorações feitas com essas ferramentas. 


\subsubsection{Conceitos e Definições}

O processo de mineração de dados, ou seja, o processo de extração de conhecimento a partir de grandes bases de dados, foi definido por Fayyad, Piatetsky-Shapiro, \& Smyth (1996) como o processo de identificação de padrões válidos, novos, potencialmente úteis e compreensíveis embutidos nos dados. Como não se pode esperar a extração de conhecimento útil e compreensível simplesmente submetendo um conjunto de dados a uma "caixa preta" (Mannila, 1996), a mineração de dados é um processo centrado na interação entre diferentes usuários, que geralmente são divididos em três classes (Rezende, Pugliesi, Melanda, \& Paula, 2003), descritas a seguir.

Especialista do domínio: usuário que deve possuir amplo conhecimento do domínio da aplicação e fornecer apoio à execução do processo.

Analista: usuário especialista no processo de mineração de dados e responsável por sua execução. Esse usuário deve conhecer profundamente as etapas que compõem esse processo.

Usuário final: representa os usuários que utilizam o conhecimento extraído no processo de mineração de dados como apoio em tomadas de decisão. Não é necessário que esse usuário possua conhecimento profundo do domínio da aplicação.

O sucesso do processo de mineração de dados depende, em parte, dessa interação. A participação do especialista do domínio e/ou do usuário final tem grande importância na definição dos objetivos e dos dados que serão utilizados no processo de mineração de dados, bem como na avaliação do conhecimento extraído.

\subsubsection{O Processo de Mineração de Dados}

Na Figura 2.1 é apresentado o processo de mineração de dados. Esse processo é iterativo, sendo seu ciclo principal formado por três grandes etapas: pré-processamento, extração de padrões e pós-processamento (Rezende, Pugliesi, Melanda, \& Paula, 2003). Além dessas etapas também devem ser consideradas uma fase anterior ao ciclo, referente à identificação do problema, e outra posterior, referente à utilização do conhecimento obtido. A seguir são descritas todas as etapas do processo de mineração de dados.

\section{Identificação do Problema}

A compreensão do domínio da aplicação é um pré-requisito para a extração de conhecimento útil dos dados. Nessa fase de identificação do problema é realizado um estudo do domínio da aplicação e são definidos os objetivos e metas a serem alcançados com o 


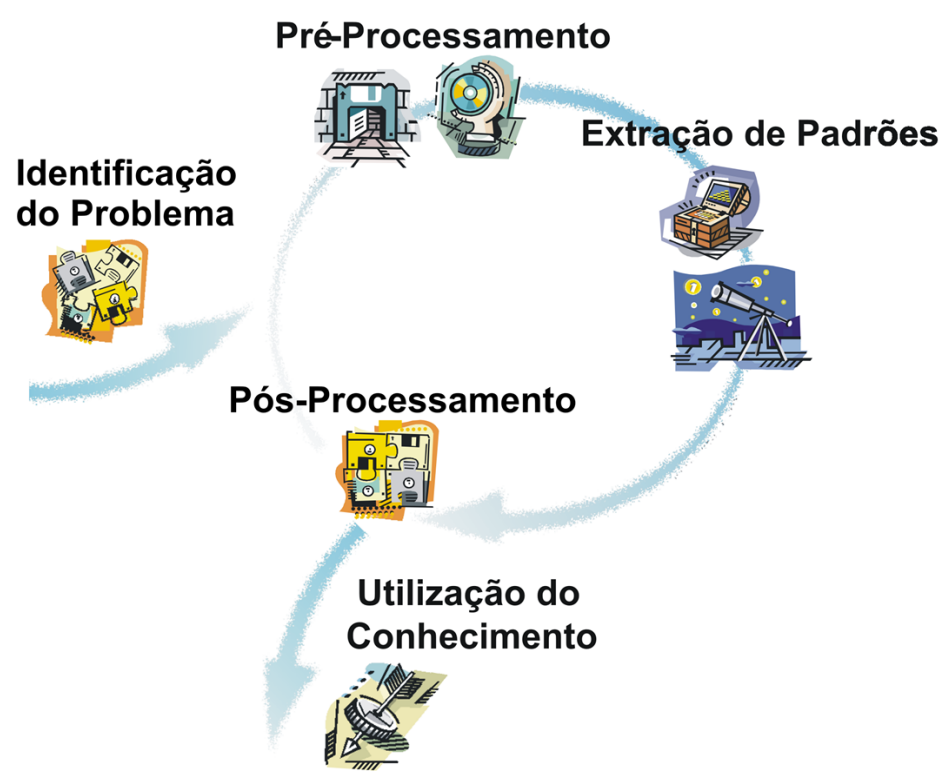

Figura 2.1: Etapas do processo de mineração de dados (Rezende, Pugliesi, Melanda, \& Paula, 2003)

processo de mineração de dados. Também são selecionados os conjuntos de dados a serem utilizados na extração de conhecimento.

Além disso, o conhecimento sobre o domínio adquirido nessa fase pode fornecer subsídio para todas as etapas do processo de mineração de dados (Rezende, Pugliesi, Melanda, \& Paula, 2003). Mais especificamente, na etapa de pré-processamento, esse conhecimento pode ajudar os analistas na escolha do melhor conjunto de dados para realizar a extração de padrões e na identificação de valores válidos para os atributos, de critérios de preferência entre os possíveis atributos, de restrições de relacionamentos ou de informações para geração de novos atributos. Já na etapa de extração de padrões, o conhecimento sobre o domínio pode ajudar os analistas na definição de um critério de preferência entre os modelos gerados, no ajuste dos parâmetros do processo de indução, ou até mesmo na geração de um conhecimento inicial a ser fornecido como entrada para o algoritmo de mineração, com a finalidade de aumentar a eficiência no aprendizado dos conceitos, melhorar a precisão ou a compreensão do modelo final. Na etapa de pós-processamento, o conhecimento extraído pelos algoritmos de extração de padrões deve ser avaliado. Alguns critérios de avaliação utilizam o conhecimento do especialista para saber, por exemplo, se o conhecimento extraído é interessante (Hilderman \& Hamilton, 2001; Liu \& Hsu, 1996; Piatetsky-Shapiro \& Matheus, 1994).

\section{Pré-Processamento}

Geralmente os dados selecionados para o processo de mineração de dados não estão em um formato adequado para a extração de conhecimento. Além disso, durante o pro- 
cesso de coleta de dados podem ocorrer diversos problemas que devem ser tratados, como erros de digitação e geração de dados incorretos ou inconsistentes. A aplicação direta de alguns algoritmos de extração de padrões a todo o conjunto de dados também pode ser impossibilitada por limitações de memória ou tempo de processamento. Assim, geralmente, é necessário tratar os dados antes de realizar a etapa de extração de padrões. Diferentes atividades podem ser realizadas com essa finalidade na etapa de pré-processamento, entre elas: extração e integração (obtenção e unificação desses dados, formando uma única fonte de dados), transformação (resumo, transformação de tipo e normalização de atributos contínuos), limpeza (tratamento de valores inválidos de atributos, de exemplos errôneos, de atributos incompletos, de conjuntos de exemplos não balanceados e remoção de ruído) (Batista, 2003; Batista, Carvalho, \& Monard, 2000) e redução de dados (redução do número de exemplos, do número de atributos e do número de valores de um atributo) (Weiss \& Indurkhya, 1998).

É importante ressaltar que os objetivos do processo de mineração de dados, definidos na fase de identificação do problema, devem sempre guiar a execução das atividades de préprocessamento, de maneira que o conjunto de dados utilizado apresente as características necessárias para se atingir tais objetivos. Além disso, essas atividades devem ser realizadas criteriosamente e com o devido cuidado, garantindo que as informações presentes nos dados originais continuem presentes nas amostras geradas, para que os modelos finais representem o comportamento dos dados originais.

\section{Extração de Padrões}

A etapa de extração de padrões é direcionada ao cumprimento dos objetivos definidos na identificação do problema, com a execução de um ou mais algoritmos para extração de conhecimento. Para atingir esses objetivos, essa etapa deve compreender: a escolha da tarefa de mineração de dados a ser empregada, a escolha do algoritmo e a extração dos padrões propriamente dita.

A escolha da tarefa é feita de acordo com os objetivos do processo de mineração de dados, definidos na fase de identificação do problema. Diferentes tarefas podem extrair diferentes tipos de conhecimento, sendo necessário decidir já no início do processo qual o tipo de conhecimento que o algoritmo deve extrair. As possíveis tarefas da etapa de extração de padrões podem ser agrupadas em atividades preditivas e descritivas. As atividades preditivas consistem na generalização de exemplos ou experiências passadas com respostas conhecidas em um modelo, denominado preditor, capaz de identificar a classe (atributo meta) de um novo exemplo (Weiss \& Indurkhya, 1998). As duas principais tarefas de predição são classificação e regressão. Já as atividades descritivas consistem na identificação de comportamentos intrínsecos do conjunto de dados, sendo que estes dados não possuem uma classe especificada. Algumas das tarefas de descrição são clustering, sumarização e associação. 
A escolha do algoritmo é feita de maneira subordinada à linguagem de representação dos padrões a serem encontrados. Entre os tipos mais freqüentes de representação de padrões destacam-se: árvores de decisão, regras de produção, modelos lineares, modelos não-lineares (redes neurais artificiais), modelos baseados em exemplos (k-nearest neighbour, raciocínio baseado em casos) e modelos de dependência probabilística (redes bayesianas). Segundo Kohavi, Sommerfield, \& Dougherty (1996) não existe um algoritmo que seja mais adequado à qualquer aplicação do processo de mineração de dados. Assim, pode-se utilizar diferentes algoritmos durante a etapa de extração de padrões, gerando vários modelos que serão tratados na etapa de pós-processamento a fim de selecionar um bom modelo para o usuário final.

A extração dos padrões consiste na configuração dos parâmetros e na aplicação dos algoritmos selecionados. É importante ressaltar que, dependendo do problema, podem ser necessárias diversas execuções dos algoritmos.

No caso da tarefa de associação, descrita na Seção 2.2, pode-se realizar apenas uma execução do algoritmo sem comprometer a qualidade do conhecimento extraído. Segundo Zheng, Kohavi, \& Mason (2001), os algoritmos para obter regras de associação devem sempre gerar a mesma solução. Além disso, os parâmetros de entrada utilizados durante a geração das regras são, geralmente, suporte e confiança mínimos, e a alteração desses valores irá apenas incluir ou excluir regras do conjunto de regras extraídas.

Como o processo de mineração de dados é iterativo, pode ser necessário que a etapa de extração de padrões seja executada diversas vezes para ajustar o conjunto de parâmetros do algoritmo de mineração, visando a obtenção de resultados mais adequados aos objetivos pré-estabelecidos. O conjunto de padrões extraídos nessa etapa é disponibilizado para o usuário ou incorporado a um sistema inteligente após ser analisado e/ou processado na etapa de pós-processamento.

\section{Pós-Processamento}

Na etapa de pós-processamento, o conhecimento extraído pode ser simplificado, avaliado, visualizado ou simplesmente documentado para o usuário final. A análise desse conhecimento poderá determinar se o processo de extração deve ser repetido ou não. Caso o conhecimento extraído não seja de interesse para o usuário ou não esteja de acordo com os objetivos pré-estabelecidos, pode ser necessário refazer etapas específicas ou refazer todo o processo, ajustando-se os parâmetros utilizados na extração de padrões ou realizando-se melhorias na seleção de dados.

Assim, a etapa de pós-processamento consiste de métodos e procedimentos, que na maioria das vezes utilizam medidas de avaliação para processar o conhecimento. Esses métodos e procedimentos podem ser agrupados nas categorias apresentadas a seguir (Bruha \& Famili, 2000). 
Filtragem Realizada por meio de mecanismos de poda, para o caso de árvores de decisão, ou de truncagem, no caso de conjuntos de regras de decisão. Outra forma de filtragem do conhecimento, especialmente útil para regras de associação, é o emprego de restrição de atributos ou ordenação de regras por meio de medidas de avaliação.

Interpretação e Explanação Documentar, visualizar ou modificar o conhecimento de forma a torná-lo compreensível para o usuário. O conhecimento extraído também pode ser comparado ao conhecimento pré-existente para a verificação de conflitos ou de conformidade e pode ser sumarizado e/ou combinado com o conhecimento prévio do domínio.

Avaliação Avaliar o conhecimento extraído a fim de verificar se o mesmo cumpre os objetivos do processo de mineração de dados.

Integração do Conhecimento Incorporar novo conhecimento em uma base de conhecimento já existente.

Caso seja verificado por meio das atividades de pós-processamento que o conhecimento cumpre os objetivos do processo de mineração de dados, pode ser realizada a última fase desse processo, ou seja, a utilização do conhecimento.

\section{Utilização do Conhecimento}

Essa fase sucede o ciclo principal do processo de mineração de dados. O conhecimento extraído, depois de ser avaliado e validado na etapa de pós-processamento, é consolidado na fase de utilização do conhecimento, podendo ser incorporado a um sistema inteligente, utilizado diretamente pelo usuário final como apoio em algum processo de tomada de decisão ou, simplesmente, relatado às pessoas interessadas.

\subsubsection{Considerações sobre Mineração de Dados}

A descoberta de conhecimento em bases de dados é um campo de pesquisa cujo desenvolvimento tem sido dirigido principalmente pelas necessidades sociais e econômicas. Muitos dos dados armazenados possuem informações valiosas, como tendências e padrões que podem ser usados, por exemplo, para tornar as decisões de negócios mais eficientes. Considerando que, em geral, as bases contêm uma grande quantidade de dados, tornouse necessário o desenvolvimento de processos de análise automática, como o processo de mineração de dados.

As diversas técnicas de mineração de dados podem ser agrupadas em duas categorias: descritivas e preditivas. A primeira descreve o conjunto de exemplos (também chamados de casos ou dados) de uma maneira concisa e sumarizada, apresentando algumas propriedades gerais dos dados. Exemplos: associação, clustering e sumarização. A segunda 
constrói hipóteses fazendo inferências acerca dos exemplos disponíveis, na tentativa de prever o comportamento de novos casos. Exemplos: classificação e regressão.

Contudo, existem aspectos importantes que devem ser considerados quando se aplica a mineração de dados a problemas reais, como a qualidade e a confiança do conhecimento extraído durante a etapa de pós-processamento. Esses aspectos são decisivos para o sucesso do processo, pois muitos dos problemas do mundo real que se beneficiam da mineração de dados envolvem atividades de risco. A clareza e facilidade de interpretação do conhecimento também são importantes, visto que o processo de mineração de dados é

interativo. É necessário apoiar os usuários na análise do conhecimento extraído, já que a participação dos mesmos na identificação de conhecimento interessante durante o pósprocessamento é imprescindível. Esse auxílio é especialmente importante em associação, uma vez que o volume de regras gerado é muito grande, o que dificulta sua análise e interpretação.

Na próxima seção é apresentada uma tarefa de mineração de dados que tem grande aplicabilidade a problemas reais, a associação.

\subsection{Associação}

A associação é uma tarefa de mineração de dados que tem despertado grande interesse (Baesens, Viaene, \& Vanthienen, 2000), tanto na área acadêmica como em aplicações. Pesquisas vêm sendo desenvolvidas e organizações têm utilizado seus resultados em aplicações relacionadas a comércio, contratos de seguro, geoprocessamento, serviços bancários e outras áreas (Antonie \& Zaane, 2004; Oliveira, Zaane, \& Saygin, 2004; Besemann, Denton, Yekkirala, Hutchison, \& Anderson, 2004; Clementini, Felice, \& Koperski, 2000; Semenova, Hegland, Graco, \& Williams, 2001; Aggelis, 2004). Um exemplo do emprego da associação na área comercial pode ser observado em páginas na internet, que apresentam sugestões do tipo "quem comprou o produto que você procura também comprou estes outros produtos".

\subsubsection{Conceitos e Definições}

Entre as tarefas de mineração de dados, a associação pode ser categorizada como uma atividade descritiva, como citado anteriormente. Desde a sua introdução em Agrawal, Imielinski, \& Swami (1993) a associação tem recebido grande atenção e sua popularização deve-se à aplicabilidade em problemas de negócio e à compreensibilidade inerente às regras de associação, pois até mesmo usuários não especialistas em mineração de dados podem compreendê-las facilmente (Hipp, Güntzer, \& Nakhaeizadeh, 2002).

A idéia de extrair regras de associação surgiu da análise de dados de cestas de compras, em que são geradas regras do tipo "um cliente que compra os produtos $x_{1}, x_{2}, \ldots, x_{n}$ também irá comprar o produto y com probabilidade $c \%$ ". Entretanto, as regras de associação 
não estão restritas a análises de dependência no contexto de aplicações de varejo uma vez que elas são aplicadas com sucesso a uma ampla gama de problemas como contratos de seguros e geoprocessamento.

Uma regra de associação, representada como uma implicação na forma $L H S \Rightarrow R H S$, em que $L H S$ e RHS são, respectivamente, o antecedente (Left Hand Side) e o conseqüente (Right Hand Side) da regra, é definida da seguinte maneira (Agrawal \& Srikant, 1994):

Seja $D$ uma base de dados composta por um conjunto de itens $A=\left\{a_{1}, \ldots, a_{m}\right\}$ ordenados lexicograficamente e por um conjunto de transações $T=\left\{t_{1}, \ldots, t_{n}\right\}$, na qual cada transação $t_{i} \in T$ é composta por um conjunto de itens ordenados lexicograficamente (itemset) tal que $t_{i} \subseteq A$.

A regra de associação é uma implicação ${ }^{1}$ na forma $L H S \Rightarrow R H S$, em que $L H S \subset A, R H S \subset A$ e $L H S \cap R H S=\varnothing$. A regra $L H S \Rightarrow R H S$ ocorre no conjunto de transações $T$ com confiança conf se em conf $\%$ das transações de $T$ em que ocorre $L H S$ ocorre também $R H S$. A regra $L H S \Rightarrow R H S$ tem suporte sup se em sup\% das transações em T ocorre LHS $\cup$ RHS.

Em associação as medidas mais empregadas são suporte e confiança, tanto na avaliação do conhecimento na etapa de pós-processamento como na seleção de itemsets (conjuntos de itens) durante o processo de geração das regras. Tais medidas são definidas a seguir:

Suporte: quantifica a incidência de um itemset $X$ ou de uma regra no conjunto de dados, ou seja, indica a frequiência com que $X$ ou com que $L H S \cup R H S$ ocorre no conjunto de dados. Da maneira como foi definido, o suporte para um itemset $X$ pode ser representado por:

$$
\sup (X)=\frac{n(X)}{N}
$$

em que $n(X)$ é o número de transações nas quais $X$ ocorre e $N$ é o número total de transações consideradas. Já o suporte de uma regra $L H S \Rightarrow R H S$ pode ser representado por:

$$
\sup (L H S \Rightarrow R H S)=\sup (L H S \cup R H S)=\frac{n(L H S \cup R H S)}{N},
$$

em que $n(L H S \cup R H S)$ é o número de transações nas quais $L H S$ e $R H S$ ocorrem juntos e $N$ é o número total de transações consideradas.

Confiança: indica a freqüência com que $L H S$ e $R H S$ ocorrem juntos em relação ao número total de transações em que $L H S$ ocorre. Do modo como foi definida, a confiança de uma regra $L H S \Rightarrow R H S$ pode ser representada por:

\footnotetext{
${ }^{1}$ A noção de implicação aqui utilizada é diferente da noção usual de implicação em inteligência artificial. Entretanto, optou-se por essa notação por ser a utilizada por Agrawal, Imielinski, \& Swami (1993).
} 


$$
\operatorname{conf}(L H S \Rightarrow R H S)=\frac{\sup (L H S \cup R H S)}{\sup (L H S)}=\frac{n(L H S \cup R H S)}{n(L H S)},
$$

em que $n(L H S)$ é o número de transações nas quais $L H S$ ocorre.

Antes de descrever o procedimento para geração de regras de associação, é necessário definir os termos itemset e $k$-itemset. Um itemset ${ }^{2}$ é definido como um conjunto de itens ordenados lexicograficamente. Já um $k$-itemset é um conjunto de $k$ itens ordenados lexicograficamente. Um $k$-itemset freqüente é definido como um conjunto de $k$ itens ordenados lexicograficamente que possui valor de suporte maior que o suporte mínimo (sup-min) definido pelo usuário.

Dadas as definições de regras de associação, das medidas suporte e confiança e dos termos itemset e $k$-itemset, o problema de obtenção de regras de associação pode ser decomposto em dois sub-problemas (Agrawal, Imielinski, \& Swami, 1993):

1. Encontrar todos os $k$-itemsets que possuam suporte maior ou igual ao suporte mínimo especificado pelo usuário. Os itemsets com suporte igual ou superior a supmin são definidos como itemsets freqüentes, os demais conjuntos são denominados itemsets não-freqüentes;

2. Utilizar os $k$-itemsets freqüentes, com $k \geq 2$, para gerar as regras de associação. Para cada itemset freqüente $l \subseteq A$, encontrar todos os subconjuntos $\tilde{a}$ de itens de $l$, não vazios e diferentes de $l$. Para cada subconjunto $\tilde{a} \subseteq l$, gerar uma regra na forma $\tilde{a} \Rightarrow(l-\tilde{a})$ se a razão de $\sup (l)$ por $\sup (\tilde{a})$ for maior ou igual a confiança mínima especificada pelo usuário (conf-min). Com um itemset freqüente $\{a, b, c, d\}$ e um subconjunto $\{a, b\}$, por exemplo, pode-se gerar a regra $a, b \Rightarrow c, d$, desde que $\operatorname{conf}(a, b \Rightarrow c, d) \geq \operatorname{conf-min}$, em que, $\operatorname{conf}(a, b \Rightarrow c, d)=\sup (a, b, c, d) / \sup (a, b)$.

Para melhor compreensão do processo de extração de regras de associação, na próxima seção é apresentado o procedimento para geração de itemsets freqüentes e um exemplo para realizar os dois passos descritos.

\subsubsection{Geração de itemsets freqüentes}

Considerando-se uma base de dados $D$ no formato de uma tabela de itens-transações, é possível gerar todos os $k$-itemsets freqüentes e, a partir destes, construir as regras de associação. Um exemplo do processo de geração de itemsets freqüentes é apresentado a seguir. Esse exemplo tem como objetivo apenas demonstrar visualmente o corte realizado por meio do suporte mínimo. Posteriormente será apresentado um exemplo detalhado da

\footnotetext{
${ }^{2}$ Em Adamo (2001) é empregado o termo CAS - Canonical Attribute Sequences (Seqüência Canônica de Atributos) ao invés do termo itemset.
} 
utilização dos valores de suporte e confiança mínimos para gerar os itemsets freqüentes e as regras de associação.

No início do procedimento para geração de regras de associação cada itemset $X \subseteq A$ ( $A$ é um conjunto de itens distintos) é considerado potencialmente freqüente. Ou seja, o espaço inicial de busca de itemsets freqüentes é composto de todos os subconjuntos de $A$ com exceção do conjunto vazio. Assim, mesmo os conjuntos com poucos itens tendem a possuir um espaço de busca grande. O espaço de busca para um conjunto de itens $A=\{a, b, c, d, e\}$ é ilustrado na Figura 2.2.

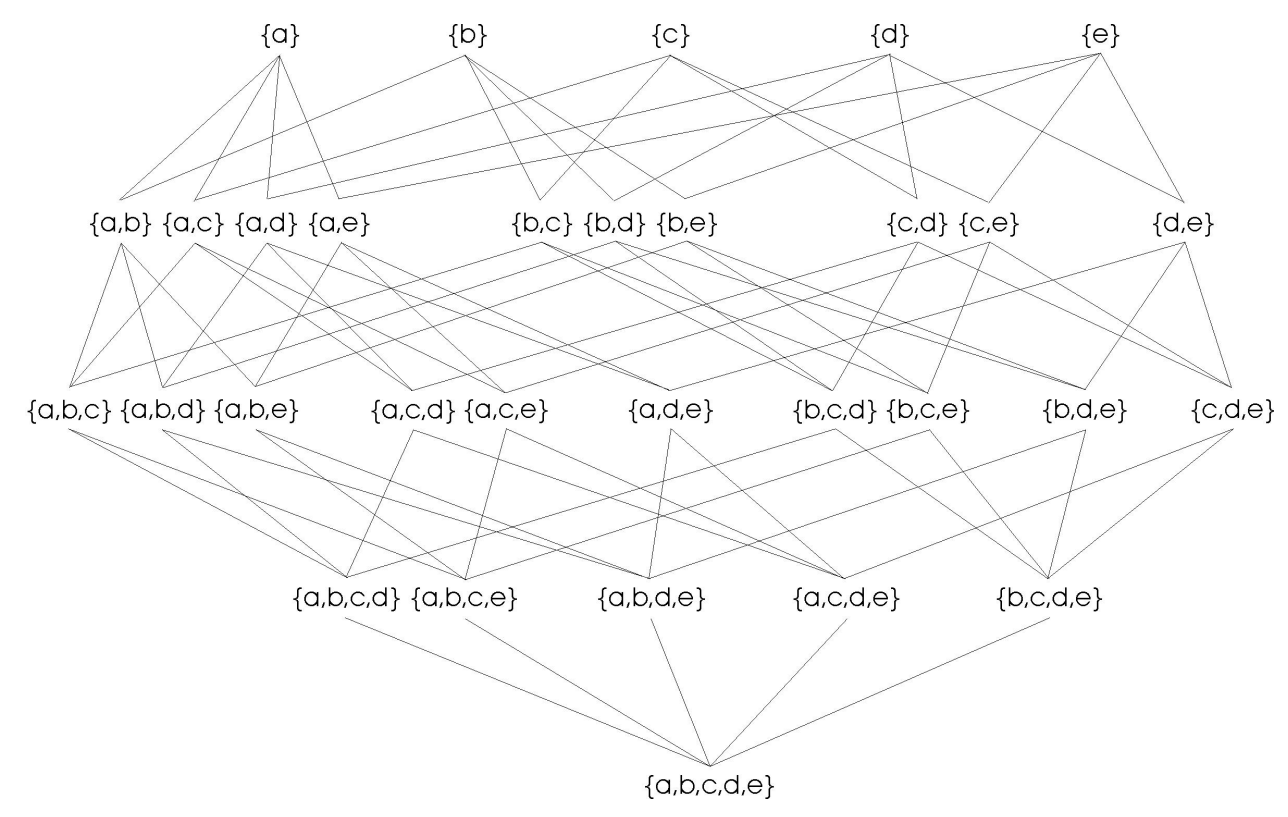

Figura 2.2: Espaço de busca para o conjunto de itens $A=\{a, b, c, d, e\}$ (Hipp, Güntzer, \& Nakhaeizadeh, 2002)

Para que não haja necessidade de percorrer todo o espaço de busca à procura dos itemsets de fato freqüentes, os algoritmos atuais para minerar regras de associação utilizam um método que gera e testa itemsets candidatos. Esses algoritmos geram conjuntos de itemsets potencialmente freqüentes chamados conjuntos de itemsets candidatos e utilizam-se da propriedade de linha de fronteira (downward closure) do suporte de um itemset (Agrawal \& Srikant, 1994), que determina que todo subconjunto de um itemset freqüente deve ser freqüente (para remover os itemsets com pelo menos um subconjunto de itens não-freqüentes). Então, calcula-se o valor de suporte para cada itemset candidato (não removido) utilizando a base de dados $D$, removendo-se, na seqüência, os itemsets candidatos com suporte inferior ao suporte mínimo definido pelo usuário. O algoritmo inicia uma nova iteração utilizando os itemsets freqüentes gerados na última iteração e tem encerrada sua execução quando não houver nenhum itemset potencialmente freqüente podendo ser considerado um itemset candidato.

Na Figura 2.3, a linha em negrito representa o suporte mínimo definido pelo usuário e separa os itemsets freqüentes (acima da linha) dos itemsets não-freqüentes (abaixo da 
linha). Assim, ao invés de se percorrer todo o espaço de busca à procura de itemsets freqüentes, percorre-se apenas o espaço de busca acima da linha em negrito.

Os itemsets freqüentes para gerar regras de associação podem ser obtidos utilizando-se diferentes algoritmos, como: AIS (Agrawal, Imielinski, \& Swami, 1993), Apriori e AprioriTid (Agrawal \& Srikant, 1994), AIS (Agrawal, Imielinski, \& Swami, 1993), SETM (Houtsma \& Swami, 1995), Opus (Webb, 1995), Dynamic Set Couting (DIC) (Brin, Motwani, Ullman, \& Tsur, 1997), Direct Hashing and Pruning (DHP) (Park, Chen, \& Yu, 1997), Closet (Pei, Han, \& Mao, 2000), FP-Growth (Han, Pei, \& Yin, 2000; Wang, Tang, Han, \& Liu, 2002), Charm (Zaki \& Hsiao, 2002). Ainda que diferentes, esses algoritmos teoricamente devem gerar sempre um mesmo resultado para um mesmo valor de suporte e confiança mínimos e para um mesmo conjunto de dados (Zeng, Kohavi, \& Manson, 2001).

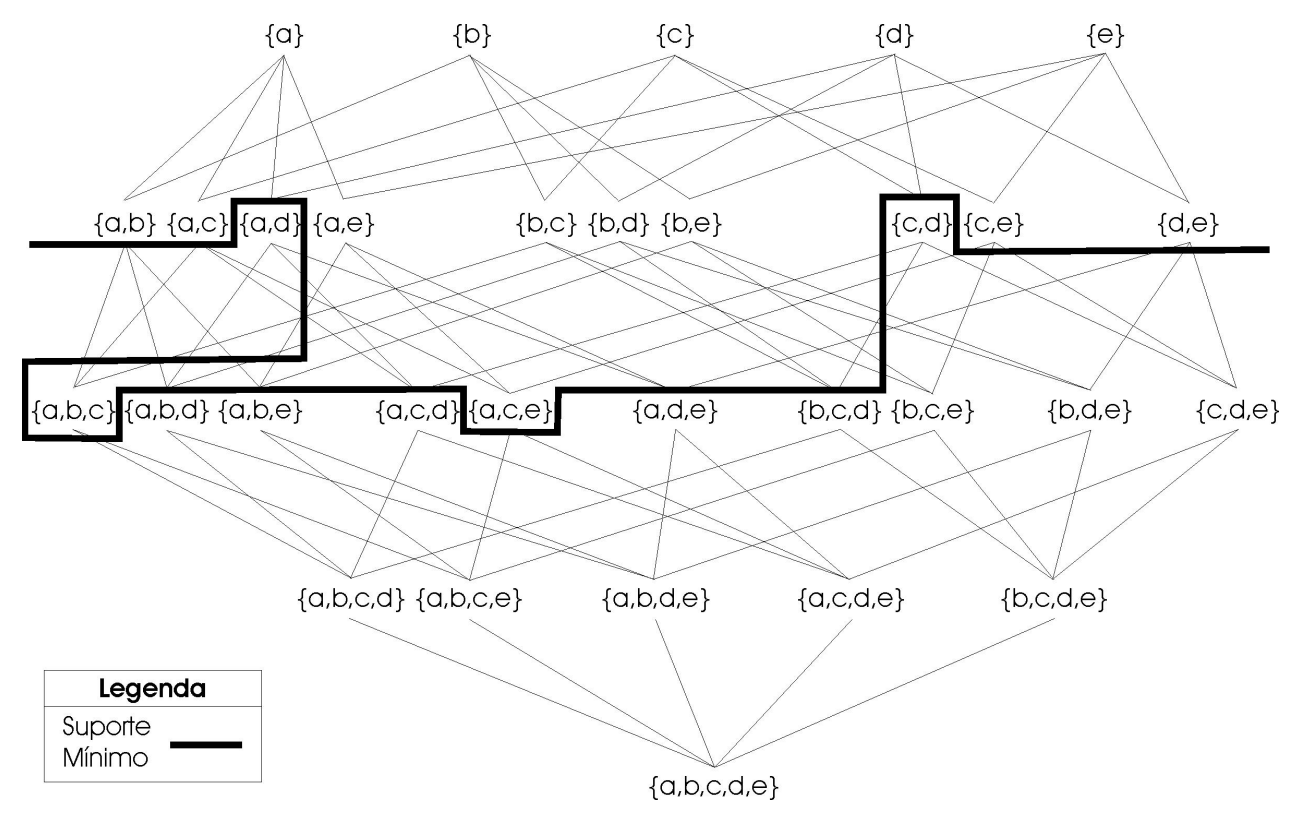

Figura 2.3: Separação de itemsets freqüentes e não-freqüentes no espaço de busca $A=$ $\{a, b, c, d, e\}$ (Hipp, Güntzer, \& Nakhaeizadeh, 2002)

No Exemplo 1 é apresentada a utilização do procedimento descrito.

Exemplo 1 Seja $D$ uma base de dados que contém um conjunto de itens $A=\{$ bermuda, calça, camiseta, sandália, tênis $\}$ e um conjunto de transações $T=\{\{$ calça, camiseta, tê$n i s\},\{$ camiseta, tênis $\},\{$ bermuda, tênis $\},\{$ calça, sandália $\}\}$, no qual a relação de itens comprados por cada transação ti é apresentada na Tabela 2.1.

Tabela 2.1: Relação de itens comprados por transação

\begin{tabular}{|c|c|}
\hline Transações & Itens comprados \\
\hline \hline 1 & calça, camiseta, tênis \\
\hline 2 & camiseta, tênis \\
\hline 3 & bermuda, tênis \\
\hline 4 & calça, sandália \\
\hline
\end{tabular}


Considerando o valor de $\boldsymbol{s u p}-\boldsymbol{m i n}=50 \%$ (2 transações) e conf- $\boldsymbol{m i n}=50 \%$, é possível obter as regras de associação contidas na Tabela 2.3 seguindo os passos:

I) Encontrar todos os k-itemsets contidos na Tabela 2.1 e que possuam suporte maior ou igual a sup-min (itemsets freqüentes). Na Tabela 2.2 são apresentados os $k$-itemsets freqüentes.

Tabela 2.2: Itemsets freqüentes

\begin{tabular}{|c|c|}
\hline Itemsets Freqüientes & Suporte \\
\hline \hline$\{$ tênis & $75 \%$ \\
\hline calça\} & $50 \%$ \\
\hline camiseta & $50 \%$ \\
\hline camiseta, tênis & $50 \%$ \\
\hline
\end{tabular}

II) Com os $k$-itemsets freqüentes, com $k \geq 2$, gerar todas as regras de associação contidas na Tabela 2.3, da seguinte maneira:

regra 1: tênis $\Rightarrow$ camiseta,

- suporte $=$ suporte $(\{$ tênis, camiseta $\})=50 \%$, que é igual a sup-min.

- confiança $=\frac{\text { suporte }(\{\text { tênis, camiseta }\})}{\text { suporte }(\{\text { tênis }\})}=\frac{50}{75}=66,66 \%$, que é maior do que conf-min.

regra 2: camiseta $\Rightarrow$ tênis,

- suporte $=$ suporte $(\{$ camiseta, tênis $\})=50 \%$, que é igual a sup-min.

- confiança $=\frac{\text { suporte }(\{\text { camiseta, tênis }\})}{\text { suporte }(\{\text { camiseta }\})}=\frac{50}{50}=100 \%$, que é maior do que conf-min.

Tabela 2.3: Regras geradas

\begin{tabular}{|c|c|c|}
\hline Regra & suporte & confiança \\
\hline tênis $\Rightarrow$ camiseta & $50 \%$ & $66,66 \%$ \\
\hline camiseta $\Rightarrow$ tênis & $50 \%$ & $100 \%$ \\
\hline
\end{tabular}

Com base nos itemsets obtidos no passo I, no passo II são geradas as regras de associação. É importante destacar que a complexidade de um sistema de extração de regras de associação é dependente do algoritmo utilizado para gerar os itemsets freqüentes (Zhang \& Zhang, 2002). 


\subsubsection{Desafios da Aplicação de Associação}

A partir da proposição da técnica de associação por Agrawal, Imielinski, \& Swami (1993), a maioria dos esforços em pesquisas sobre a mesma tem sido direcionada ao aprimoramento do desempenho dos algoritmos de extração de regras, em especial no sentido de propor soluções mais eficientes para o problema da identificação e contagem dos itemsets. Em paralelo, diversos aplicativos foram desenvolvidos incorporando os avanços proporcionados por essas pesquisas, como os algoritmos apresentados na Seção 2.2.2.

No entanto, existe outra problemática associada à associação que está relacionada à quantidade de regras geradas, mesmo quando a técnica é aplicada em bases de dados relativamente pequenas. Na Tabela 2.4, são apresentados os resultados obtidos por meio da aplicação de algoritmos de associação a algumas bases de dados (benchmark). Pode-se notar a grande quantidade de regras geradas quando se compara às quantidades usuais obtidas por outras tarefas de mineração de dados (classificação e regressão, por exemplo). Esta quantidade geralmente excede a dimensão da base de dados minerada (a quantidade de registros é consideravelmente menor do que o número de regras geradas) e, principalmente, vai além da capacidade de interpretação do ser humano. Adicionalmente, o especialista do domínio ou o usuário final está interessado em uma pequena fração das regras, aquelas que apresentam algum conhecimento útil, interessante ou inovador (Imieliński \& Virmani, 1998). Assim, é necessário desenvolver metodologias e ferramentas eficientes que apóiem o usuário na avaliação e identificação de regras interessantes durante a etapa de pós-processamento do conhecimento (Paula, 2003). A generalização de regras de associação é uma técnica que tem sido utilizada com esse objetivo, uma vez que reduz o conjunto de regras e facilita sua análise e interpretação (Domingues, 2004; Carvalho, 2004)

\begin{tabular}{|l|c|c|c|c|c|}
\hline Base & $\begin{array}{c}\text { No de } \\
\text { atributos }\end{array}$ & $\begin{array}{c}\text { No de } \\
\text { exemplos }\end{array}$ & $\begin{array}{c}\text { No de } \\
\text { regras }\end{array}$ & $\begin{array}{c}\text { suporte } \\
\mathbf{( \% )}\end{array}$ & $\begin{array}{c}\text { confiança } \\
\text { (\%) }\end{array}$ \\
\hline \hline Talassemia Alfa & 10 & 339 & 8.827 & 2 & 50 \\
Art A & 10 & 18.539 & 2.147 & 6 & 25 \\
Art B & 1.000 & 1.000 & 18.150 & 6 & 25 \\
Art E & 100 & 25.000 & 596.626 & 6 & 25 \\
nt60t1150ni1pa20 & 995 & 60.000 & 1.459 .070 & 6 & 25 \\
\hline
\end{tabular}

Tabela 2.4: Problema do volume de regras de associação (Melanda, 2004)

\subsection{Considerações Finais}

Neste capítulo foi apresentado o processo de mineração de dados, que tem muita utilidade na aquisição automática de conhecimento a partir de grandes bases de dados. No contexto de mineração de dados estruturados, este trabalho insere-se na avaliação de regras de associação. 
Quando a mineração de dados é aplicada a problemas reais deve ser dada atenção à análise e compreensão do conhecimento, visto que deve ser garantida a sua qualidade para que seja utilizado em algum processo de tomada de decisão. A análise e compreensão do conhecimento é especialmente difícil para a tarefa de associação devido ao grande número de regras que podem ser geradas. Portanto, é de grande importância o desenvolvimento de métodos para solucionar esse problema, como a generalização de regras de associação usando taxonomias. A generalização de conceitos expressa um conhecimento mais amplo do domínio o que, juntamente com a redução do volume de regras, facilita a compreensão do conhecimento extraído.

A qualidade das taxonomias e a facilidade para construí-las são características importantes que auxiliam a generalização de regras de associação. Dessa maneira, é interessante que seja desenvolvido um ambiente que apóie a construção de taxonomias usando procedimentos automáticos e interativos. Os primeiros garantem um aumento na velocidade do processo e os segundos captam o conhecimento do especialista e validam a boa qualidade das taxonomias, além de permitir que o processo seja guiado conforme as necessidades definidas para o problema.

No próximo capítulo são abordados os conceitos e definições de taxonomias e sua importância na generalização de regras de associação e na avaliação do conhecimento. São também apresentados três trabalhos relacionados com este e nos quais foram desenvolvidas ferramentas que auxiliam o pós-processamento de regras de associação por meio da sua exploração e generalização. 


$\overline{3}$

\section{Taxonomias para Generalização de Regras de Associação e Trabalhos Relacionados}

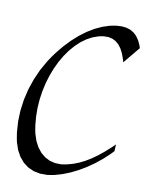

omo a técnica de associação permite identificar associações entre itens e conjuntos de itens de uma base de dados, os algoritmos produzem grandes quantidades de regras, muitas das quais podem não ser interessantes para o usuário (Liu, Hsu, Chen, \& Ma, 2000).

Devido a essa grande quantidade de regras geradas, a análise e a compreensão do conhecimento tornam-se tarefas difíceis para o usuário. O uso de taxonomias em regras de associação pode reduzir o volume de regras extraídas além de facilitar a análise e compreensão do conhecimento.

Neste capítulo são abordados os conceitos e definições de taxonomias, sua utilização em regras de associação e é discutida a importância da construção semi-automática de taxonomias na generalização de regras de associação. Também são apresentados os trabalhos desenvolvidos e em desenvolvimento no LABIC que estão relacionados com o uso de taxonomias na generalização de regras de associação.

\subsection{Taxonomias}

Por serem muito parecidos, os conceitos de hierarquias, taxonomias e ontologias são freqüentemente confundidos. Para justificar o uso de taxonomias na generalização de regras de associação, esses três conceitos serão brevemente discutidos a seguir:

Hierarquia É um conjunto parcialmente ordenado e finito de conceitos (Beneditto, 2004). Cada item pode possuir um ou mais itens no nível inferior. A hierarquia pode 
também representar uma organização de forma crescente ou decrescente de acordo com a relação existente entre os itens.

Ontologia É um esquema conceitual de um domínio, ou seja, pode representar uma estrutura hierárquica dos itens desse domínio contendo todas as entidades relevantes e os relacionamentos entre elas (Horrocks, Fensel, Broekstra, Decker, Erdmann, Goble, van Harmelen, Klein, Staab, Studer, \& Motta, 2000).

Taxonomia Permite realizar uma classificação hierárquica de itens por meio de uma visão coletiva ou individual. Eventualmente, a presença simultânea de diversas taxonomias reflete a possibilidade de classificações distintas para o mesmo conjunto de itens. Na taxonomia, os níveis inferiores são especializações dos itens superiores e os itens superiores são generalizações dos itens inferiores (Adamo, 2001).

Tanto as ontologias como as taxonomias classificam os itens de um domínio de maneira hierárquica. Porém, ambas se diferenciam de hierarquias por necessariamente utilizarem algum conhecimento para agrupar os itens similares (uma hierarquia pode representar apenas uma organização sem grupos). O nível mais baixo das taxonomias e das ontologias representa os itens mais específicos, enquanto que uma hierarquia pode não representar generalização/especialização.

As ontologias, descrevem conceitos de um domínio usando uma organização taxonômica hierárquica (baseada em generalização e especialização). Porém, as ontologias também podem representar os relacionamentos entre os conceitos por meio de propriedades como "é-um", "parte-de", entre outros relacionamentos específicos de um domínio. Uma taxonomia também pode ser vista como uma ontologia, que possui apenas o relacionamento "is-a". Parte de uma ontologia para o diagnóstico de câncer de mama é apresentada na Figura 3.1, a qual foi desenvolvida durante um estágio de mestrado na Universidade de Murcia, Espanha.

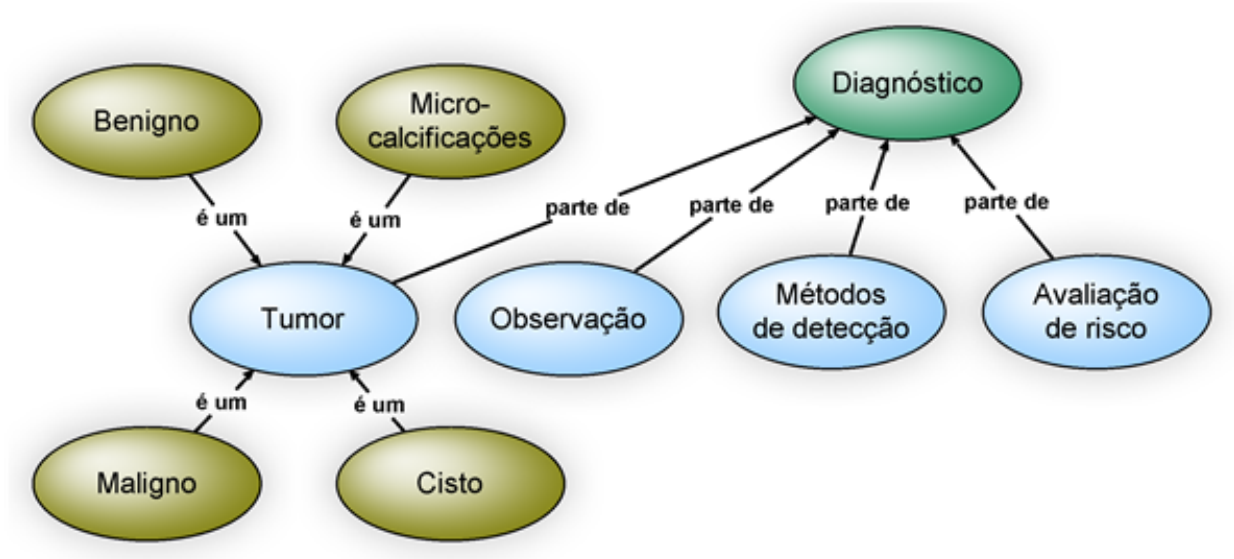

Figura 3.1: Parte de uma ontologia para diagnóstico de câncer de mama 
O domínio representado pela ontologia da Figura 3.1 corresponde ao diagnóstico de câncer de mama. Como é possível observar, existem as entidades "diagnóstico", "tumor", "observação", "métodos de detecção", "avaliação de risco", "benigno", "maligno", "microcalcificações" e "cisto". Já os relacionamentos entre as entidades são representados por "parte de" e "é um". As entidades "tumor", "observação", "métodos de detecção" e "avaliação de risco" fazem parte do diagnóstico, ou seja, podem ser realizadas de maneira isolada ou combinada a fim de encontrar um diagnóstico. Isso está representado por meio do relacionamento "parte de". Já as entidades "benigno", "maligno", "micro-calcificações" e "cisto" são os tipos de tumores que podem ser detectados, o que está representado por meio do relacionamento "é um".

Neste trabalho é proposta uma metodologia para construção semi-automática de taxonomias para generalização de regras de associação. A utilização de taxonomias se deve aos objetivos do processo de generalização de regras de associação: a melhora da compreensão e a redução do volume de padrões gerados. Para atingir esses objetivos, o relacionamento "is-a" existente nas taxonomias é suficiente, pois representa os agrupamentos entre os itens e não possui a complexidade dos relacionamentos das ontologias. Por outro lado, a representação na forma de hierarquia não é suficiente, uma vez que é necessário que os grupos dos itens representem generalização/especialização para se obter regras mais gerais (por exemplo, o conjunto formado por todas as marcas de café). Vale ressaltar que o conceito de taxonomia é aplicado, no contexto desse trabalho, para os itens e não para os atributos de uma base de dados.

\subsubsection{Conceitos e Definições}

As taxonomias refletem uma caracterização coletiva ou individual de como os itens podem ser hierarquicamente classificados (Adamo, 2001). Eventualmente, múltiplas taxonomias podem estar presentes simultaneamente, refletindo a existência de diversos pontos de vista ou a possibilidade de classificações distintas para o mesmo conjunto de itens. $\mathrm{Na}$ Figura 3.2 é apresentado um exemplo de uma taxonomia. Nesse exemplo pode-se verificar que: camiseta é uma roupa leve, bermuda é uma roupa leve, roupa leve é um tipo de roupa, sandália é um tipo de calçado, etc.

Uma das razões que torna interessante a aplicação de taxonomias em associação referese à possibilidade de geração de regras que utilizem itens contidos em qualquer nível da taxonomia e não apenas os itens contidos no nível inferior, como ocorre em regras de associação que não utilizam taxonomias (Srikant \& Agrawal, 1997). Usando a taxonomia apresentada na Figura 3.2 pode-se gerar a regra "pessoas que compram roupas leves também compram sandálias", baseado no fato de pessoas comprarem camisetas com sandálias e bermudas com sandálias, sem necessidade de utilizar as regras: pessoas que compram camisetas também compram sandálias e pessoas que compram bermudas também compram sandálias. 


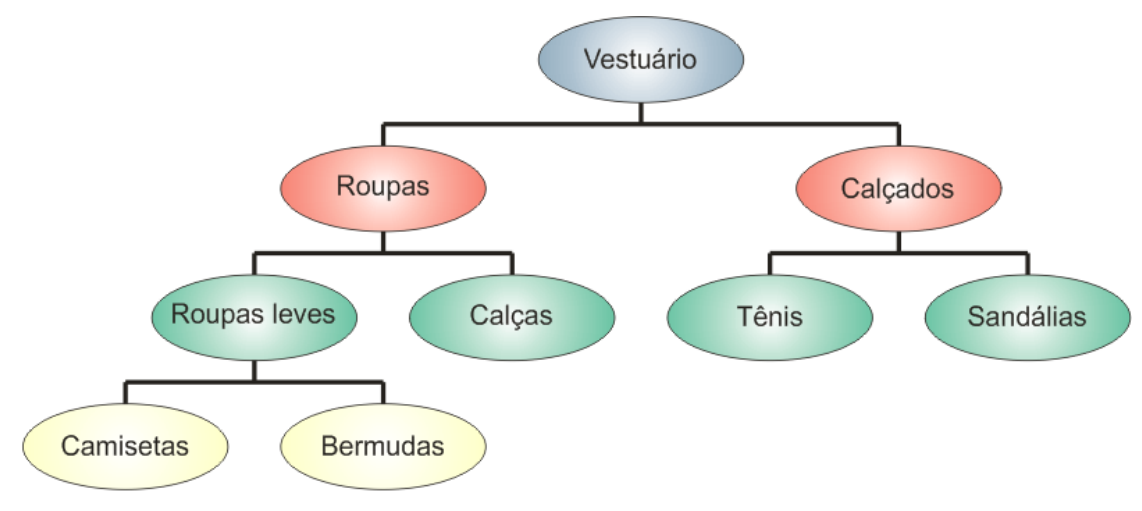

Figura 3.2: Exemplo de uma taxonomia para vestuário (Domingues, 2004)

Outro motivo que torna o uso de taxonomias em associação interessante é que as informações contidas nas taxonomias podem ser utilizadas na avaliação subjetiva do conhecimento (gerado no formato de regras de associação), em termos de compreensão e interesse/surpresa (Liu, Hsu, Chen, \& Ma, 2000). Srikant (2001) apresenta outras razões para o emprego de taxonomias em associação:

- regras simples (cujos elementos são compostos apenas por itens terminais na taxonomia) podem não ter suporte suficiente para serem incluídas na solução, mas podem representar conhecimento interessante ao serem agrupadas segundo uma taxonomia;

- regras muito específicas podem ser generalizadas. De maneira similar ao item anterior, mesmo considerando as regras simples com elevados níveis de suporte e confiança, essas podem ser agrupadas em regras mais gerais, melhorando a sua compreensão e ainda podendo aumentar os valores de suporte e confiança;

- regras interessantes podem ser identificadas com o uso de informações contidas nas taxonomias.

\subsubsection{Uso de Taxonomias na Generalização de Regras de Associação}

A seguir são apresentadas algumas notações e definições sobre o uso de taxonomias em regras de associação (Adamo, 2001).

Generalização ou ancestral Considerando $X$ um itemset no qual $X \subseteq L H S$ ou $X \subseteq$ $R H S$ e $L H S \Rightarrow R H S$ uma regra de associação, as notações $X \uparrow$ e $(L H S \Rightarrow R H S) \uparrow$ representam novos itemsets e regras que derivam de $X$ e $L H S \Rightarrow R H S$, respectivamente, pela substituição de um ou mais itens pelos seus ancestrais na taxonomia. Os novos itemsets e regras são ditos generalizações ou ancestrais de $X$ e $L H S \Rightarrow R H S$.

Especialização ou descendente Considerando $X$ um itemset no qual $X \subseteq L H S$ ou $X \subseteq R H S$ e $L H S \Rightarrow R H S$ uma regra de associação, as notações $X \downarrow$ e $(L H S \Rightarrow R H S) \downarrow$ 
representam novos itemsets e regras que derivam de $X$ e $L H S \Rightarrow R H S$, respectivamente, pela substituição de um ou mais itens pelos seus descendentes na taxonomia. Os novos itemsets e regras são ditos especializações ou descendentes de $X$ e $L H S \Rightarrow R H S$.

Pai Um itemset $X \uparrow$ é dito ser pai de $X$ se não há nenhum itemset $X^{\prime}$ tal que $X^{\prime}$ é um ancestral de $X$ e $X \uparrow$ é um ancestral de $X^{\prime}$.

Filho Um itemset $X \downarrow$ é dito ser filho de $X$ se não há nenhum itemset $X^{\prime}$ tal que $X^{\prime}$ é um descendente de $X$ e $X \downarrow$ é um descendente de $X^{\prime}$.

Generalização máxima Um itemset $X$ é dito ser uma generalização máxima, se nenhum item em $X$ pode ser substituído por um item ancestral na taxonomia. $\mathrm{O}$ mesmo é válido para uma regra $L H S \Rightarrow R H S$ e para um item $a$.

Especialização máxima Um itemset $X$ é dito ser uma especialização máxima, se nenhum item em $X$ pode ser substituído por um item descendente na taxonomia. $\mathrm{O}$ mesmo também é válido para uma regra $L H S \Rightarrow R H S$ e para um item $a$.

Uma regra de associação usando taxonomias pode ser definida como (Srikant \& Agrawal, 1997):

Seja $D$ uma base de dados composta por um conjunto de itens $A=\left\{a_{1}, \ldots, a_{m}\right\}$ ordenados lexicograficamente e por um conjunto de transações $T=\left\{t_{1}, \ldots, t_{n}\right\}$, na qual cada transação $t_{i} \in T$ é composta por um conjunto de itens tal que $t_{i} \subseteq A$. É dito que uma transação $t_{i}$ suporta um item $a_{j} \in A$, se $a_{j}$ está em $t_{i}$ ou $a_{j}$ é um ancestral de algum item em $t_{i}$. Seja $\tau$ um grafo direcional e acíclico com os itens, representando um conjunto de taxonomias. Se há uma aresta em $\mathcal{T}$ de um item $a_{p} \in A$ para um item $a_{c} \in A, a_{p}$ é dito ser pai de $a_{c}$ e $a_{c}$ é dito ser filho de $a_{p}$.

Uma regra de associação usando taxonomias é uma implicação na forma $L H S \Rightarrow R H S$, em que $L H S \subset A, R H S \subset A, L H S \cap R H S=\varnothing$ e nenhum item em $R H S$ é um ancestral de qualquer item em $L H S$. A regra $L H S \Rightarrow R H S$ ocorre no conjunto de transações $T$ com confiança conf se em conf\% das transações de $T$ em que ocorre $L H S$ ocorre também $R H S$. A regra $L H S \Rightarrow R H S$ tem suporte sup se em sup\% das transações de T ocorre $L H S \cup R H S$.

Em regras de associação utilizando taxonomias, o suporte de um item terminal na taxonomia $a_{j} \in A$ é definido de maneira semelhante à apresentada no Capítulo 2. $\mathrm{O}$ suporte para um item $a_{j}$ não terminal na taxonomia é definido em Adamo (2001) como: $\sup \left(a_{j}\right)=\sup \left(\cup \operatorname{des}\left(a_{j}\right)\right)$, em que des $\left(a_{j}\right)$ é o conjunto de descendentes de $a_{j}$. No Exemplo 2 é apresentado como é calculado o suporte de itens terminais e não terminais da taxonomia. 
Exemplo 2 Considerando a taxonomia apresentada na Figura 3.2 e D uma base de dados que contém um conjunto de itens $A=\{$ bermudas, calças, camisetas, sandálias, tênis $\}$ e um conjunto de transações $T=\{\{$ camisetas, calças, tênis $\},\{$ bermudas, tênis, sandálias $\}$, \{camisetas, bermudas, calças, tênis, sandálias\},\{tênis, sandálias\},\{camisetas, bermudas, calças $\},\{$ calças, tênis, sandálias\}, $\{$ bermudas, calças, sandálias $\}$, no qual a relação de itens comprados por cada transação ti é apresentada na Tabela 3.1.

Tabela 3.1: Relação de itens comprados por transação

\begin{tabular}{|c|c|}
\hline Transações & Itens comprados \\
\hline \hline 1 & camisetas, calças, tênis \\
\hline 2 & bermudas, tênis, sandálias \\
\hline 3 & camisetas, bermudas, calças, tênis, sandálias \\
\hline 4 & tênis, sandálias \\
\hline 5 & camisetas, bermudas, calças \\
\hline 6 & calças, tênis, sandálias \\
\hline 7 & bermudas, calças, sandálias \\
\hline
\end{tabular}

A partir dessas informações são calculados os suportes dos itens terminais e não terminais da taxonomia, como apresentado a seguir:

- Itens terminais:

$$
\begin{aligned}
\text { sup }(\text { camisetas }) & =\{1,3,5\}=3 \\
\text { sup }(\text { bermudas }) & =\{2,3,5,7\}=4 \\
\text { sup }(\text { calças }) & =\{1,3,5,6,7\}=5 \\
\text { sup }(\text { tênis }) & =\{1,2,3,4,6\}=5 \\
\text { sup }(\text { sandálias }) & =\{2,3,4,6,7\}=5
\end{aligned}
$$

- Itens não terminais:

$$
\begin{aligned}
\text { sup }(\text { roupas leves }) & =\text { sup }(\text { camisetas } \cup \text { bermudas }) \\
& =\{1,3,5\} \cup\{2,3,5,7\} \\
& =\{1,2,3,5,7\}=5 \\
\text { sup }(\text { calçados }) & =\text { sup }(\text { tênis } \cup \text { sandálias }) \\
& =\{1,2,3,4,6\} \cup\{2,3,4,6,7\} \\
& =\{1,2,3,4,6,7\}=6 \\
\text { sup }(\text { roupas }) & =\text { sup }(\text { roupas leves } \cup \text { calças }) \\
& =\{1,2,3,5,7\} \cup\{1,3,5,6,7\} \\
& =\{1,2,3,5,6,7\}=6
\end{aligned}
$$

Como pode ser observado, o cálculo do suporte de itens não terminais na taxonomia é 
realizado utilizando os itens terminais descendentes.

Em relação aos algoritmos para obter regras de associação generalizadas, desde o trabalho apresentado por Han (1995) sabe-se que pode ser utilizada uma das seguintes abordagens:

1. No aprofundamento progressivo o algoritmo inicia o processo de geração das regras pelo nível mais alto da hierarquia e então seletivamente e progressivamente aprofunda o processo de mineração pelos níveis mais baixos.

2. A generalização progressiva inicia o processo de geração das regras pelo nível mais baixo da hierarquia e então progressivamente generaliza os resultados obtidos para os níveis superiores.

3. Na abordagem interativa o processo de descoberta do conhecimento pode subir ou descer nos diferentes níveis da hierarquia por meio de instruções e interações realizadas com os usuários.

Han (1995) afirma que é difícil trabalhar eficientemente com os algoritmos que utilizam a abordagem de generalização progressiva. Isso porque, na mineração realizada com abordagens de aprofundamento progressivo, somente os descendentes dos itemsets freqüentes dos níveis mais altos serão considerados nos níveis mais baixos, isto é, os descendentes de um grande número de itemsets não freqüentes contidos nos níveis mais altos não precisam ser considerados na mineração dos níveis mais baixos. Entretanto, esse mecanismo não é válido para a abordagem de generalização progressiva: se um itemset não é freqüente seus ancestrais ainda precisam ser considerados como candidatos nos níveis superiores, ou seja, nenhum itemset pode ser desconsiderado quando se caminha para os níveis mais altos da hierarquia.

Assim como no caso "tradicional", o problema de obtenção de regras de associação aplicando taxonomias é decomposto em dois passos:

1. Encontrar todos os k-itemsets que possuam suporte maior ou igual ao suporte mínimo especificado pelo usuário. Entretanto, nesse caso, os itens que constituem os $k$-itemsets encontram-se presentes em qualquer nível da taxonomia (no caso "tradicional" os itens só podem pertencer ao último nível).

2. Utilizar todos os k-itemsets freqüentes para gerar as regras de associação.

Existem diversos algoritmos que extraem regras de associação generalizadas obtidas a partir de taxonomias, como o Básico, o Cumulate e o Stratify (que possui as variações Estimate e EstMerge) propostos por Srikant \& Agrawal (1997, 1995), os da família $M L$ $T^{*}$ propostos por Han \& Fu $(1999,1995)$, o Prutax proposto por Hipp, Myka, Wirth, \& Güntzer (1998) e o Genex proposto por Weber (1998). 
São poucos os trabalhos encontrados na literatura que generalizam regras de associação usando taxonomias na etapa de pós-processamento do conhecimento. O procedimento para realizar o cálculo do suporte e da confiança, proposto por Domingues (2004) e por Carvalho (2004) para esse caso, é o mesmo que o descrito nesta seção. Em Carvalho (2004) também é proposto um estudo sobre a utilização de taxonomias nas três etapas do ciclo principal do processo de mineração de dados: pré-processamento, extração de padrões e pós-processamento. Esse estudo tem o objetivo de analisar a importância do uso de taxonomias em cada uma dessas etapas.

\subsubsection{Importância da Construção Semi-automática de Taxonomias}

A identificação e construção de taxonomias de um domínio não é uma tarefa simples de ser executada. É necessário um grande conhecimento e estudo do domínio para identificar as informações e conceitos e também para, posteriormente, agrupá-los e organizá-los em uma taxonomia. Sendo assim, a realização dessa tarefa é muito custosa, em termos de tempo e de conhecimento.

Dessa maneira, é importante o desenvolvimento de ferramentas que auxiliem o usuário na construção das taxonomias. Alguns trabalhos vêm sendo desenvolvidos com esse objetivo, porém, em geral, as propostas apresentadas nesses trabalhos geram taxonomias específicas para um domínio de aplicação, como textos de discurso (Chien, Huang, Teng, \& Chuang, 2002) ou da Web (Kumar, Raghavan, Rajagopalan, \& Tomkins, 2001).

Uma combinação de métodos automáticos e interativos para construir taxonomias é uma opção interessante, uma vez que grupos seriam gerados automaticamente sem descartar o conhecimento do especialista do domínio. Dessa maneira, o especialista estaria interagindo com a ferramenta, guiando a construção das taxonomias e fornecendo as informações necessárias para que sejam identificadas taxonomias corretas, úteis e interessantes. Além disso, a intervenção do especialista também é importante para analisar e validar as taxonomias geradas.

\subsection{Trabalhos Relacionados Desenvolvidos no LABIC}

Diferentes ferramentas têm sido desenvolvidas para apoiar a exploração de regras (Paula, 2003; Jorge, Poças, \& Azevedo, 2002; Liu, Hsu, Chen, \& Ma, 2000; Ma, Liu, \& Wong, 2000). Nessa seção são apresentados o ambiente RulEE e seu módulo para generalização de regras de associação na etapa de pós-processamento, o RULEE-GAR (Domingues, 2004). Também será apresentada a proposta de Carvalho (2004), que analisa a generalização usando taxonomias nas três etapas do ciclo principal do processo de mineração de dados: pré-processamento, extração de padrões e pós-processamento. Todos esses trabalhos foram ou estão sendo desenvolvidos no LABIC. 
O ambiente RulEE apóia a exploração de regras de classificação, regressão e associação por meio de filtros com medidas. Além disso ele possui alguns módulos de pósprocessamento de regras de associação, como o RULEE-GAR, que generaliza regras de associação usando taxonomias e provê funcionalidades para auxiliar a análise e exploração de regras generalizadas. Há ainda um módulo para construção semi-automática de taxonomias, o RuLEE-SACT, desenvolvido neste trabalho e apresentado na Seção 4.3.

O módulo RulEE-SACT foi desenvolvido para viabilizar o uso da metodologia proposta, apoiando a construção de taxonomias. Essas taxonomias depois podem ser utilizadas por algoritmos de generalização de regras de associação, contanto que as mesmas sejam convertidas para o formato utilizado por esses algoritmos. O módulo pode auxiliar na redução do tempo gasto com a construção de taxonomias e foi integrado ao RuLEE como um de seus módulos de pós-processamento.

\subsubsection{Ambiente RulEE}

O pós-processamento de regras é uma etapa muito importante do processo de mineração de dados, pois é quando o conhecimento extraído é analisado e interpretado para ser utilizado em um sistema inteligente ou em tomadas de decisão. A dificuldade na realização dessa etapa é maior no caso de regras de associação, devido ao grande volume de regras gerado. Dessa maneira, o desenvolvimento de um ambiente para exploração de regras que viabilize a análise, interpretação e disponibilização de regras é essencial para o sucesso dessa etapa. Visando atender essa necessidade foi projetado e desenvolvido um protótipo de um ambiente computacional para exploração de regras, o RuLEE, com o objetivo de apoiar a etapa de pós-processamento e a disponibilização do conhecimento no processo de mineração de dados (Paula, 2003). No momento, o ambiente RulEE está sendo desenvolvido no LABIC com base nesse protótipo, além de módulos de pós-processamento com funcionalidades adicionais específicas não implementadas no protótipo.

Uma característica importante do RULEE é facilitar o acesso ao conhecimento descoberto. Isso é realizado por meio de uma interface para disponibilização do conhecimento baseada na Web. Dessa maneira, algumas características importantes da Web são incorporadas ao ambiente, como a independência de plataforma e a facilidade de utilização pelos usuários independente de sua localização física e da ferramenta de extração de conhecimento utilizada.

A arquitetura do ambiente RulEE que está em desenvolvimento, apresentada na Figura 3.3, é composta por:

- Repositório de Dados Gerenciais, no qual são armazenadas informações sobre os usuários e os projetos.

- Repositório de Conjuntos de Regras, no qual são armazenados conjuntos de regras de associação, classificação e regressão. 


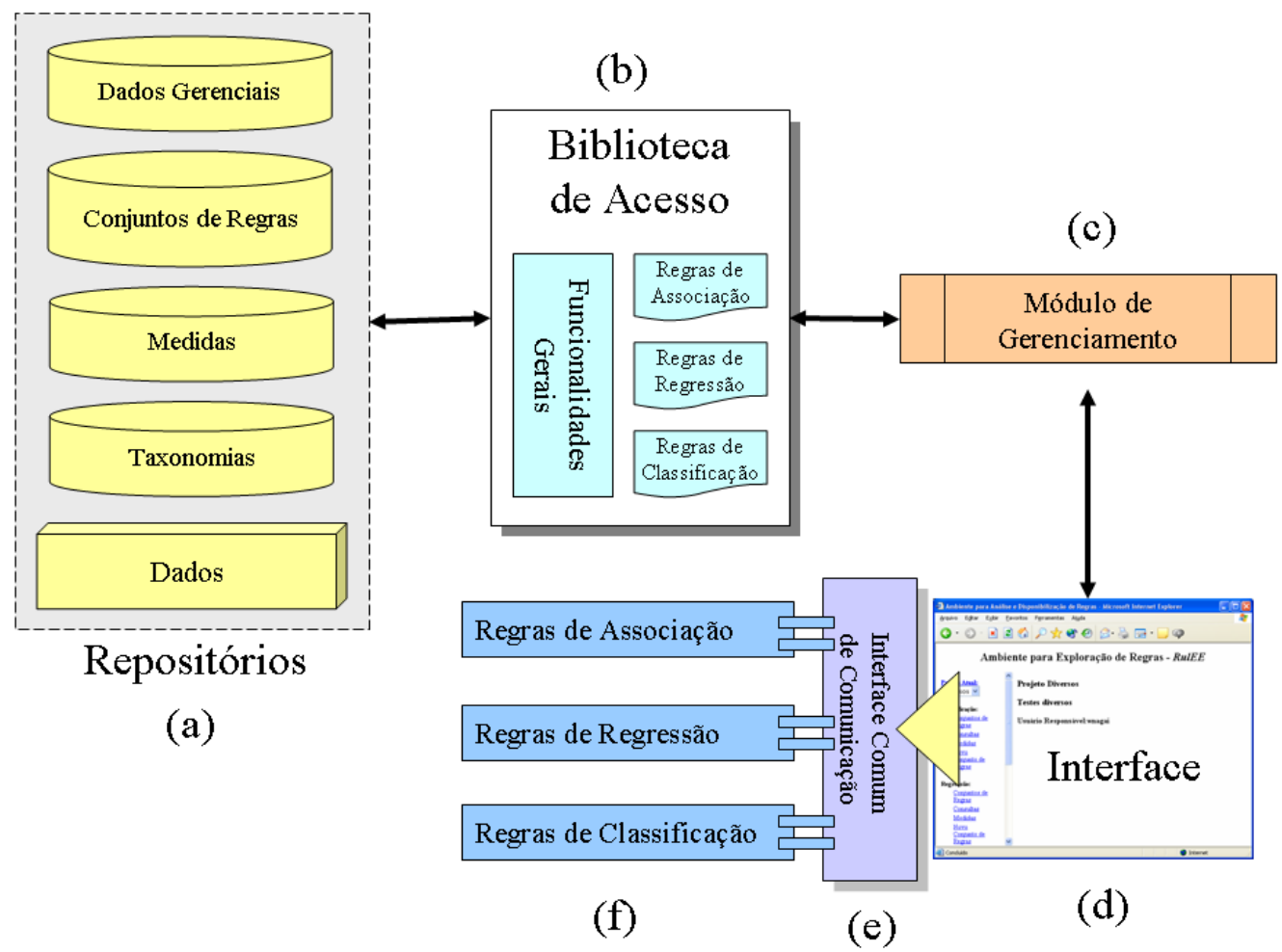

Figura 3.3: Arquitetura geral do ambiente RuLEE

- Repositório de Medidas, contendo informações sobre medidas de avaliação de conhecimento, tanto objetivas quanto subjetivas. Nesse repositório também são armazenados os valores das medidas calculadas para cada regra presente no repositório de conjunto de regras.

- Repositório de Taxonomias, no qual são armazenadas as taxonomias para um determinado domínio. Essas taxonomias são utilizadas para generalizar regras de associação e para analisar conjuntos de regras generalizadas.

- Repositório de Dados, formado pelos conjuntos de dados do domínio utilizados na extração e teste de determinado conjunto de regras.

- Biblioteca de Acesso, que consiste em um conjunto de programas com funções específicas de acesso, manipulação e obtenção dos dados dos repositórios. A biblioteca faz a ligação entre o módulo de gerenciamento e os repositórios.

- Módulo de Gerenciamento, que possui a função de gerenciar as informações sobre os usuários do RulEE, manter os repositórios com valores consistentes e manter a comunicação entre os dados dos repositórios e a interface, por meio da biblioteca de acesso.

- Interface, baseada na Web, com os objetivos de disponibilizar o conhecimento e permitir que um especialista do domínio explore o conjunto de regras com facilidade. 
O RulEE, assim como o seu protótipo, auxilia a análise de regras de classificação, regressão e associação. Ele recebe como entrada arquivos com conjuntos de regras representadas utilizando a sintaxe padrão definida no Discover (Prati, Baranauskas, \& Monard, 2001; Pugliesi, Dosualdo, \& Rezende, 2003; Melanda \& Rezende, 2003). O DisCOVER é um ambiente desenvolvido no LABIC para apoiar todo o processo de extração de conhecimento, que combina uma série de ferramentas para facilitar a configuração e execução de experimentos (Batista, 2003; Prati, 2003). Por utilizar as regras na sintaxe padrão do Discover e com a utilização dos scripts de conversão dos diversos tipos de regras para a sintaxe padrão, também implementados no DisCoveR, podem ser inseridas no ambiente as saídas de uma grande variedade de algoritmos para extração de conhecimento de dados. Dentre esses algoritmos, encontram-se os mais utilizados na literatura, como o C4.5, CN2, Cubist e Apriori.

Uma vez que o conhecimento descoberto tenha sido armazenado no ambiente, as regras são disponibilizadas para o usuário juntamente com métodos para que ele possa avaliá-las. O RulEE apresenta um conjunto de medidas de avaliação que pode ser utilizado pelo usuário para ordenação e seleção de regras, auxiliando a identificação do conhecimento interessante. O ambiente provê fácil acesso às regras e aos valores dessas medidas, permitindo também que elas sejam utilizadas de forma combinada na análise das regras. Isso é realizado por meio de consultas utilizando a aplicação de restrições (ou filtros) e medidas para a ordenação dos conjuntos de regras.

Além disso, esse ambiente foi modelado para permitir, com pequenas alterações no seu código fonte, a incorporação de novas medidas de avaliação e novas funcionalidades por meio de módulos de pós-processamento. Assim, com a utilização do RulEE os pesquisadores podem realizar experimentos com novas medidas de avaliação e novas técnicas de pós-processamento sem despender muito tempo com implementações.

Aproveitando as facilidades de integração de novas funcionalidades ao RULEE, foram desenvolvidos cinco módulos de pós-processamento. O $\mathcal{A R} \operatorname{InE}$ (Environment for Association Rules Interactive Exploration - Ambiente para Exploração Interativa de Regras de Associação), que auxilia a avaliação de regras de associação utilizando medidas objetivas (Melanda, 2004), o RulEE-GAR (Domingues, 2004), que será descrito na próxima seção, o RulEE-SEAR (Subjective Exploration of Association Rules - Exploração Subjetiva de Regras de Associação), que possui funcionalidades para a exploração de regras de associação com medidas subjetivas (Sinoara, 2006) e o RULEE-SACT, desenvolvido neste trabalho e apresentado no próximo capítulo.

\subsubsection{Módulo RulEE-GAR}

O módulo computacional RulEE-GAR (Domingues, 2004) tem como objetivo fornecer funcionalidades para generalizar regras de associação na etapa de pós-processamento do conhecimento e também para analisar as regras generalizadas. A generalização é re- 
alizada utilizando o algoritmo GART. Já para prover as funcionalidades de análise de regras de associação generalizadas, o módulo utiliza a base de dados e a biblioteca de classes desenvolvidas para o protótipo do ambiente de exploração de regras RuLEE. A contextualização do módulo RULEE-GAR no protótipo do ambiente RuLEE, bem como as suas funcionalidades são ilustradas na Figura 3.4. Como pode ser verificado, o módulo computacional RULEE-GAR foi desenvolvido como um módulo de pós-processamento do protótipo do ambiente RULEE.

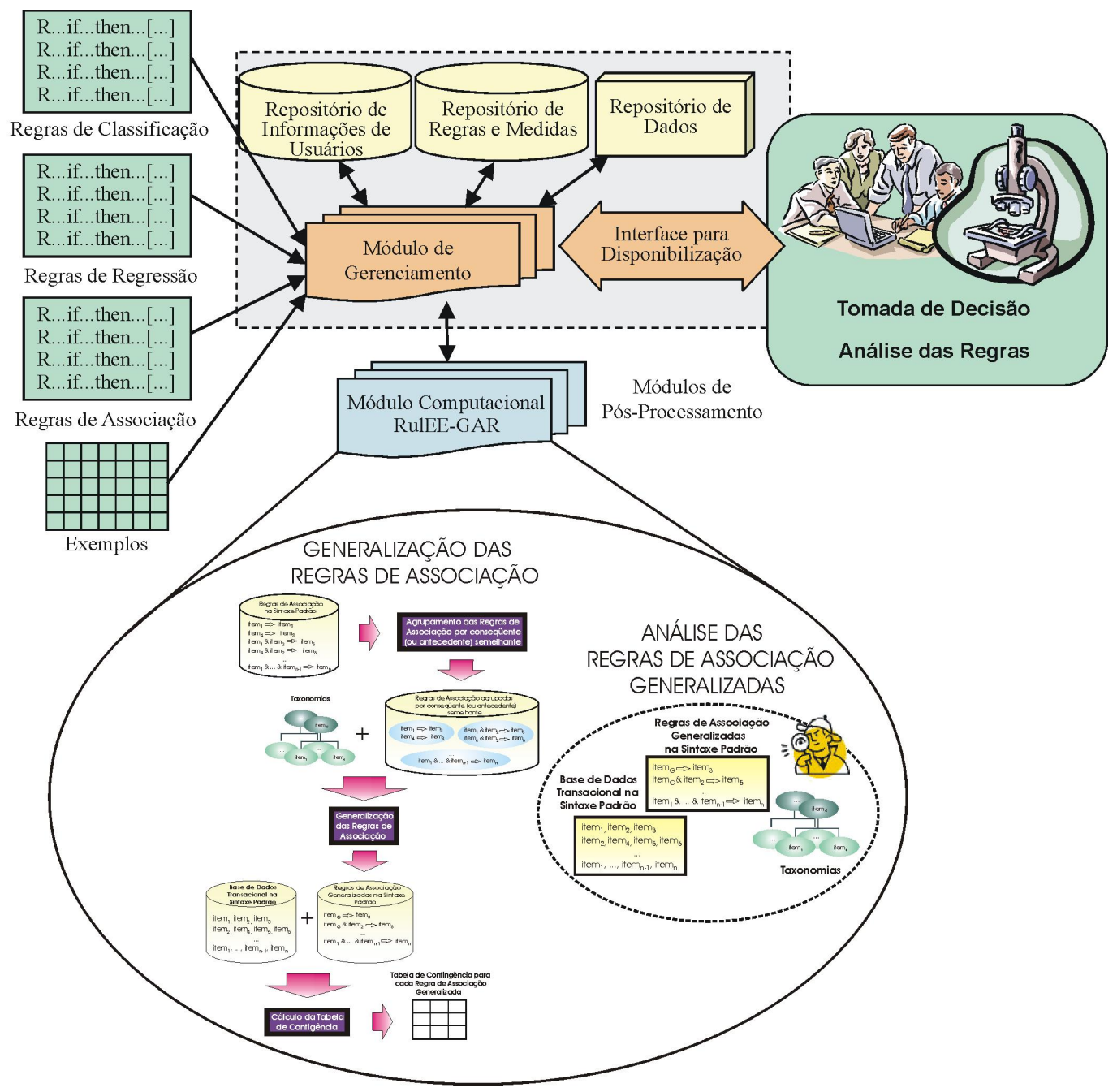

Figura 3.4: Contextualização e funcionalidades do módulo computacional RuLEE-GAR no protótipo do ambiente RULEE (Domingues, 2004)

É possível generalizar regras de associação utilizando o algoritmo GART, apresentado na Figura 3.5 da maneira descrita a seguir.

Inicialmente os itens camiseta e bermuda das regras

$$
\begin{aligned}
& \text { camiseta \& chinelo } \Rightarrow \text { boné, } \\
& \text { camiseta \& sandália } \Rightarrow \text { boné, } \\
& \text { bermuda \& sandália } \Rightarrow \text { boné e } \\
& \text { bermuda \& chinelo } \Rightarrow \text { boné, }
\end{aligned}
$$


são substituídos pelo item roupas leves (que representa uma generalização) gerando duas regras roupas leves $\&$ chinelo $\Rightarrow$ boné e duas regras roupas leves \& sandália $\Rightarrow$ boné. Em seguida, as regras repetidas são removidas permanecendo apenas as regras

$$
\begin{aligned}
& \text { roupas leves \& chinelo } \Rightarrow \text { boné e } \\
& \text { roupas leves \& sandália } \Rightarrow \text { boné. }
\end{aligned}
$$

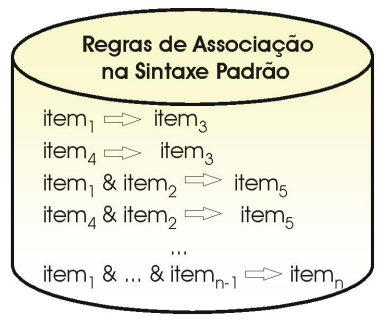

Agrupamento das Regras de

Associação por conseqüente

(ou antecedente) semelhante

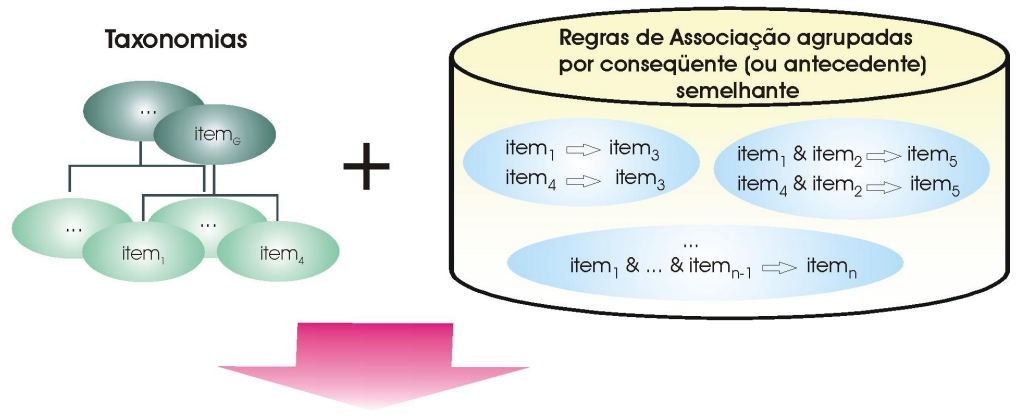

Generalização

das Regras de

Associação
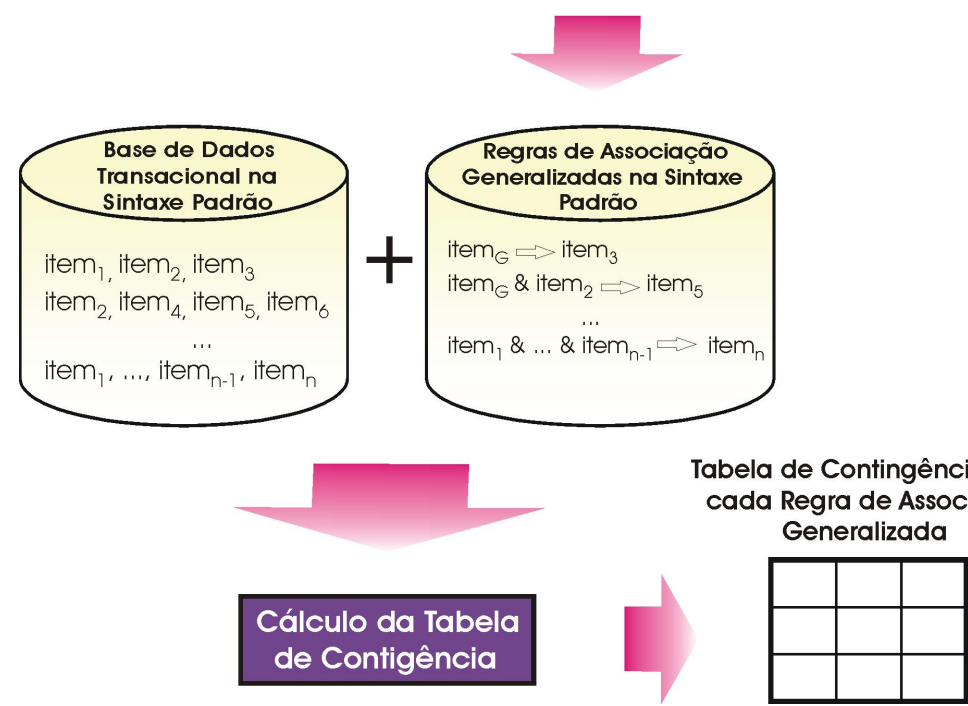

Cálculo da Tabela de Contigência

Figura 3.5: Processo para generalização de regras de associação no algoritmo GART (Domingues, 2004)

As duas regras resultantes são novamente generalizadas, sendo os itens chinelo e sandália substituídos pelo item calçados abertos (que representa outra generalização), gerando duas regras roupas leves \& calçados abertos $\Rightarrow$ boné. Em seguida, as regras repetidas são removidas permanecendo apenas a regra de associação generalizada 
roupas leves \& calçados abertos $\Rightarrow$ boné.

O processo proposto generaliza apenas um dos lados ( $L H S$ ou $R H S)$ das regras de associação. Inicialmente as regras, representadas na sintaxe padrão definida por Melanda \& Rezende (2003), são agrupadas em subconjuntos que apresentam antecedente ou conseqüente semelhante. Se o processo for utilizado para generalizar o lado esquerdo das regras $(L H S)$, os subconjuntos são gerados utilizando conseqüentes $(R H S)$ semelhantes e se o processo for utilizado para generalizar o lado direito das regras ( $R H S$ ), os subconjuntos são gerados utilizando antecedentes $(L H S)$ semelhantes. Na Figura 3.5 é ilustrado o processo de generalização do lado esquerdo das regras, por conseqüência, os subconjuntos são agrupados utilizando semelhanças no lado direito das regras. Em seguida são utilizadas as taxonomias para generalizar cada subconjunto e, ao final da generalização, os itens de cada regra são ordenados lexicograficamente e a regra é armazenada em um conjunto de regras de associação generalizadas.

A interface do módulo RuLEE-GAR utiliza o algoritmo GART para generalizar os conjuntos de regras de associação armazenados no ambiente RULEE, além de possibilitar a análise e exploração de regras generalizadas.

\subsubsection{Generalização de Regras de Associação Usando Taxonomias}

Carvalho (2004) propõe analisar os conjuntos de regras de associação gerados quando taxonomias são utilizadas nas diferentes etapas do ciclo principal do processo de mineração de dados (pré-processamento, extração de padrões e pós-processamento). A partir dessa análise, espera-se verificar em qual das etapas o uso de taxonomias é mais eficiente para a obtenção de um bom conjunto de regras, em termos de quantidade e qualidade das regras, a fim de auxiliar os usuários na análise e interpretação das mesmas.

Para isso, estão sendo desenvolvidas metodologias para generalizar regras de associação em cada uma das três etapas citadas anteriormente. O algoritmo da etapa de pré-processamento é uma modificação do Apriori e substitui todos os itens da base de transações pelos itens gerais encontrados na taxonomia. Posteriormente, o algoritmo gera as regras de associação normalmente. Dessa maneira, não são geradas regras específicas, uma vez que os itens específicos foram substituídos por itens gerais.

Para a etapa de extração de padrões também foi realizada uma modificação no algoritmo Apriori para que o mesmo gerasse regras de associação generalizadas. Esse algoritmo acrescenta os itens gerais (ascendentes) nas transações em que o item específico é encontrado, criando uma espécie de base de dados extendida. Com essa base de dados, o algoritmo gera as regras de associação normalmente, com o cuidado de não permitir que um descendente implique no seu ascendente. Nesse caso, são geradas as regras específicas e generalizadas.

A abordagem de pós-processamento, assim como no RuLEE-GAR (Domingues, 2004), 
consiste em generalizar um conjunto de regras de associação obtidas por um algoritmo tradicional de extração de regras em regras mais gerais com base em uma taxonomia fornecida pelo usuário. Essa generalização das regras poderá ser feita em apenas um dos lados da regra (antecedente ou conseqüente) ou em ambos os lados da regra e as regras generalizadas poderão não utilizar todos os itens contidos na taxonomia. Essa segunda característica pode ser melhor compreendida por meio do exemplo a seguir. Supondo que a regra leite $\Rightarrow$ pão represente uma regra generalizada e que leite esteja representado na taxonomia por leite $\mathrm{A}$, leite $\mathrm{B}$, leite $\mathrm{C}$, leite $\mathrm{D}$ e leite $\mathrm{E}$. $\mathrm{A}$ regra leite $\Rightarrow$ pão será generalizada mesmo que não exista uma regra para cada tipo de leite. Sendo assim, para orientar o usuário na compreensão da regra generalizada, é gerada uma lista contendo a participação de cada um dos itens específicos nos itens gerais. Para a regra acima descrita, seria gerada a listagem apresentada na Figura 3.6.

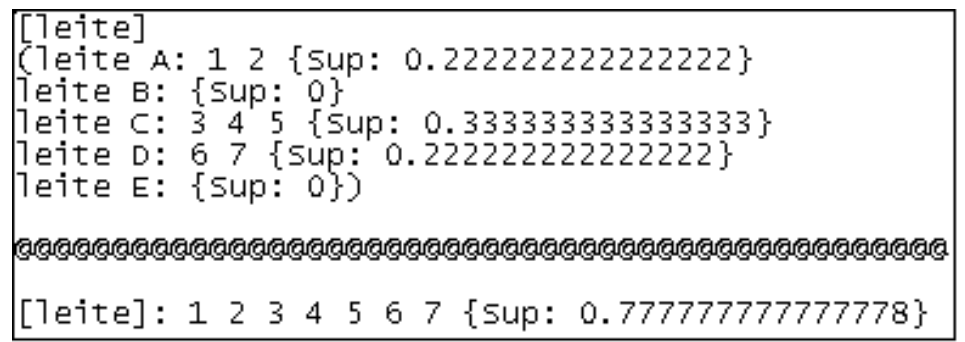

Figura 3.6: Exemplo de uma listagem de contribuição dos itens

\subsection{Considerações Finais}

O pós-processamento de regras de associação não é uma tarefa trivial, visto que um grande volume de regras é gerado dificultando a análise e compreensão do conhecimento. Para solucionar esse problema, taxonomias podem ser utilizadas. As taxonomias permitem que o conhecimento obtido seja generalizado, tornando-o mais compreensível ao usuário e reduzindo o conjunto de regras.

Neste capítulo foram apresentados os conceitos e definições de taxonomias e sua utilização em regras de associação. Também foram apresentadas ferramentas que auxiliam a análise e interpretação de regras de associação por meio de medidas ou da sua generalização usando taxonomias. O desenvolvimento de ferramentas como essas tem grande importância, especialmente no caso das regras de associação, uma vez que o número de regras gerado dificulta ou até mesmo inviabiliza sua avaliação.

Para utilizar os ambientes de generalização de regras de associação descritos nesse capítulo, o usuário deve fornecer um conjunto de taxonomias. A construção manual dessas taxonomias representa um alto custo, uma vez que consome muito tempo e exige profundo conhecimento do domínio. Por outro lado, uma construção completamente automática, em geral, é uma solução restritiva. Isso porque o conhecimento e a análise do especialista 
são imprescindíveis para que sejam obtidas taxonomias úteis, corretas e interessantes.

No próximo capítulo é apresentada uma metodologia para construção de taxonomias de maneira semi-automática. Nessa metodologia são utilizados métodos automáticos e interativos, combinando a velocidade proporcionada pela construção automática com o conhecimento obtido pela interação com o especialista. 


\section{Metodologia para Construção}

\section{Semi-automática de Taxonomias para Generalização de Regras de Associação}

omo discutido nos capítulos anteriores, a identificação de conhecimento interessante é um fator determinante para o sucesso do processo de mineração de dados.

No caso de regras de associação, a generalização usando taxonomias pode ser de grande auxílio, podendo reduzir o conjunto de regras e facilitando sua análise e interpretação. Porém, estudar o domínio e identificar suas taxonomias é uma tarefa custosa, pois exige grande conhecimento do domínio e muito tempo para ser realizada. Por outro lado, não é interessante que o conhecimento do especialista ${ }^{1}$ do domínio seja descartado, uma vez que ele é muito importante para garantir a obtenção de taxonomias úteis, corretas e interessantes. Por esse motivo, é interessante a proposta de uma metodologia que auxilie o usuário na identificação de taxonomias combinando métodos automáticos e interativos, ou seja, métodos que utilizem conceitos básicos de taxonomias e o conhecimento do especialista para gerá-las.

Neste capítulo é apresentada uma metodologia para construção semi-automática de taxonomias a partir de bases de dados para generalização de regras de associação, que utiliza métodos automáticos e interativos para gerar conhecimento expresso em taxonomias (Martins \& Rezende, 2006a). A metodologia proposta foi desenvolvida baseada nos conceitos básicos de taxonomias e no seu uso para generalizar regras de associação (Adamo, 2001), apresentados no Capítulo 3. Assim, foi definido que:

\footnotetext{
${ }^{1}$ Nesse capítulo, os termos "usuário" e "especialista do domínio" são utilizados de maneira indiscriminada, uma vez que os dois tipos de usuários do processo de mineração de dados podem utilizar a metodologia proposta.
} 
- Cada item da taxonomia deve possuir apenas um pai. Essa característica facilita o processo de generalização, uma vez que assim não será necessário escolher entre diversos itens para substituir uma especialização. Além disso, caso os itens tivessem diversos pais e as regras pudessem ser generalizadas com todos eles, seriam geradas muitas regras, o que dificultaria ainda mais a análise e compreensão do conhecimento extraído na forma de regras de associação. Caso seja necessário representar um mesmo domínio com taxonomias diferentes, deve ser realizada outra construção.

- Um item pode possuir $n$ filhos. Este é um conceito básico de taxonomia que também se aplica sem problemas às regras generalizadas.

- Se um item possuir filhos ele não pode ser excluído da taxonomia para que não seja descartada toda a sua especialização. Para realizar a exclusão, é necessário realocar os filhos definindo seus novos pais ou excluindo-os da taxonomia.

- Os itens do nível ${ }^{2}$ mais alto da taxonomia (generalização máxima ou raiz) não possuem pai.

- Os itens do nível mais baixo da taxonomia (especialização máxima ou folha) não possuem filhos.

\subsection{Metodologia Proposta}

Na metodologia para construção semi-automática de taxonomias para generalização de regras de associação proposta neste trabalho, os elementos iniciais da taxonomia são gerados automaticamente a partir de um arquivo texto contendo a descrição dos elementos do domínio e seus atributos. Esse arquivo é descrito na Seção 4.3.4. Para a implementação dessa funcionalidade, foram considerados os conceitos e definições de taxonomias discutidos na Seção 3.1.1. Após gerada uma taxonomia o usuário pode explorá-la, manipulando como desejar os elementos e também selecionando e/ou coordenando outras funcionalidades automáticas para gerar novos grupos.

Na Figura 4.1 é ilustrada a metodologia proposta, que, a partir da descrição dos itens do domínio contida no arquivo fornecido pelo usuário, gera um conjunto de itens freqüentes contando as palavras existentes nas descrições dos registros. Esses itens freqüentes ficarão, inicialmente, no nível mais alto da taxonomia (generalização máxima) e cada um desses itens receberá como filhos os elementos que possuirem em sua descrição o nome do próprio item freqüente. Assim é obtida a taxonomia inicial, que poderá ser modificada pelo usuário. Também é possível selecionar e coordenar outras funcionalidades automáticas para obter novos grupos. Uma delas realiza um reagrupamento de acordo com um atributo (existente no arquivo texto fornecido) selecionado pelo usuário, comparando o valor desse

\footnotetext{
${ }^{2}$ Um nível representa uma generalização/especialização, sendo que o nível mais alto (raiz) é a generalização máxima e o nível mais baixo (folha) é a especialização máxima.
} 


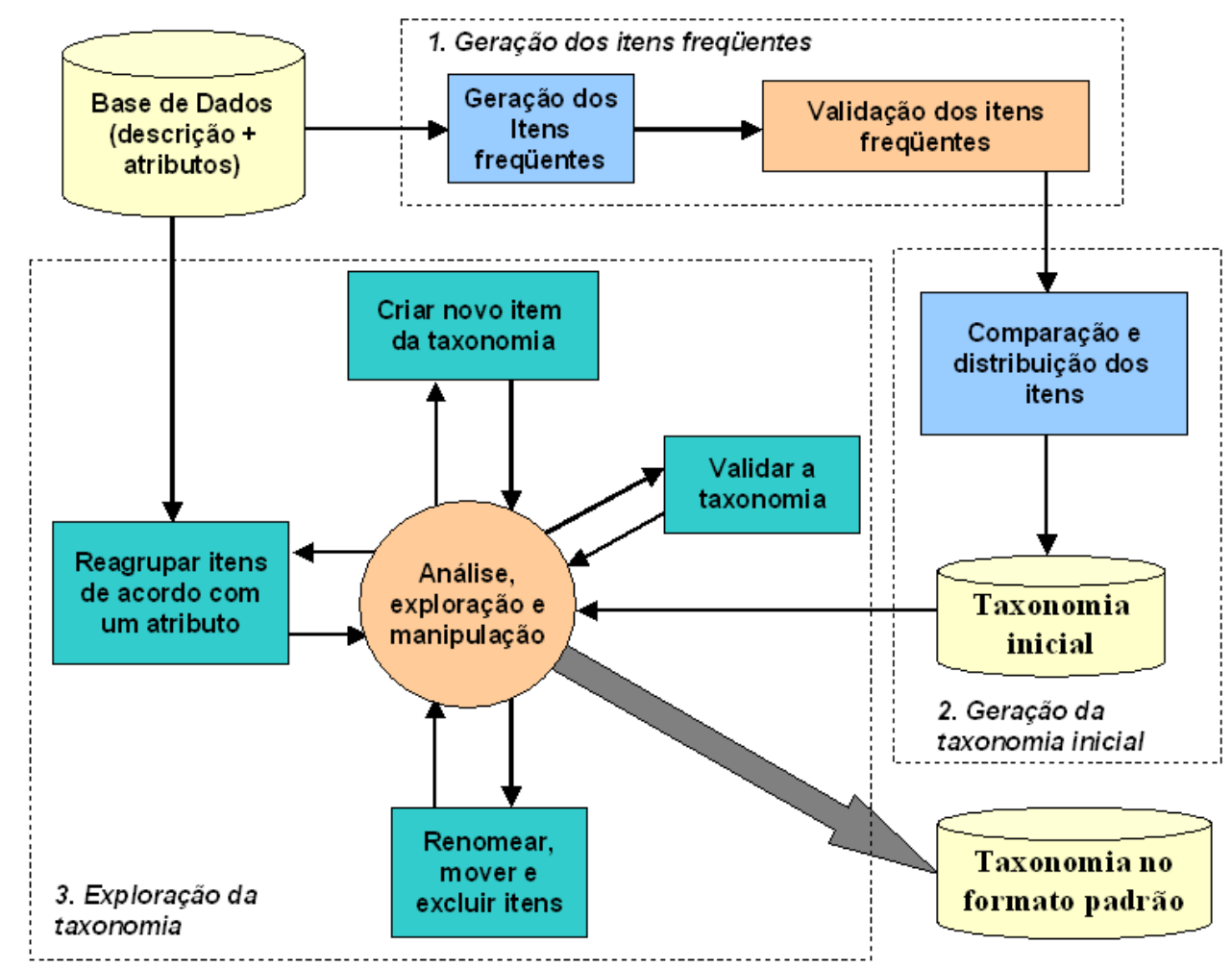

Figura 4.1: Metodologia para construção semi-automática de taxonomias para generalização de regras de associação

atributo para os itens folha (especialização máxima) selecionados e redistribuindo-os na taxonomia. A outra funcionalidade permite que o usuário insira uma nova informação para itens da taxonomia que correspondam à generalização máxima a fim de agrupar os que possuam os mesmos valores para a informação e, assim, criar novos itens da taxonomia que a partir desse momento corresponderão à generalização máxima. A seguir, são descritas as três etapas da metodologia.

\section{Geração dos Itens Freqüentes}

Essa etapa é realizada a fim de obter os itens freqüentes a partir das descrições dos registros da tabela (arquivo) fornecida pelo usuário. Ela determina toda a taxonomia, uma vez que os itens existentes no conjunto de dados serão distribuídos de acordo com a semelhança das palavras de sua descrição com determinado item freqüente. Após a geração automática dos itens freqüentes, eles devem ser analisados e selecionados, podendo ser excluídos um por um ou de acordo com um valor de "corte", que representa a freqüência mínima que os itens devem ter para serem considerados. Essa tarefa deve ser realizada cuidadosamente para que, posteriormente, não sejam gerados grupos indesejados e nem omitidos grupos importantes.

\section{Geração da Taxonomia Inicial}

Nessa etapa é realizada uma comparação entre as três primeiras palavras existentes na descrição de cada item da tabela e os itens freqüentes, com o objetivo de definir a distribuição dos itens na taxonomia. A quantidade de palavras a serem comparadas 
foi definida neste projeto após a realização de uma análise de diversas bases de dados, por meio da qual foi possível perceber que apenas as três primeiras palavras das descrições dos registros eram importantes para distribuir os itens da taxonomia. As restantes normalmente correspondem à informações específicas de cada registro, não tendo utilidade para esse problema. Considerando, por exemplo, uma base de dados de produtos alimentícios e os produtos que contêm a palavra "leite" em sua descrição, como "leite", "creme de leite", "doce de leite" e "leite condensado". É possível observar que, em geral, as palavras restantes apenas contêm informações como a quantidade do produto e sua marca.

Quando existe um elemento do conjunto de dados com uma palavra de sua descrição igual ao item freqüente, é gerado um grupo no qual:

- O item freqüente é a generalização máxima da taxonomia (exemplo: "leite";

- O nome do item freqüente mais a posição em que ele se encontra na descrição do elemento do conjunto de dados ("Item freqüente + posição") também se torna um item da taxonomia (exemplo: "leite 1"e é filho do item freqüente que o gerou;

- O elemento que está sendo comparado é filho do "Item freqüente + posição" (exemplo "leite molico") e especialização máxima da taxonomia.

Um item freqüente só se tornará um item da taxonomia caso ele seja encontrado em alguma das três primeiras palavras da descrição de algum elemento do conjunto de dados. Dessa maneira, ele possuirá no mínimo um filho e no máximo três (que correspondem à posição em que ele foi encontrado), pois a comparação é realizada com as três primeiras palavras da descrição de cada item, como definido anteriormente. Cada item da taxonomia correspondente à posição do item freqüente na descrição do elemento da base de dados, receberá o próprio elemento como filho e possuirá, portanto, $n$ filhos.

Existe também a possibilidade de gerar grupos apenas a partir do "Item freqüente + posição", ou seja, ele seria a generalização máxima e os itens freqüentes não se tornariam itens da taxonomia. Essa opção provê maior flexibilidade na construção de taxonomias, uma vez que o usuário pode não querer agrupar palavras que possuam o item freqüente em diferentes posições de sua descrição. Por exemplo, considerando um item freqüente MAÇÃ. Os diferentes tipos de maçã, como maçã verde, maçã fuji e maçã vermelha, seriam agrupados em MAÇ̃̃ 1 e produtos como bala de maçã e torta de maçã seriam agrupados em MAÇ̃̃ 3. Na primeira opção da metodologia, os itens MAÇÃ 1 e MAÇÃ 3 seriam agrupados em MAÇÃ, o que é uma representação válida, uma vez que esse pode ser considerado um grupo de produtos de maçã. Porém, também é possível que o usuário deseje agrupar os elementos de MAÇÃ 1 com frutas e os elementos de MAÇÃ 3 com sobremesas. Assim, a segunda opção seria mais indicada pois facilita a realização desses grupos. 
Após a realização da comparação e a geração da taxonomia inicial não é permitido editar itens freqüentes, uma vez que isso implicaria em inconsistência entre os itens freqüentes e a taxonomia gerada. Porém é possível alterar a taxonomia e realizar novos grupos.

\section{Exploração da Taxonomia}

A exploração da taxonomia pode ser realizada diversas vezes durante o processo ${ }^{3}$ de construção de taxonomias a partir do momento em que a taxonomia inicial é gerada. A exploração da taxonomia aborda seis funcionalidades, as quais são descritas a seguir:

- Renomear um item da taxonomia: a metodologia permite que os nomes dos itens sejam modificados. Assim, é possível tornar a taxonomia mais compreensível e correta, pois pode-se excluir partes da descrição de um item que não sejam consideradas interessantes e/ou mudar o nome do pai de um grupo com o objetivo de que ele o represente melhor.

- Mover um item da taxonomia: é possível que, durante a análise da taxonomia gerada, seja verificado que determinado item se encaixa melhor em outro grupo. Dessa maneira, pode-se mover o item, bastando definir o pai desse grupo como seu novo pai. Porém um item só poderá ser movido se mantiver a consistência da taxonomia, ou seja, se nenhum dos grupos ficar com nível menor que um (nível mínimo de uma taxonomia).

- Excluir um item da taxonomia: caso seja identificado algum item que não possui utilidade para a representação taxonômica esperada ou que não deveria ter sido gerado, é possível excluí-lo da taxonomia. Essa funcionalidade só pode ser realizada se o item não possuir filhos, para que não seja descartada toda a sua especialização. Se for realmente necessária sua exclusão, deve-se mover ou excluir seus filhos de maneira que o item que se deseja excluir se torne um item folha da taxonomia.

- Reagrupar de acordo com um atributo: por meio dessa funcionalidade o usuário pode selecionar um atributo da tabela fornecida (no formato de um arquivo texto) para que os itens folha da taxonomia, que correspondem à descrição dos registros, sejam reagrupados de acordo com o seu valor para o atributo determinado. Para isso, também devem ser selecionados o itens folha que deverão ser realocados. Assim, é realizada, para o atributo e o item selecionados, uma comparação entre o valor do atributo para o item e os valores desse mesmo atributo para os outros itens que estão no mesmo grupo (possuem o mesmo pai). Depois são procurados todos os itens que possuem o mesmo valor para o atributo selecionado e o item selecionado é colocado no grupo que tiver maior número de filhos com o mesmo valor para o atributo selecionado.

\footnotetext{
${ }^{3} \mathrm{Um}$ processo compreende as etapas de construção semi-automática de taxonomias.
} 
- Criar um novo item da taxonomia: o objetivo dessa funcionalidade é criar novos elementos da taxonomia, ou seja, continuar sua construção. Ao visualizar a taxonomia, o usuário pode identificar alguma característica que pode representar um grupo para os elementos do nível mais alto. Dessa maneira, ele pode inserir um novo atributo e definir o mesmo valor desse atributo para os itens que deseja agrupar. Então, definido o atributo e seus valores, é gerado um grupo dos itens que possuem o mesmo valor para esse atributo e a geração de um novo item da taxonomia, que corresponderá ao nível mais alto (generalização máxima). O nome desse novo item será o nome do valor do atributo. Sendo assim, caso o usuário tenha definido o mesmo atributo com diferentes valores para diversos itens da taxonomia, haverá um grupo para cada valor do atributo, resultando em um novo item da taxonomia para cada valor do atributo. Cada valor de um atributo pode ser utilizado apenas uma vez para gerar um novo item da taxonomia, para que posteriormente não existam grupos diferentes com o mesmo nome.

- Validar a taxonomia: quando considerar que a taxonomia está de acordo com suas expectativas e é válida, o usuário pode obter um arquivo texto com a taxonomia no formato padrão do algoritmo $S A C T$.

Como é possível perceber, a etapa exploração da taxonomia inicial é iterativa, ou seja, é executada diversas vezes durante o processo de construção semi-automática de taxonomias para generalização de regras de associação. É também interativa, pois é realizada com o apoio do usuário.

Após a finalização da construção da taxonomia, um arquivo com a representação da mesma no formato padrão do algoritmo $S A C T$ pode ser obtido a fim de que a taxonomia possa ser utilizada para generalizar regras de associação. Nesse formato os grupos são representados da seguinte maneira: PAI(FILHOS)(NÍVEL). Os itens (filhos) são separados por vírgula.

\subsection{Considerações sobre a Metodologia}

Como apresentado anteriormente, a metodologia proposta utiliza métodos automáticos e interativos para construir taxonomias para generalização de regras de associação. A sua utilidade no próprio processo de construção de taxonomias e na generalização de regras de associação são aspectos que são discutidos a seguir:

- A combinação de métodos automáticos e manuais é de grande auxílio na identificação e construção de taxonomias, pois reduz a quantidade de informação e o tempo necessários para a realização dessa tarefa sem descartar o conhecimento que o especialista pode fornecer. Além disso, a metodologia auxilia a construção de taxonomias 
mais interessantes e que representam melhor o domínio, uma vez que a participação do especialista provê qualidade para as mesmas e os procedimentos automáticos possibilitam a identificação de grupos novos, que poderiam não ser identificados em um processo totalmente manual.

- A utilização de taxonomias mais interessantes e representativas no processo de generalização de regras de associação tem como resultado regras generalizadas que podem apresentar uma melhor representação do itens. As regras generalizadas também são, em geral, mais compreensíveis uma vez que as taxonomias utilizadas podem representar o conhecimento de maneira mais clara e intuitiva. Além disso, por meio de experimentos realizados com taxonomias construídas manualmente foi possível perceber que quanto maior a qualidade e expressividade das taxonomias, melhor a taxa de redução e compreensibilidade das regras na generalização de regras de associação (na etapa de pós-processamento).

- As taxonomias geradas por meio da metodologia podem ser utilizadas para obter regras de associação generalizadas em qualquer etapa do processo de mineração de dados.

Para viabilizar a utilização da metodologia apresentada na Figura 4.1 foi desenvolvido o módulo de construção semi-automática de taxonomias que apóia a generalização de regras de associação no ambiente RulEE, uma vez que gera taxonomias a partir dos dados.

\subsection{Módulo de Construção Semi-automática de Taxonomias para Generalização de Regras de Associação - RulEE-SACT}

O módulo de construção semi-automática de taxonomias para generalização de regras de associação RulEE-SACT é um dos módulos de pós-processamento do ambiente RuLEE e foi desenvolvido com o objetivo de viabilizar a utilização da metodologia proposta neste trabalho e apresentada neste capítulo. No RULEE-SACT, podem ser realizadas todas as etapas descritas na Seção 4.1 e apresentadas na Figura 4.1. Um arquivo com as taxonomias de um domínio construídas no módulo RULEE-SACT pode ser obtido no formato padrão do algoritmo $S A C T$, a fim de que elas sejam usadas por algoritmos que generalizam regras de associação.

Nessa seção é apresentado o módulo RuLEE-SACT, descrevendo sua implementação e sua utilização. Vale ressaltar que, por ser um módulo do RulEE, o RulEE-SACT utiliza seus repositórios e métodos para acesso aos dados. A seguir é apresentado o documento de requisitos, elaborado durante a fase de análise e projeto do desenvolvimento do módulo. Na seqüência são descritas as inclusões realizadas nos repositórios do RuLEE 
necessárias para a implementação do RuLEE-SACT, as classes implementadas para executar a metodologia proposta e o arquivo que deve ser fornecido pelo usuário para iniciar o processo. Também são apresentados nessa seção o procedimento adotado para a geração de itens freqüentes e da taxonomia inicial e a descrição de um processo de construção de taxonomias realizado no RULEE-SACT.

\subsubsection{Requisitos}

A primeira atividade realizada para o desenvolvimento do RULEE-SACT foi o levantamento de requisitos. Com esse levantamento definiu-se as funcionalidades do módulo, que são:

- Especificação de um processo de construção semi-automática de taxonomias;

- Geração e seleção dos itens freqüentes;

- Geração da taxonomia inicial, baseada na comparação dos itens freqüentes com as palavras existentes nas descrições dos registros;

- Visualização e alteração da taxonomia de um processo;

- Redistribuição dos itens de acordo com algum atributo selecionado pelo usuário;

- Geração de novo item da taxonomia, compreendendo a inserção de novos atributos para os itens do nível mais alto da taxonomia (generalização máxima) e o grupo de itens com o mesmo valor de um atributo criado pelo usuário.

A partir da realização dessa atividade foi elaborado um documento de requisitos, que é apresentado no Apêndice A.

\subsubsection{Repositório}

Para a implementação do módulo RuLEE-SACT foi necessária a criação de cinco novas tabelas no repositório de taxonomias do ambiente RuLEE, nomeadas EXPLO_TAX, FREQ, PROD, TAX e ATTRIBUTE. Uma breve descrição dessas tabelas encontra-se na Tabela 4.1 e na Figura 4.2 é apresentada parte do diagrama físico da base de dados do ambiente RulEE, contendo essas atualizações e as principais tabelas utilizadas na implementação do RULEE-SACT. A descrição completa das tabelas criadas e de seus atributos está disponível em Martins \& Rezende (2006b). 


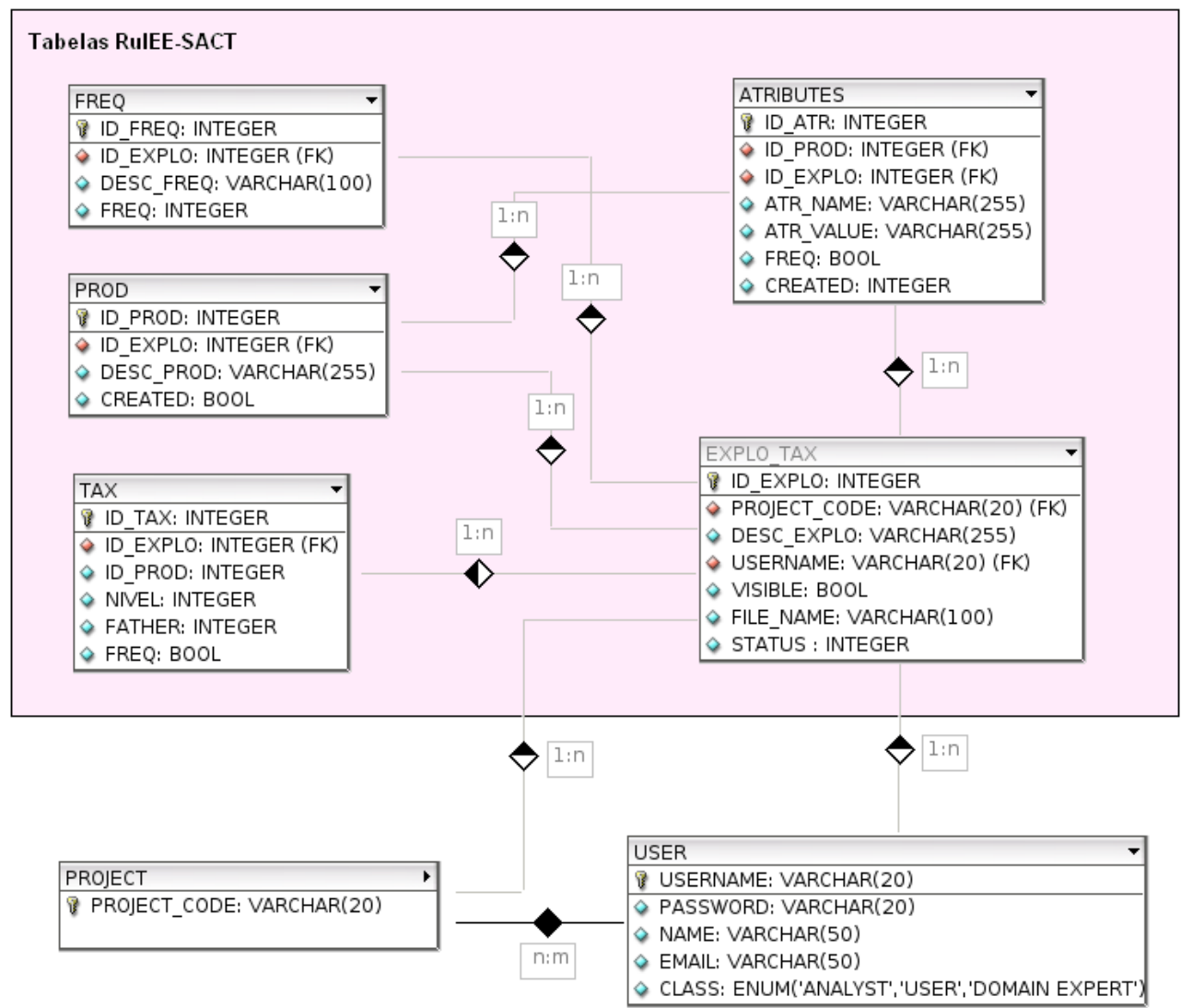

Figura 4.2: Parte do diagrama físico da base de dados do RulEE

\begin{tabular}{|l|l|}
\hline \multicolumn{1}{|c|}{ Nome da Tabela } & \multicolumn{1}{c|}{ Descrição } \\
\hline \hline EXPLO_TAX & $\begin{array}{l}\text { Armazena dados referentes a um processo de construção } \\
\text { de taxonomias iniciado no RULEE-SACT, como número } \\
\text { de identificação e nome do processo, usuário responsável, } \\
\text { código do projeto no RuLEE e etapas já realizadas. }\end{array}$ \\
\hline FREQ & $\begin{array}{l}\text { Armazena os itens freqüentes gerados e selecionados pelo } \\
\text { usuário, suas freqüências e o número de identificação do } \\
\text { processo em que foram gerados. }\end{array}$ \\
\hline PROD & $\begin{array}{l}\text { Armazena as informações dos elementos da taxonomia } \\
\text { gerados a partir da tabela inserida pelo usuário e dos } \\
\text { elementos gerados durante a construção da taxonomia. } \\
\text { Armazena também o número de identificação do processo } \\
\text { em que esses dados foram gerados. }\end{array}$ \\
\hline TAX & $\begin{array}{l}\text { Armazena as informações das taxonomias, como número } \\
\text { de identificação, número de identificação do item, nível, } \\
\text { pai e número de identificação do processo. }\end{array}$ \\
\hline ATTRIBUTE & $\begin{array}{l}\text { Armazena os atributos e seus respectivos valores para } \\
\text { cada registro da tabela fornecida pelo usuário. }\end{array}$ \\
\hline
\end{tabular}

Tabela 4.1: Descrição das tabelas criadas para o RuLEE-SACT 


\subsubsection{Classes}

Para implementar a metodologia proposta nesse trabalho, foi criada a classe SACT, que armazena todos os métodos utilizados para manipular um processo de construção semi-automática de taxonomias.

Os principais métodos dessa classe e suas funcionalidades são apresentadas na Tabela 4.2. Descrições detalhadas sobre a classe SACT podem ser encontradas em Martins \& Rezende (2006b).

\subsubsection{Definição e Tratamento dos Dados de Entrada}

Para construir as taxonomias utilizando o RuLEE-SACT, o usuário deve fornecer um arquivo texto com as informações sobre um domínio. As informações devem estar representadas no formato de uma tabela, ou seja, como uma base de dados com seus atributos e registros (tudo separado por tabulação). A primeira linha do arquivo deve conter o nome do atributo que representa a descrição dos registros da base de dados e as linhas seguintes devem conter a tabela propriamente dita. Isso porque é o atributo de descrição que será utilizado na contagem dos itens freqüentes e na geração dos elementos folhas da taxonomia.

Também é necessário que seja realizada uma limpeza e seleção nos dados de entrada, selecionando os atributos e registros interessantes e excluindo da descrição caracteres que não tenham utilidade para o processo. Um exemplo de arquivo representando uma base de dados de um supermercado que poderia ser fornecido ao sistema é apresentado na Figura 4.3 e uma descrição detalhada sobre o arquivo de entrada pode ser encontrada em Martins \& Rezende (2006b).

\begin{tabular}{|lll|}
\hline DESCRICAO & CODIGO & SETOR \\
DESCRICAO & 1 & 1 \\
LEITE A & 2 & 1 \\
LEITE B & 3 & 1 \\
LEITE C & 4 & 2 \\
VINHO A & 5 & 2 \\
VINHO B & 6 & 2 \\
CERVEJA A & 7 & 2 \\
CERVEJA B & 8 & 1 \\
QUEIJO A & 9 & 1 \\
QUEIJO B & 9 & \\
\hline
\end{tabular}

Figura 4.3: Exemplo de um arquivo texto de entrada do módulo RulEE-SACT para um domínio de supermercado

\subsubsection{Visão Geral do Algoritmo SACT}

Como apresentado na Seção 4.1, o algoritmo SACT possui três etapas principais. No Algoritmo 1 são apresentadas duas delas: geração dos itens freqüentes e geração da taxonomia inicial (opção para gerar os itens freqüentes como generalização máxima). A 


\begin{tabular}{|c|c|}
\hline Nome do Método & Funcionalidade \\
\hline CreateExplo & Cria um processo de construção semi-automática de taxonomias. \\
\hline CountFreq & $\begin{array}{l}\text { Lê a tabela inserida pelo usuário e salva a freqüência das palavras } \\
\text { nas descrições dos registros. }\end{array}$ \\
\hline ReadProd & $\begin{array}{l}\text { Lê a tabela inserida pelo usuário e salva as descrições dos registros } \\
\text { e os seus atributos. }\end{array}$ \\
\hline GetFreq & $\begin{array}{l}\text { Retorna as informações dos itens freqüentes de determinado pro- } \\
\text { cesso. }\end{array}$ \\
\hline GetProd & Retorna as informações dos itens. \\
\hline DeleteFreq1 & $\begin{array}{l}\text { Exclui os itens freqüentes com freqüência menor ou igual a um } \\
\text { número determinado pelo usuário. }\end{array}$ \\
\hline DeleteFreq2 & Exclui os itens freqüentes selecionados pelo usuário. \\
\hline Compare & $\begin{array}{l}\text { Gera as taxonomias iniciais comparando os itens freqüentes com } \\
\text { as descrições dos elementos dos registros e criando as taxonomias } \\
\text { de níveis } 1 \text { e } 2 \text { de acordo com a posição da palavra freqüente nas } \\
\text { descrições dos elementos. }\end{array}$ \\
\hline ShowTax & $\begin{array}{l}\text { Seleciona os itens da taxonomia e os organiza de uma maneira } \\
\text { compreensível ao usuário. }\end{array}$ \\
\hline UpdateTax & Move ou exclui taxonomias. \\
\hline UpdateName & Altera o nome dos itens da taxonomia. \\
\hline CompareProd & $\begin{array}{l}\text { Redistribui um item do nível mais baixo da taxonomia de um } \\
\text { processo de acordo com um atributo selecionado pelo usuário, } \\
\text { colocando-o no grupo onde existem mais produtos com o mesmo } \\
\text { valor para esse atributo. }\end{array}$ \\
\hline NewInfo & $\begin{array}{l}\text { Insere uma nova informação (nome de atributo e valor de atri- } \\
\text { buto) para determinado item do nível mais alto da taxonomia. A } \\
\text { informação inserida também é salva para todos os filhos daquele } \\
\text { elemento. }\end{array}$ \\
\hline NewTax & $\begin{array}{l}\text { Agrupa itens de um processo segundo um atributo criado pelo } \\
\text { usuário e gera um item de nível superior, que será o pai dos itens } \\
\text { agrupados. }\end{array}$ \\
\hline GenerateTaxFile & Gera um arquivo no formato padrão do algoritmo $S A C T$. \\
\hline GetExplorations & $\begin{array}{l}\text { Retorna os processos criados no RULEE-SACT por um determi- } \\
\text { nado usuário em um projeto especificado. }\end{array}$ \\
\hline GetVisibleExplorations & $\begin{array}{l}\text { Seleciona os processos que podem ser visualizados por determinado } \\
\text { usuário em um determinado projeto. Isso inclui todos os processos } \\
\text { do usuário e os processos visíveis de outros usuários. }\end{array}$ \\
\hline GetStatus & $\begin{array}{l}\text { Retorna a situação de um processo, ou seja, quais etapas já foram } \\
\text { realizadas. }\end{array}$ \\
\hline GetFrequency & Retorna as frequências dos itens freqüentes do processo. \\
\hline GetTax & Retorna as informações das taxonomias de um processo. \\
\hline GetAtrProd & Retorna as informações dos atributos de determinado elemento. \\
\hline
\end{tabular}

Tabela 4.2: Descrição dos principais métodos da classe SACT

combinação dessas duas etapas tem como objetivo gerar a taxonomia inicial, na qual o especialista poderá utilizar as outras funcionalidades a fim de obter a taxonomia desejada. Uma descrição de todas as funcionalidades e o algoritmo completo podem ser encontrados em Martins \& Rezende (2006b).

Para que o algoritmo fosse executado com rapidez, o mesmo foi implementado utilizando a estrutura de dados "hash de vetores". Isso porque essa estrutura possui uma 


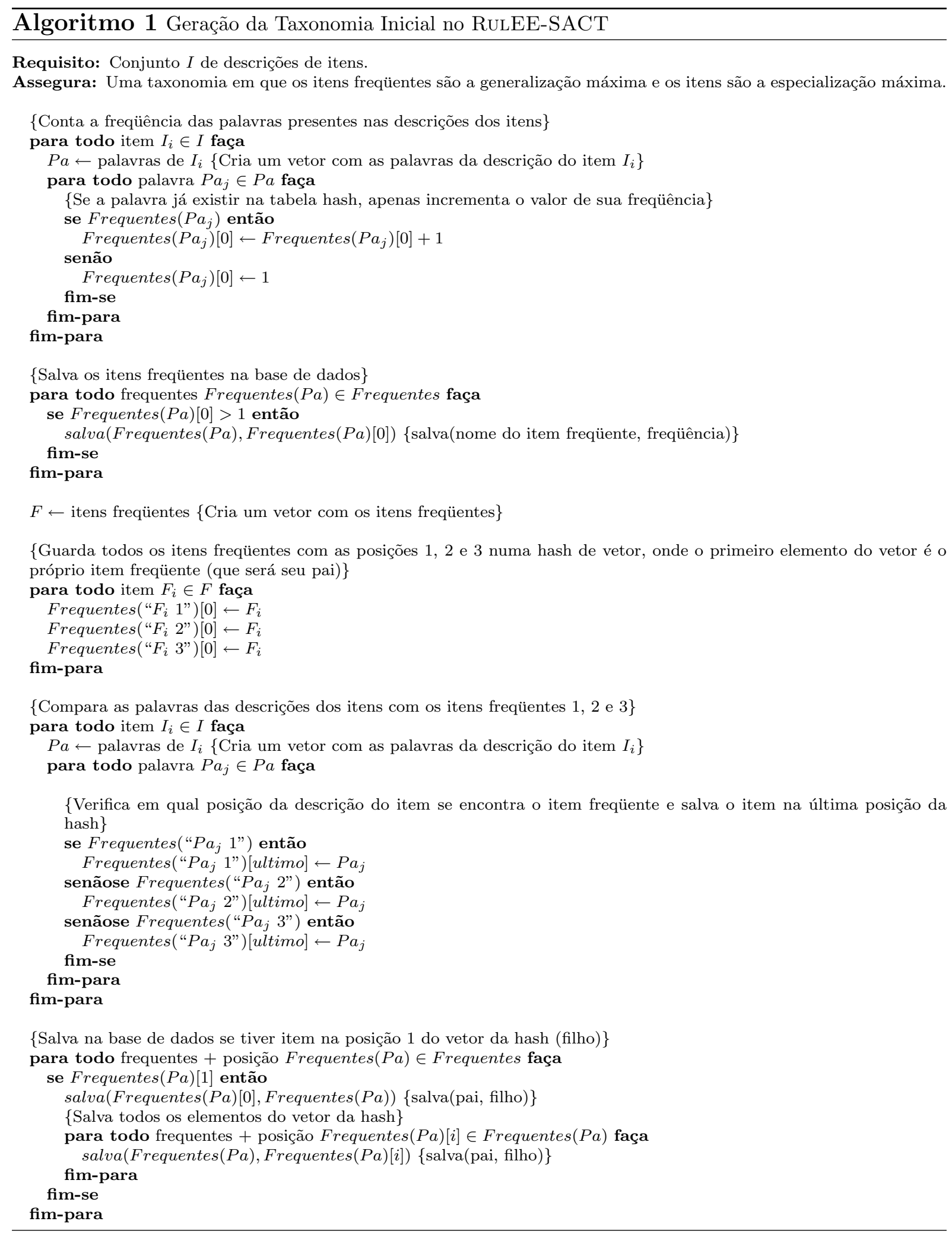

função implementada internamente que permite que auxilia a localização direta do conteúdo desejado, diferente de um "vetor", para o qual deve-se fornecer o índice a fim de acessar um conteúdo. Sendo assim, o conteúdo da "hash de vetores" é composto por elementos e cada elemento possui um ponteiro para um vetor. Dessa maneira, as informações de cada elemento podem ser salvas em seu respectivo vetor.

Inicialmente o algoritmo conta a freqüência das palavras existentes nas descrições dos 
produtos e as salva na base de dados. Vale ressaltar que antes de iniciar a etapa de comparação, deve haver uma interação com o usuário para que sejam selecionados os itens freqüentes interessantes para o processo. Assim, é realizada a comparação entre as descrições dos registros da base de dados e os itens freqüentes selecionados. A partir dessa comparação é criada a taxonomia inicial, na qual são salvos apenas os itens freqüentes que obtiveram filhos, ou seja, elementos nos quais ele foi encontrado em alguma palavra da descrição. Os filhos dos itens freqüentes corresponderão à sua posição na descrição dos itens da base de dados ("Item freqüente 1", "Item freqüente 2" e "Item freqüente 3"). Os itens da base de dados que possuem o item freqüente na primeira posição de sua descrição serão filhos de "Item freqüente 1" e assim por diante. Por exemplo, um item freqüente "leite" geraria os seguintes itens da taxonomia: "leite 1" e "leite 3". O item "leite 1" será pai de "leite A" e "leite B" e o item "leite 3" será pai de "doce de leite A" e "creme de leite A".

Caso seja utilizada a opção para gerar a taxonomia sem os itens freqüentes, são salvas apenas as posições dos itens freqüentes que obtiveram filhos e os itens da base de dados serão distribuídos da mesma maneira. Então o "Item freqüente + posição" será a generalização máxima da taxonomia.

Como pode ser observado no algoritmo apresentado, os registros da base de dados receberão como pai o "Item freqüente + posição" correspondente à menor posição. Sendo assim, um registro "biscoito de leite" seria filho do item freqüente "biscoito 1" e não de "leite 3". Isso porque foi levado em consideração que a primeira palavra da descrição, em geral, é mais representativa para agrupar itens.

\subsubsection{Descrição do Processo de Construção Semi-automática de Taxonomias no Módulo RulEE-SACT}

Nessa seção é descrita a realização de um processo de construção semi-automática de taxonomias no RULEE-SACT, sendo apresentadas as principais telas de sua interface. O acesso à esse módulo é realizado por meio da interface do ambiente RuLEE ${ }^{4}$ e assim são mantidas as vantagens adquiridas com a utilização da Web, que são a independência de plataforma e de localização física de seus usuários. Portanto, é possível que o analista do processo de mineração de dados e o especialista do domínio estejam em lugares distintos durante a execução do processo.

Após a autenticação do usuário no RuLEE, ele deve selecionar o projeto com o qual deseja trabalhar e o RULEE-SACT pode ser acessado por meio do link do menu lateral. Ao acessar o RULEE-SACT, o usuário pode iniciar um novo processo de construção de taxonomias, dar continuidade a algum que ele tenha criado anteriormente ou apenas visualizar um processo do projeto do RuLEE selecionado que não foi criado por ele e

\footnotetext{
${ }^{4}$ http://143.107.231.137/rulee/index.html
} 
para o qual ele possui permissão de visualização. Selecionando a opção de iniciar um novo processo de construção de taxonomias, o usuário deve fornecer os dados necessários para a sua criação e um arquivo texto no formato descrito na Seção 4.3.4, como ilustrado na Figura 4.4. Se desejar realizar uma nova construção de taxonomias com um arquivo de um mesmo domínio utilizado em outro processo, basta selecioná-lo na lista de arquivos dos processos visíveis para aquele projeto. O usuário também deve informar se esse processo poderá ser visualizado por outros usuários do mesmo projeto.

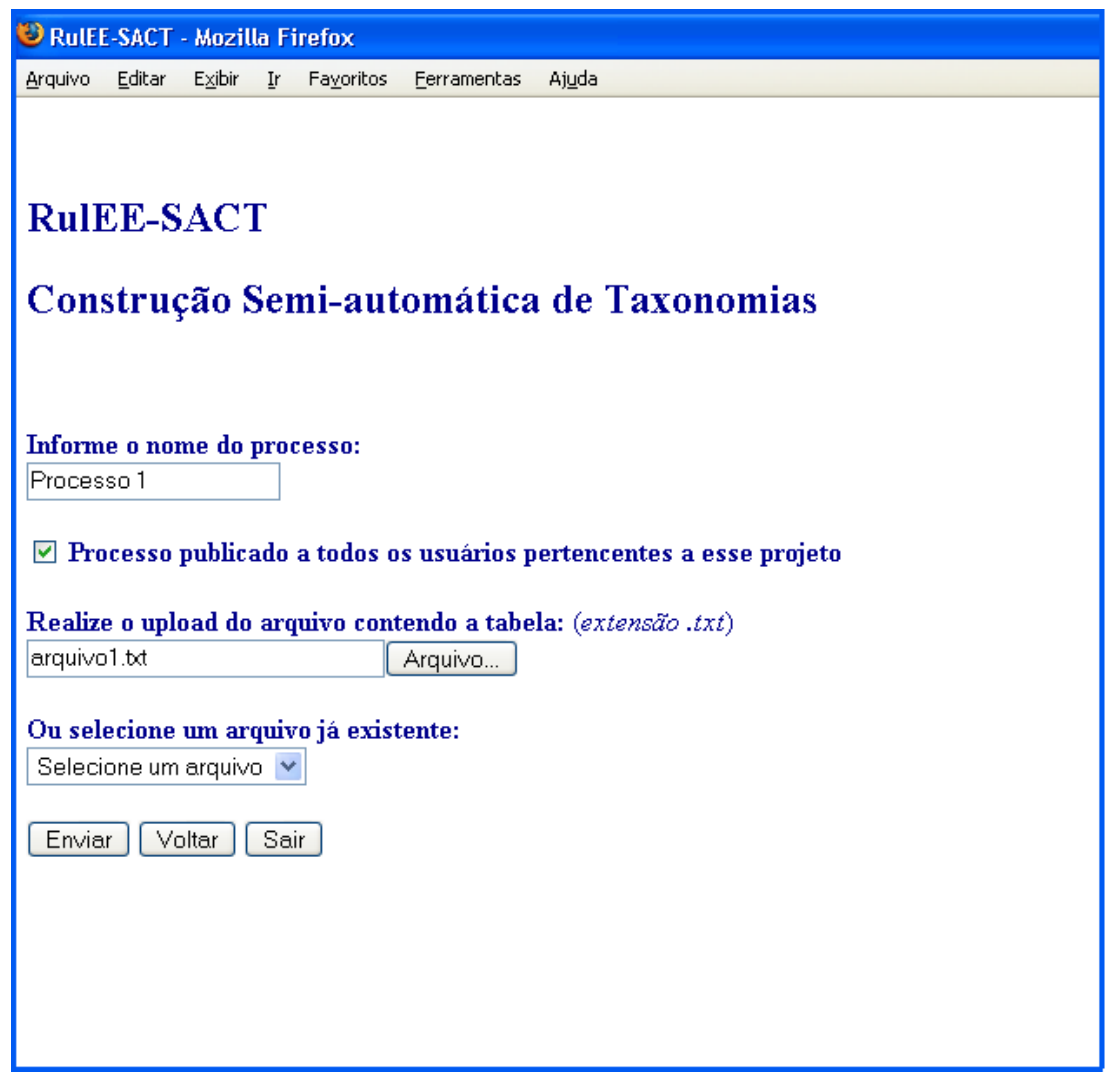

Figura 4.4: Criação de um processo de construção semi-automática de taxonomias no RulEE$\mathrm{SACT}$

Com um processo de construção de taxonomias criado o algoritmo SACT irá gerar os itens freqüentes e o próximo passo é a seleção dos mesmos, ilustrado na Figura 4.5. O usuário deve analisar os itens freqüentes gerados e excluir os que não forem interessantes. Para isso, ele pode selecionar um ou mais itens para serem excluídos ou selecionar uma freqüência mínima (os itens com freqüência menor ou igual à selecionada serão excluídos). O usuário também pode visualizar os elementos da base de dados e seus respectivos atributos (Figura 4.6). Essa visualização pode trazer auxílio na seleção dos itens freqüentes, uma vez que proporciona uma visão geral dos dados. Após a geração dos itens freqüentes, a opção "Realizar comparação entre palavras freqüentes e dados" deve ser selecionada para gerar a taxonomia inicial (Figura 4.7), ou seja, para realizar a etapa geração da taxonomia inicial. Vale ressaltar que o usuário deve especificar se deseja realizar a comparação que gera a taxonomia com ou sem os itens freqüentes como generalização máxima da taxonomia. 


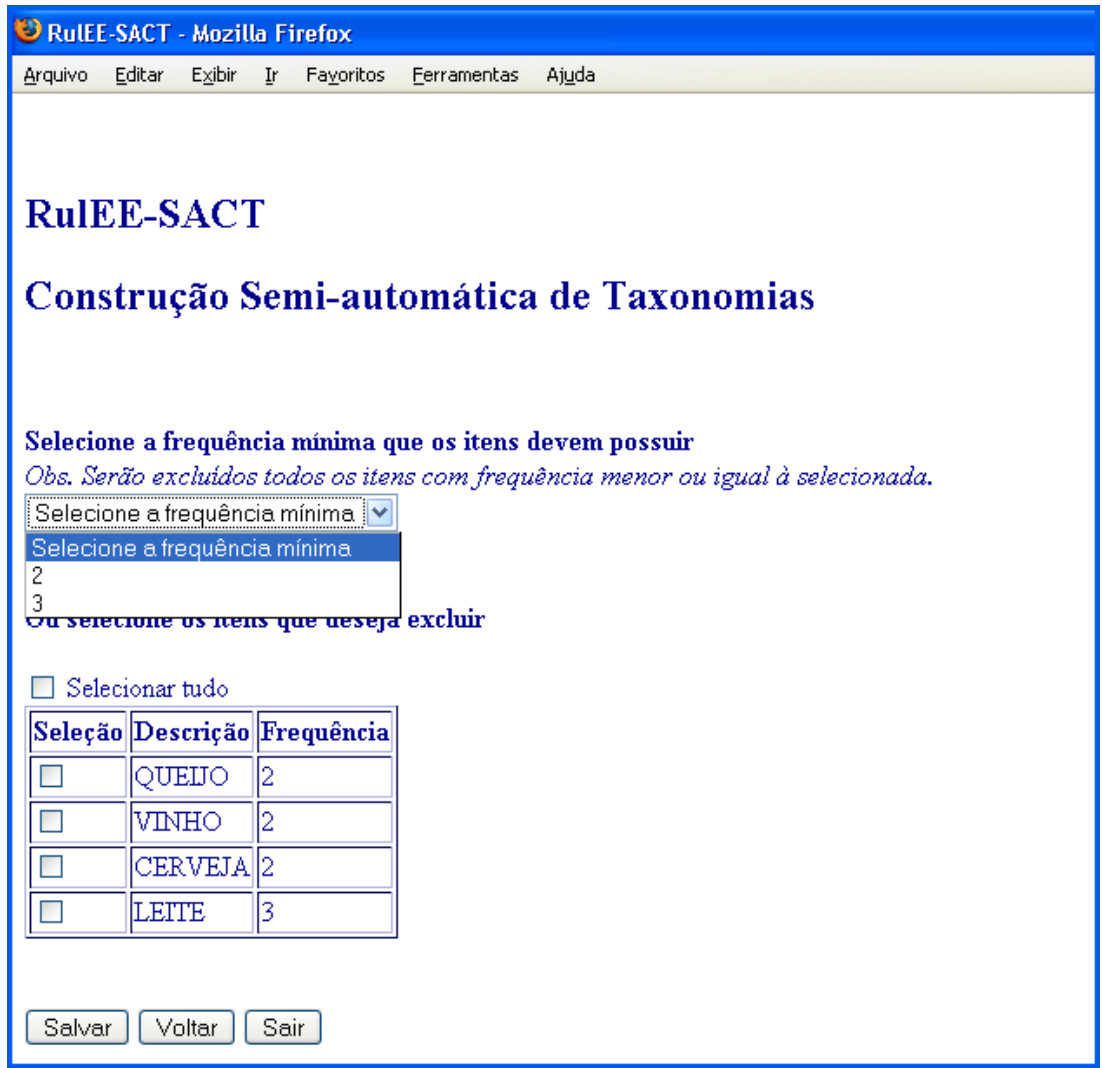

Figura 4.5: Seleção dos itens freqüentes no RuLEE-SACT

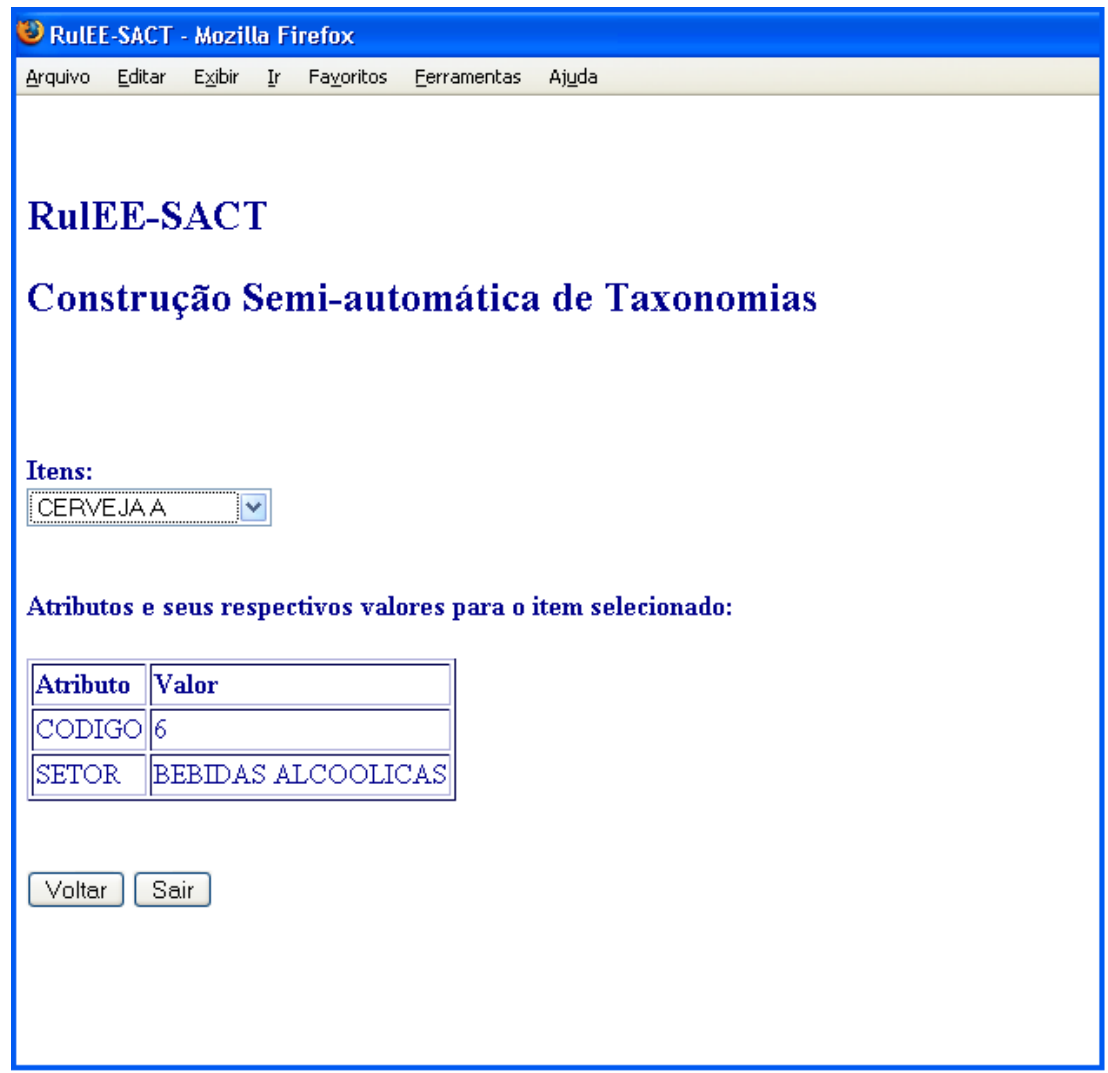

Figura 4.6: Visualização dos elementos e seus atributos no RuLEE-SACT

Com a taxonomia inicial gerada, inicia-se a etapa exploração da taxonomia por meio da opção "Explorar as taxonomias geradas", que também pode ser visualizada na Figura 4.7. 


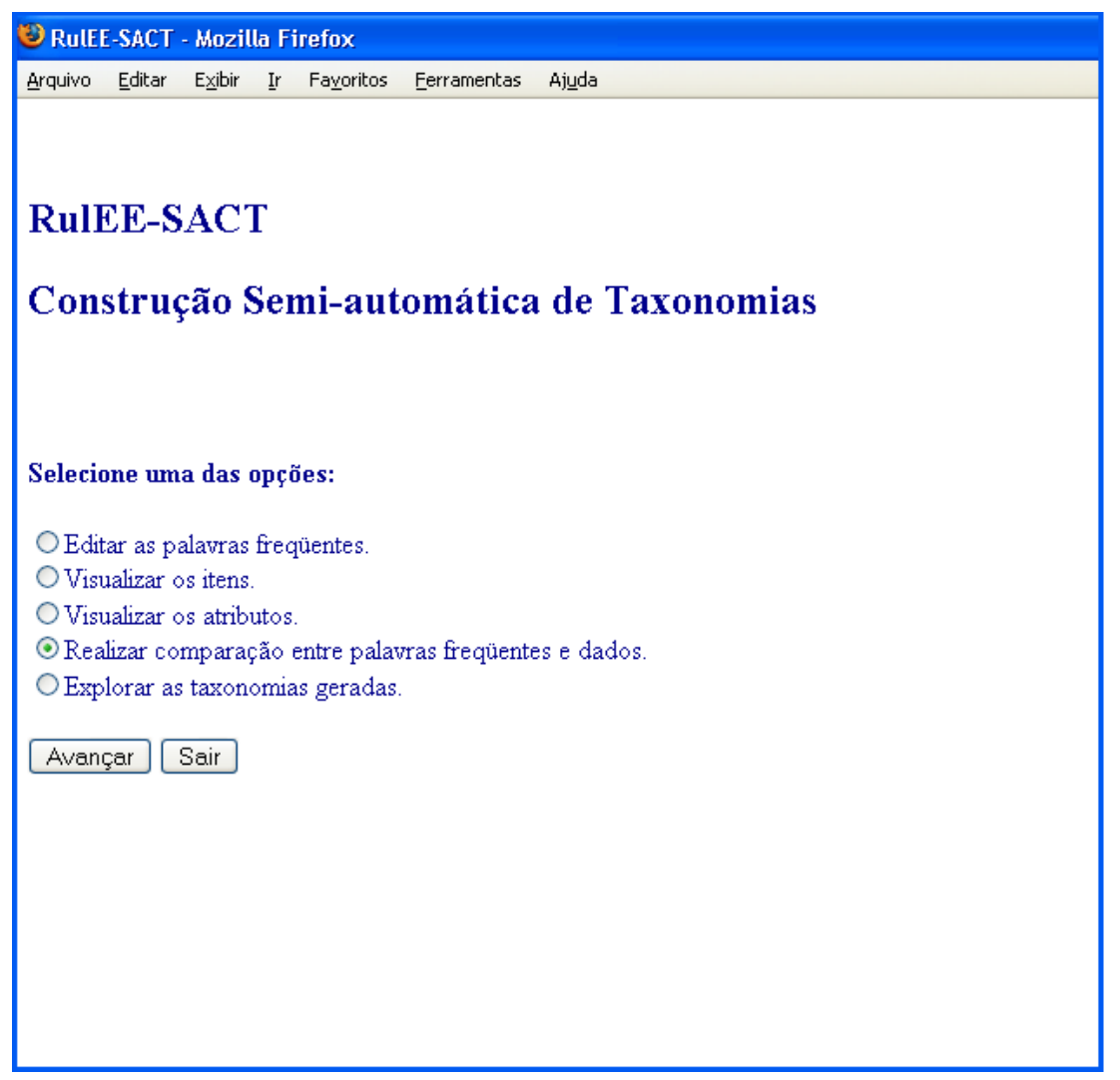

Figura 4.7: Geração da taxonomia inicial no RuLEE-SACT

Essa exploração permite a visualização da taxonomia do processo atual e a obtenção de um arquivo com a taxonomia no formato padrão do algoritmo SACT (Figura 4.8). Também permite a realização da etapa exploração da taxonomia, com a utilização das funcionalidades descritas na Seção 4.1: renomear um item da taxonomia, mover um item da taxonomia (Figura 4.9), excluir um item da taxonomia, reagrupar de acordo com um atributo (Figura 4.10), criar um novo elemento da taxonomia (Figuras 4.11 e 4.12) e validar a taxonomia. Para realizar as três primeiras funcionalidades, o usuário deve selecionar o(s) item(ns) a ser(em) alterado(s) e, no caso das duas primeiras, inserir/seleciona a informação necessária (novo nome e novo pai, respectivamente).

Para que possa ser realizado o reagrupamento de acordo com um atributo são listados os atributos da tabela que foi fornecida no início do processo. Após a seleção do atributo a ser utilizado, é apresentado o grupo formado pelo mesmo para que o usuário o analise e decida se deseja utilizá-lo para reagrupar os itens do nível mais baixo da taxonomia. Um exemplo de grupo formado utilizando o atributo "SETOR" se encontra na Figura 4.10. O objetivo dessa visualização é permitir que o usuário verifique como os itens seriam realocados e selecione a opção "Sim" caso decida realizar a redistribuição dos itens.

A funcionalidade "criar um novo item da taxonomia" pode ser utilizada por meio de duas opções do módulo. Inicialmente, deve ser inserida uma nova informação (que será tratada como um atributo) para cada item do nível mais alto da taxonomia que se deseja agrupar. Na Figura 4.11 é exemplificada a utilização dessa opção. Se o usuário considera 


\begin{tabular}{|c|c|}
\hline 징 RuIEE-SACT - Mozilla Firefox & \\
\hline Arquivo Editar Ex⿺bir Ir Fayoritos Eerramentas & Ajuda \\
\hline RulEE-SACT & \\
\hline Construção Semi-automátic & de Taxonomias \\
\hline Obs. As taxonomias são apresentadas da se & uinte forma: $P A I(F I L H O S)$ (NIVEL). \\
\hline Taxonomia do processo 1 & \\
\hline QUEIJO 1(QUEIJO A,QUEIJO B)(1). & \\
\hline VINHO 1(VINHO A,VINHO B)(1). & \\
\hline LEITE 1(LEITE A,LEITE B,LEITE C)(1). & \\
\hline CERVEJA 1(CERVEJA A,CERVEJA B)(1). & \\
\hline CERVEJA(CERVEJA 1)(2). & \\
\hline VINHO(VINHO 1)(2). & \\
\hline LEITE(LEITE 1)(2). & \\
\hline QUEIJO(QUEIJO 1)(2). & \\
\hline Arquivo da taxonomia (.tax) & \\
\hline \begin{tabular}{|l|} 
Voltar Sair \\
\end{tabular} & \\
\hline
\end{tabular}

Figura 4.8: Geração da taxonomia inicial, visualização da taxonomia e obtenção do arquivo com a taxonomia no formato padrão do RULEE-SACT

\begin{tabular}{|c|c|c|c|}
\hline 저 RuIEE-S & ACT - Mozilla Firefox & & \\
\hline Arquivo $\underline{\underline{E}}$ & ditar Exibir Ir Fayoritos Eerrament & tas Ajuda & \\
\hline Const & rução Semi-automáti & ica de & Taxonomias \\
\hline Selecione & o item a ser alterado e o seu no & ovo pai: & \\
\hline Seleção & Descrição (item a ser alterado) & Seleção & Descrição (novo pai) \\
\hline$\square$ & VINHO & 0 & VINHO \\
\hline$\square$ & VTNHO 1 & 0 & VTNHO 1 \\
\hline$\square$ & VINHO A & 0 & QUEIJO \\
\hline$\square$ & VINHO B & 0 & QUEIJO 1 \\
\hline$\square$ & QUEIJO & 0 & CERVEJA \\
\hline$\square$ & QUEIJO 1 & 0 & CERVEJA 1 \\
\hline$\square$ & QUEIJO A & 0 & LEITE \\
\hline$\square$ & QUEIJO B & 0 & LEITE 1 \\
\hline$\square$ & CERVEJA & & \\
\hline$\square$ & CERVEJA 1 & & \\
\hline$\square$ & CERVEJA A & & \\
\hline$\square$ & CERVEJA B & & \\
\hline$\square$ & LEITE & & \\
\hline Avançar & Voltar Sair & & \\
\hline
\end{tabular}

Figura 4.9: Deslocamento de um item RulEE-SACT 


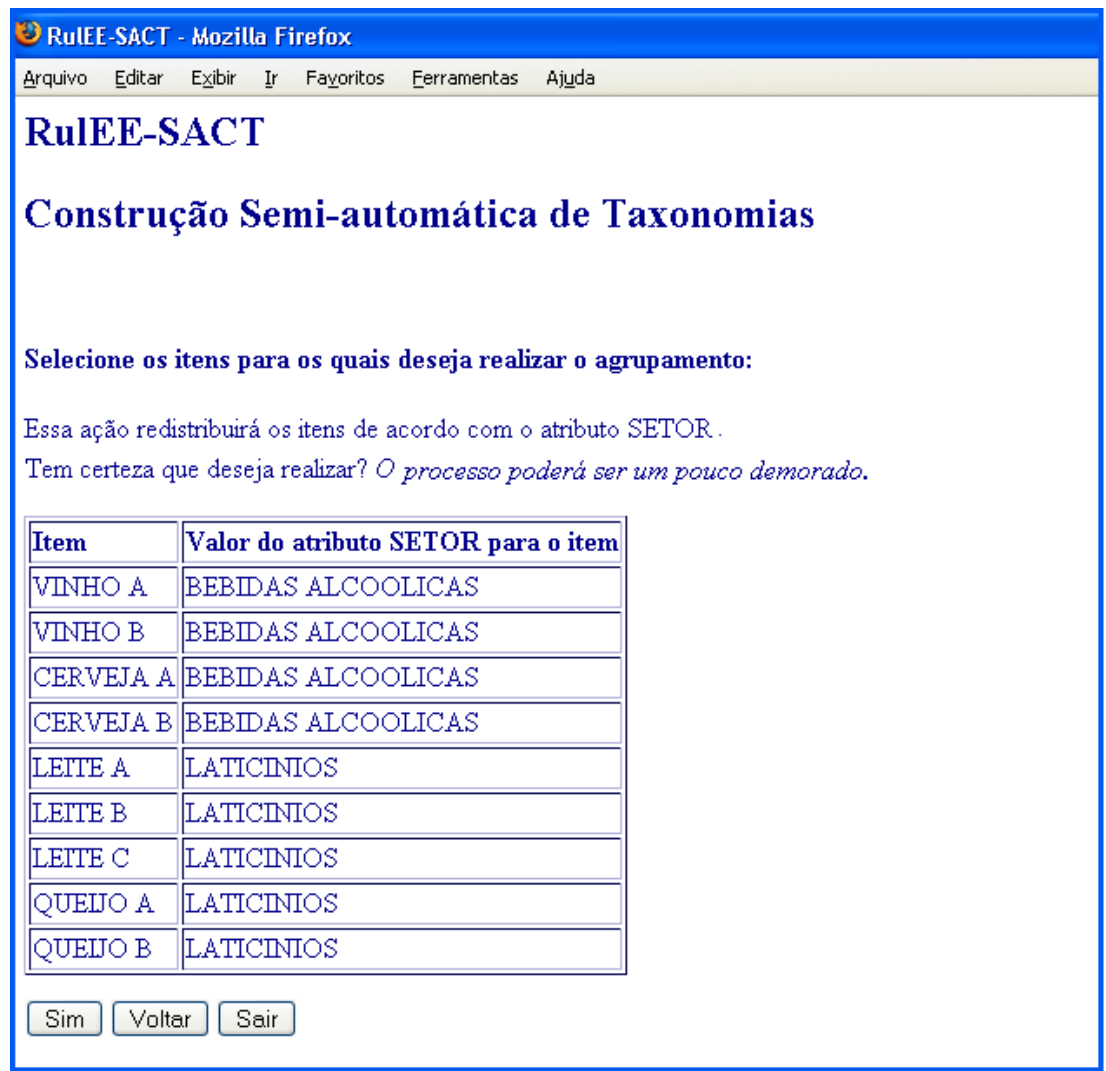

Figura 4.10: Reagrupamento de acordo com um atributo no RulEE-SACT

que LEITE, CERVEJA E VINHO devem ser agrupados como BEBIDAS, ele deve inserir um novo atributo com o valor BEBIDAS para cada um desses itens. Assim será gerado um novo item da taxonomia com o nome de BEBIDAS. Cada valor de um atributo pode ser utilizado apenas uma vez para gerar um novo item da taxonomia, para que posteriormente não existam grupos diferentes com o mesmo nome.

Após a inserção dessa nova informação (atributo) o usuário pode, por meio da lista dos atributos criados por usuários (por exemplo, TIPO DE PRODUTOS, Figura 4.12), selecionar o atributo e o valor com o qual deseja criar um novo item da taxonomia. $\mathrm{Na}$ Figura 4.12 é exemplificada utilização dessa opção para o atributo definido anteriormente e na Figura 4.13 pode ser visualizada a taxonomia atual, com o novo item.

Em qualquer momento do processo de construção de taxonomias, o usuário pode sair do sistema e continuar depois, por meio da opção "Explorar um processo já criado" na página inicial. Quando essa opção é selecionada, são apresentados todos os processos criados por ele e os processos criados por outros usuários do mesmo projeto que estão disponíveis para visualização. Selecionada a exploração desejada, o usuário tem acesso à todas as funcionalidades descritas anteriormente, recordando que as etapas geração dos itens freqüentes e geração da taxonomia inicial só podem ser executadas se a segunda etapa ainda não foi realizada para não haver inconsistência entre os itens freqüentes e os itens da taxonomia. Caso o usuário não tenha criado o processo mas tenha permissão para visu- 


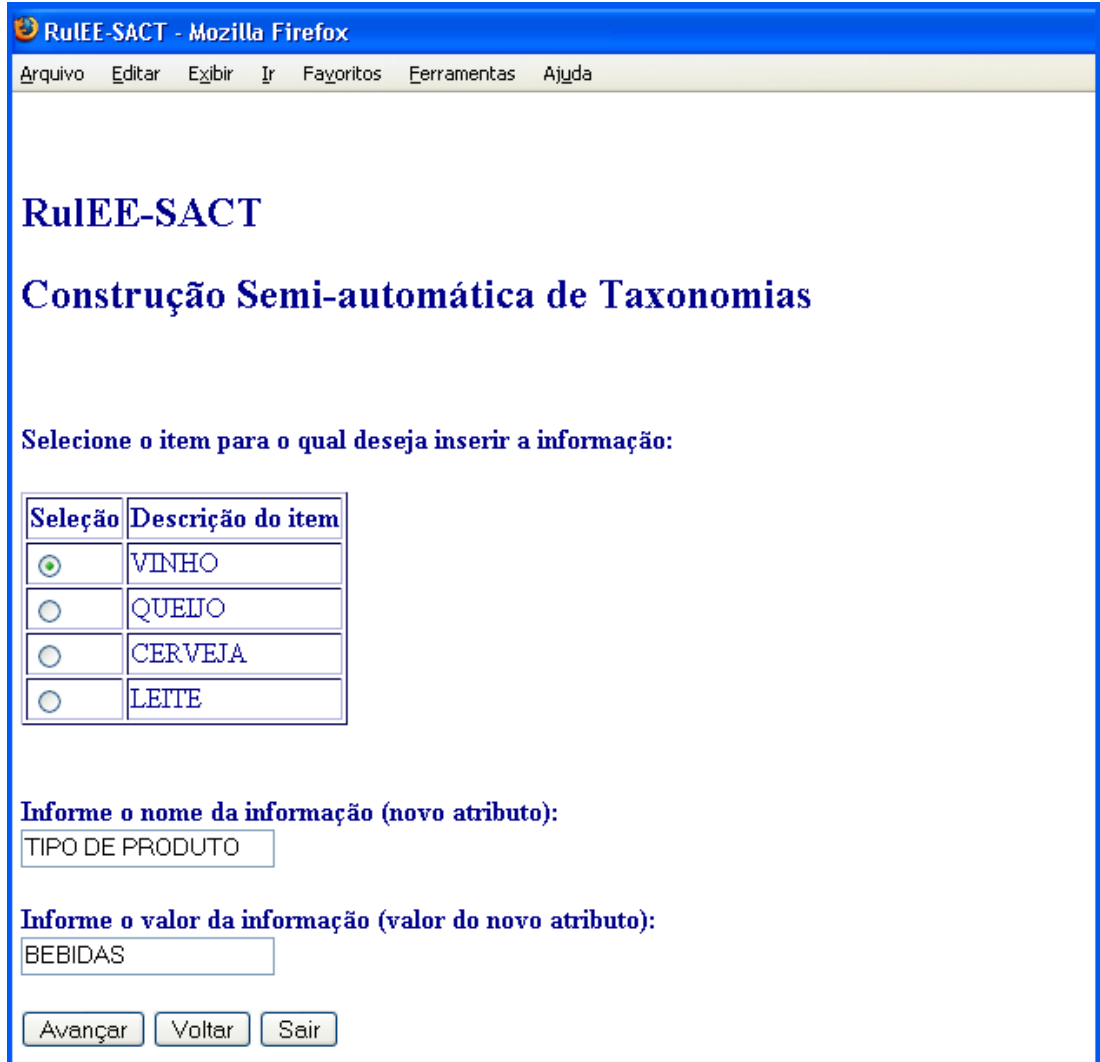

Figura 4.11: Inserção de nova informação (atributo) no RuLEE-SACT

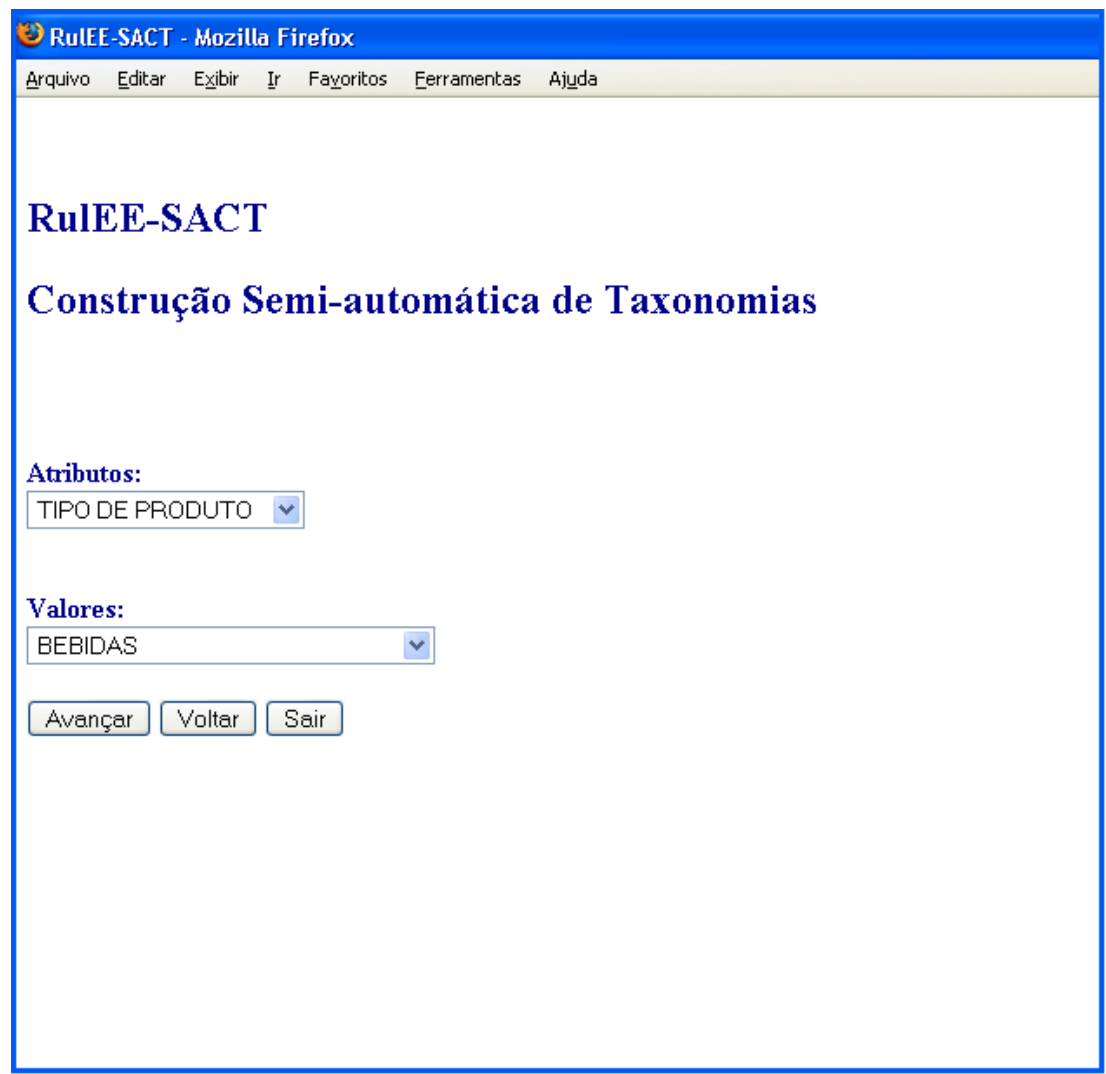

Figura 4.12: Criação de um novo item da taxonomia no RulEE-SACT

alizá-lo, ele não poderá realizar alterações na taxonomia mas poderá visualizar todas 


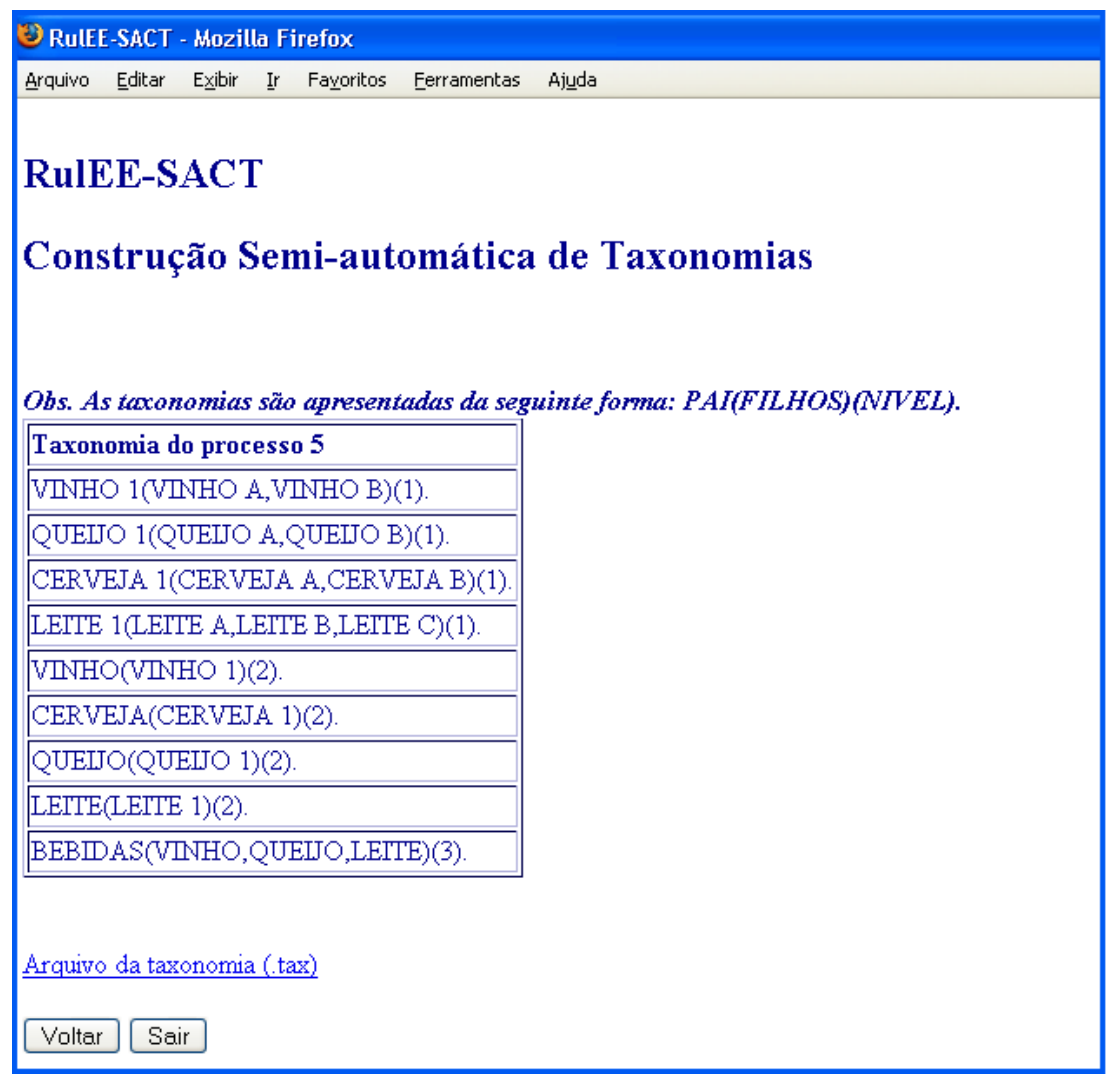

Figura 4.13: Visualização da taxonomia com o novo item criado no RULEE-SACT

as informações disponíveis e obter o arquivo com a taxonomia. Por meio dessas visualizações ocorre a disponibilização e compartilhamento do conhecimento entre os usuários do módulo RuLEE-SACT.

\subsection{Considerações Finais}

Neste capítulo foi apresentada uma metodologia para construção semi-automática de taxonomias. A metodologia foi motivada pela necessidade da construção de taxonomias para a generalização de regras de associação. O objetivo desta proposta é obter conhecimento interessante expresso em taxonomias, a fim de auxiliar o processo de generalização de regras de associação. Além disso, por meio de experimentos realizados com taxonomias construídas manualmente, descritas em trabalhos como Domingues (2004); Carvalho, Rezende, \& de Castro (2006), foi possível verificar que quanto melhores e mais expressivas as taxonomias, maior a taxa de redução do volume de regras quando realizada a generalização na etapa de pós-processamento e melhor a compreensibilidade das regras.

A metodologia proposta é composta por três etapas: geração dos itens freqüentes, geração da taxonomia inicial e exploração da taxonomia. Todas essas etapas são realizadas utilizando métodos automáticos e interativos, contando sempre com a interação com o usuário para definir os parâmetros a serem utilizados nos métodos automáticos.

Vale ressaltar a integração que existe entre as etapas dessa metodologia. A primeira 
etapa tem grande importância para a geração de bons grupos na segunda e para que a terceira possa ser executada a fim de melhorar a taxonomia inicial e não apenas para corrigí-la. Os métodos automáticos facilitam a construção da taxonomia e proporcionam rapidez ao processo. A interação com o usuário é de extrema importância para captar seu conhecimento e seus interesses na obtenção dos grupos, incluindo o nível de generalização desejado.

Para viabilizar a utilização da metodologia proposta foi desenvolvido um módulo de pós-processamento para o ambiente RulEE, o RuLEE-SACT, também descrito neste capítulo. As taxonomias geradas no RuLEE-SACT podem ser utilizadas no módulo RulEE-GAR para generalizar regras de associação. Podem também ser utilizadas nos algoritmos desenvolvidos e em desenvolvimento no trabalho de Carvalho (2004) e ainda em outros algoritmos que generalizem regras de associação usando taxonomias, contanto que as mesmas sejam convertidas para os formatos utilizados pelos mesmos. Para validar a metodologia proposta, foi elaborado um estudo de caso utilizando os módulos RuLEESACT e alguns algoritmos já desenvolvidos por Carvalho (2004) para generalizar regras de associação usando taxonomias. Esse estudo de caso é apresentado no próximo capítulo. 



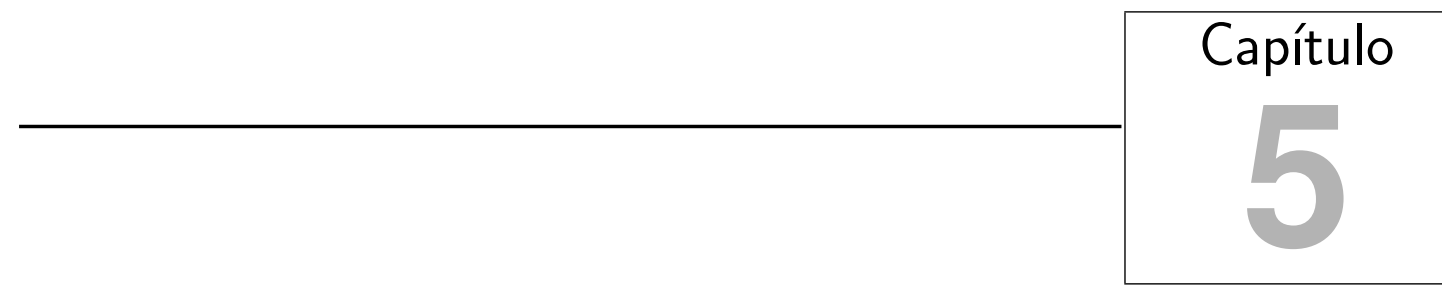

\section{Estudo de Caso}

$\mathcal{A}$ metodologia proposta no capítulo anterior tem como objetivo auxiliar o usuário na construção de taxonomias para o processo de generalização de regras de associação. O estudo de caso apresentado neste capítulo tem como objetivos mostrar que a metodologia proposta apresenta as seguintes características:

- provê auxílio e rapidez na construção de taxonomias;

- pode ser utilizada para construir taxonomias com diversas bases de dados;

- reduz a necessidade do auxílio do especialista do domínio na construção de taxonomias;

- pode ser utilizada por algoritmos de generalização de regras de associação com taxonomias.

Cabe ressaltar que o objetivo desse estudo de caso é analisar o uso da metodologia proposta para construir taxonomias e a aplicabilidade das mesmas ao problema de regras de associação, e não realizar uma análise qualitativa das regras geradas.

Como não existem bases de dados conhecidas para o problema de regras de associação, nesse estudo de caso foram realizados experimentos com duas bases de dados. Primeiramente, com a base de dados de um supermercado da cidade de São Carlos e depois com uma base de dados de uma mercearia, obtida na página do projeto $R$ para computação estatística ${ }^{1}$.

Para a realização de cada um desses experimentos, seguiu-se um planejamento que está dividido em três fases:

\footnotetext{
${ }^{1}$ http://www.r-project.org/
} 
1. Análise e preparação dos dados;

2. Construção das taxonomias utilizando o módulo RulEE-SACT;

3. Avaliação dos resultados

Na primeira fase os dados foram selecionados e convertidos para um arquivo no formato padrão do módulo RuLEE-SACT. Esse arquivo foi fornecido ao módulo e utilizado para construir as taxonomias, o que corresponde à segunda fase. Uma das taxonomias construídas nessa fase foi analisada por uma especialista do domínio. Na terceira fase, as taxonomias foram fornecidas para algoritmos utilizados para realizar a generalização de regras de associação e os resultados obtidos foram analisados.

\subsection{Primeira Fase: Análise dos Dados}

Inicialmente, os dados utilizados nos dois experimentos foram analisados. Essa análise teve como objetivo selecionar os atributos interessantes e realizar uma limpeza nos mesmos, além de convertê-los para o formato padrão utilizado pelo módulo RULEE-SACT.

Uma descrição das bases de dados e a preparação das mesmas para serem fornecidas ao módulo RULEE-SACT são apresentadas a seguir.

\subsubsection{Descrição das Bases de Dados}

O primeiro experimento foi realizado utilizando uma base de dados que contém informações sobre as operações de vendas e sobre os produtos de um supermercado da cidade de São Carlos, SP. Os dados sobre os diversos produtos que são vendidos no supermercado estão armazenados em um arquivo denominado DBPROD.DBF, que contém informações como: descrição do produto, tipo do produto, setor, preço, impostos e data de validade. O restante da base é composta por diversos arquivos no formato texto, sendo que cada arquivo armazena os dados referentes a uma venda. Para facilitar a análise dos dados, bem como o seu uso na realização dos experimentos, foram utilizados os dados pré-processados descritos em Domingues (2004). Nesse pré-processamento, os dados foram inseridos em um sistema de gerenciamento de banco de dados (SGBD).

Para construir as taxonomias foi utilizada a tabela DBPROD.DBF, que contém 12705 registros com informações sobre os produtos e, principalmente, suas descrições. Os atributos e parte dos registros utilizados neste estudo de caso são apresentados na próxima seção. Já para gerar as regras de associação foi utilizado o conjunto de dados pré-processados referente à um mês de vendas, o qual contém 37311 transações e 3625 itens. A redução no número de itens se deve à não ocorrencia de todos no período de um mês de vendas. 
O segundo experimento foi realizado com uma base de dados disponível no pacote de regras de associação do projeto $R$ para computação e estatística. Esse pacote contém diversas bases de dados pré-processadas com informações sobre diversos domínios. A base de dados selecionada foi a de mantimentos (groceries) por ser uma base relativamente pequena e bem compreensível.

A base de dados de mantimentos contém 9835 transações referentes a um mês de vendas de uma mercearia e os itens estão agrupados em 169 categorias. Para construir a taxonomia foram utilizadas as informações existentes no próprio conjunto de transações, ou seja, apenas os itens.

As alterações e limpeza realizadas nas bases de dados são descritas na próxima seção.

\subsubsection{Preparação dos Dados para o Módulo RulEE-SACT}

Para construir as taxonomias da base de dados do supermercado utilizando o RuLEESACT, foi necessário analisar a tabela DBPROD.DBF para selecionar os atributos interessantes, eliminar palavras e caracteres não importantes da descrição dos produtos, tratar dados faltantes e reduzir o conjunto de dados. O conjunto de dados utilizado corresponde aos itens da tabela DBPROD.DBF que estavam contidos no conjunto de transações de um mês. Uma parte do conjunto de dados resultante (12 dos 3625 elementos da base de transações) pode ser visualizado na Tabela 5.1, na qual são apresentados os atributos e parte dos registros selecionados para o experimento. Os atributos considerados relevantes para esse problema foram DESCPROD, que corresponde à descrição do produto e SETOPROD, que corresponde ao setor no qual o produto é armazenado.

\begin{tabular}{|c|c|}
\hline DESCPROD & SETOPROD \\
\hline \hline CHOC GAROTO & 8 \\
\hline CHOC LACTA & 8 \\
\hline CHOC MMS & 8 \\
\hline CHOC NESTLE & 8 \\
\hline LEITE NILZA & 18 \\
\hline LEITE NINHO & 18 \\
\hline LEITE PARMALAT & 18 \\
\hline CHOC PAULISTA & 18 \\
\hline BALA ARCOR & 8 \\
\hline BALA CHITA & 8 \\
\hline BALA HORTELA & 8 \\
\hline BALA ICEKISS & 8 \\
\hline
\end{tabular}

Tabela 5.1: Parte do conjunto de dados resultante, com dois atributos, da base de dados do supermercado

O atributo SETOPROD foi selecionado uma vez que o mesmo pode ser útil para agrupar produtos que não possuem nomes parecidos mas que tenham alguma relação. 
Por exemplo, considerando as marcas dos produtos chocolate e bala é possível perceber que, apesar de não apresentarem a mesma descrição, esses produtos possuem o mesmo valor para o atributo SETOPROD. Isso significa que eles poderiam ser agrupados, por exemplo, como doces.

Já na preparação dos dados do segundo experimento foram apenas excluídos caracteres indesejados, como "/" e ".", uma vez que a base de transações já estava pré-processada. Além disso, a única informação existente para gerar taxonomias é a descrição dos itens, uma vez que a base de transações contém apenas os itens. Dessa maneira, não haviam atributos relacionados a cada item, como na base de dados do supermercado. Na Tabela 5.2 é apresentada parte do conjunto de dados (8 dos 169 itens da base de dados).

\begin{tabular}{|c|}
\hline Produtos \\
\hline \hline ready soups \\
\hline organic sausage \\
\hline specialty vegetables \\
\hline snack products \\
\hline bathroom cleaner \\
\hline curd cheese \\
\hline ketchup \\
\hline cereal \\
\hline
\end{tabular}

Tabela 5.2: Parte do conjunto de dados resultante da base de dados da mercearia

Após a limpeza e seleção dos conjuntos de dados, ambos foram convertidos para o formato utilizado pelo algoritmo $S A C T$ e os arquivos gerados foram inseridos no módulo RULEE-SACT com o objetivo de gerar taxonomias.

No caso do primeiro experimento, com a base de dados do supermercado, as informações já foram obtidas diretamente de uma tabela no formato desejado, inclusive contendo os nomes dos atributos na primeira linha do arquivo. Assim, a única alteração necessária foi a especificação do atributo de descrição do produto (DESCPROD). Essa informação ficou posicionada na primeira linha do arquivo, os nomes dos atributos na segunda e no restante das linhas, ficaram os dados.

Já para o segundo experimento, foi necessário definir um nome para a lista de itens, com o objetivo de considerá-los como valores de um atributo de descrição. Dessa maneira, o nome DESC foi inserido na primeira e na segunda linha do arquivo, especificando o atributo de descrição e o nome do atributo. As linhas seguintes contêm os itens.

\subsection{Segunda Fase: Construção das Taxonomias}

Para construir as taxonomias utilizando o módulo RULEE-SACT, é necessário fornecer as informações de um domínio no formato de uma tabela, como descrito na Seção 4.3.4. 
Dessa maneira, após a conversão dos arquivos, os mesmos foram fornecidos ao módulo RULEE-SACT para realizar a construção semi-automática de taxonomias.

\subsubsection{Utilização do RulEE-SACT}

A seguir são detalhados os processos de construção de taxonomias para cada um dos experimentos.

Na construção da taxonomia para a base de dados do supermercado, após a criação do processo e do fornecimento do arquivo de entrada, foi iniciada a etapa de geração dos itens freqüentes. Nesta etapa foram ignorados os itens com freqüência menor que um, pois os mesmos foram considerados irrelevantes para a representação taxonômica esperada e, além disso, uma quantidade muito grande de grupos sobrecarregaria os algoritmos de generalização de regras de associação. Dessa maneira, dos 1269 itens freqüentes gerados foram eliminados aqueles que representavam características específicas de cada produto. Itens como marcas, quantidades e descrições específicas, por exemplo o termo "em cubos" presente na descrição do produto "beterraba em cubos", foram excluídos. Isso porque um dos objetivos desse experimento era agrupar os produtos semelhantes, ignorando suas particularidades. Ao realizar a seleção dos itens freqüentes, restaram somente 239. Cabe ressaltar que, de acordo com os objetivos discutidos anteriormente, a maior quantidade de eliminações ocorreu nos itens com freqüência mais baixa, ou seja, de freqüência 2 a 26 . Apesar de alguns itens com freqüências de 27 a 40 terem sido eliminados, a maior parte das eliminações ocorreu na faixa inferior. Além disso, dos valores de freqüência 41 a 102 (freqüência máxima encontrada) já não houve mais eliminação, o que mostra que a alta freqüência de um item no conjunto de dados é um indício de sua importância para gerar grupos.

Com os itens freqüentes selecionados, iniciou-se a etapa de geração da taxonomia inicial, na qual foram gerados os grupos de acordo com a semelhança das descrições dos itens com os itens freqüentes. Foi utilizada a opção para criar os itens freqüentes como itens da taxonomia.

Analisando a taxonomia inicial gerada, foi possível perceber algumas alterações necessárias para melhorá-la. Assim iniciou-se a etapa de exploração da taxonomia. Nessa etapa foram realizadas atividades como a mudança do nome de alguns itens ("renomear um item da taxonomia"), a fim de tornar a taxonomia mais compreensível e seus grupos mais condizentes com a realidade. Por exemplo, os nomes dos itens ABS, BISC, FD, SH, SPO foram alterados para ABSORVENTE, BISCOITO, FIO DENTAL, SHAMPOO e SABAO EM PO, respectivamente.

Alguns itens também foram movidos ("mover um item da taxonomia") pois eram melhor representados por outros grupos. Por exemplo, o item OVINHO AMENDOIM APERITIVO (salgadinhos de amendoim em forma de ovinho) foi movido de AMENDOIM 2 
para SALGADINHOS e itens como FILE ABADEJO ICAP, FILE DE BADEJO STA PAULA e FILE DE DOURADA FAST FISH foram movidos de FILE para PEIXE, pois esses grupos os representam de acordo com o objetivo definido no início do processo de construção de taxonomias: agrupar os itens semelhantes ignorando suas marcas e quantidades. Foram também movidos itens que estavam representados de maneira incorreta, como por exemplo algumas marcas de água sanitária que se encontravam agrupadas com águas potáveis e foram movidas para o grupo que representava todas as marcas de água sanitária.

Outra atividade realizada foi a exclusão de alguns itens ("excluir um item da taxonomia") para eliminar grupos incorretos, como por exemplo algumas marcas de água oxigenada que se encontravam no grupo AGUA. Não sendo possível encontrar um grupo representativo para esses itens dentre os já existentes, eles foram eliminados da taxonomia.

Após a realização dessas atividades, o resultado foi uma taxonomia melhor distribuída e com uma representação também melhor do que a inicial. Vale ressaltar que todos os "Itens freqüente + posição" foram eliminados e seus itens redistribuídos entre os itens superiores (que correspondem aos itens freqüentes). No experimento realizado, essa foi a melhor representação encontrada, o que pode não se repetir para outros casos.

Com a taxonomia inicial corrigida e melhorada, foi possível utilizar o atributo SETOR para redistribuir os itens que correspondiam às diversas marcas de leite condensado. Esses itens haviam sido colocados, inicialmente, em LEITE e com a funcionalidade "reagrupar de acordo com um atributo" esses itens foram movidos para o grupo dos produtos creme de leite.

Também foi possível continuar a construção da taxonomia por meio da funcionalidade "criar novo item da taxonomia". O objetivo da realização dessa etapa foi gerar grupos de nível superior, como por exemplo: CAFE, BEBLACTEA, GROSELHA, CHA, CAPPUCCINO, AGUA, LEITE, SUCO e GUARANA foram agrupados em BEBIDAS COMUNS; CARNES BOVINA, CARNE SUINA, KIBE, CORACAO, ATUM, PERU, PEIXE, FRANGO, CAMARAO, HAMBURGUER, ALMONDEGA e SALSICHA foram agrupados em CARNES e MILHO, SOJA, FEIJAO, CANJICA, ARROZ e ERVILHA foram agrupados em GRAOS. Para isso foi criado o atributo CLASSE com os valores BEBIDAS COMUNS, CARNES e GRAOS para os itens correspondentes apresentados e depois os itens foram agrupados de acordo com o seu valor para o atributo CLASSE, gerando os grupos descritos.

De maneira similar, foi criado o atributo TIPO com o valor BEBIDAS com o objetivo de agrupar os itens BEBIDAS COMUNS e BEBIDAS ALCOOLICAS.

Parte da taxonomia final é apresentada na Seção 5.2.2 e sua utilização para generalizar regras de associação é apresentada na Seção 5.3.

Para o segundo experimento (com a base de dados da mercearia), assim como no anterior, após a criação do processo de construção semi-automática de taxonomias e do 
fornecimento do arquivo de entrada, foi iniciada a etapa de geração dos itens freqüentes. Neste experimento também foram ignorados os itens com freqüência menor que 1, pelos mesmos motivos descritos no experimento anterior. Dessa maneira, foram gerados 42 itens freqüentes dos quais foram eliminados aqueles que representavam uma descrição específica. Isso porque um dos objetivos desse experimento era agrupar os produtos semelhantes, ignorando suas particularidades. Ao realizar a validação e eliminação dos itens freqüentes, restaram somente 29 itens. Cabe ressaltar que, de acordo com os objetivos desse experimento, foi necessário realizar eliminações apenas em itens com freqüência baixa, ou seja, de 2 a 3. Nos itens com freqüência de 4 a 8 (freqüência máxima encontrada) já não houve mais necessidade de eliminação, o que mostra que quanto maior a freqüência dos itens, maior sua importância na geração de grupos.

Com os itens freqüentes selecionados, iniciou-se a etapa de geração da taxonomia inicial, na qual foram gerados os grupos de acordo com a semelhança das descrições dos itens com os itens freqüentes. Foi utilizada a opção para não criar os itens freqüentes como itens da taxonomia. Dessa maneira a taxonomia inicial foi gerada com apenas um nível. É importante destacar que essa base de dados já apresentava uma distribuição dos itens em categorias, como descrito na Seção 5.1.1. Por exemplo, os vegetais congelados eram representados por um único item, denominado frozen vegetables. Assim, foi possível focar na geração de grupos diferentes do experimento anterior, ou seja, não havia necessidade de agrupar produtos iguais de diferentes marcas (como leite batavo, leite parmalat, leite molico) e sim produtos com características semelhantes, como todos os produtos congelados.

Analisando a taxonomia gerada, foi possível perceber algumas alterações necessárias para melhorá-la. Assim iniciou-se a etapa de exploração da taxonomia. Nessa etapa foi utilizada a funcionalidade "renomear um item da taxonomia", a fim de tornar a taxonomia mais clara e mais representativa. Por exemplo, o nome do item chocolate foi modificado para chocolate products, com o objetivo de mostrar que esse grupo contém todos os produtos derivados de chocolate.

Outra funcionalidade utilizada foi "mover um item da taxonomia", para representar melhor os itens dentro dos grupos. Por exemplo, os itens white bread e brown bread estavam inicialmente agrupados no item bread 2 e o item semi finished bread em bread 3. Como os três produtos são tipos de pão, o item semi finished bread foi movido para bread 2 e o nome deste grupo foi modificado para bread, que passou a representar todos os tipos de pão.

Outra atividade realizada foi a exclusão de alguns itens ("excluir um item da taxonomia") que após a realização do deslocamento de itens ficaram sobrando na taxonomia. Por exemplo, o item bread 3, que passou a não possuir mais filhos e assim foi removido da taxonomia.

Após a realização dessas atividades, o resultado foi uma taxonomia bem distribuída 
e já bastante genérica. Essa segunda característica se deve ao fato de os itens da base de dados já estarem distribuídos em categorias. A utilização do módulo RuLEE-SACT serviu para agrupar itens semelhantes, como por exemplo todos os produtos congelados. Dessa maneira, não foram criados novos itens da taxonomia e a mesma permaneceu com nível 1.

Uma observação importante é o fato de a base de dados ter sido obtida com os itens já generalizados, ou seja, distribuídos em 169 categorias. Neste caso, a base de dados não apresenta itens de diferentes marcas ou quantidades. Todas as marcas e tipos de iogurte são representados pelo item iogurte. Essa característica possibilitou a construção de uma taxonomia com conceitos mais gerais, uma vez que foi possível agrupar produtos com outras características semelhantes que não fossem apenas sua descrição. Dois exemplos podem ser vistos na taxonomia apresentada na próxima seção: produtos congelados e produtos enlatados.

Parte de cada uma das taxonomias geradas é apresentada na Seção 5.2.2 e a utilização das mesmas na generalização de regras de associação é apresentada na Seção 5.3.

\subsubsection{Taxonomias Geradas}

Partes de cada uma das taxonomias geradas em ambos os experimentos realizados utilizando o módulo RULEE-SACT são apresentadas a seguir. A Figura 5.1 representa parte da taxonomia gerada utilizando a base de dados do supermercado e a Figura 5.2 representa parte da taxonomia gerada utilizando a base de dados de mantimentos (mercearia).

Na taxonomia do supermercado é possível verificar grandes grupos com produtos de diversas marcas, mostrando que utilizando a metodologia proposta foi possível atingir os objetivos esperados. Também é possível visualizar algumas taxonomias criadas após a geração da taxonomia inicial, o que demonstra a facilidade que a metodologia provê para identificar e gerar novos grupos.

Essa taxonomia foi avaliada por uma especialista do domínio, que é estudante de Engenharia de Alimentos e trabalha em uma rede de supermercados com objetivo de garantir a organização e qualidade dos produtos. Durante a avaliação, a especialista ressaltou a qualidade e consistência das taxonomias geradas e observou a possibilidade da realização de diversos grupos para esse mesmo domínio, o que é permitido pela metodologia.

Já na taxonomia da mercearia, é possível perceber que diversas representações taxonômicas podem existir e ser definidas para um mesmo domínio. Por exemplo, no caso das sobremesas congeladas, que poderiam ter sido agrupadas com algum outro tipo de doce ou sobremesa, porém nessa representação foi escolhido o grupo de congelados. 


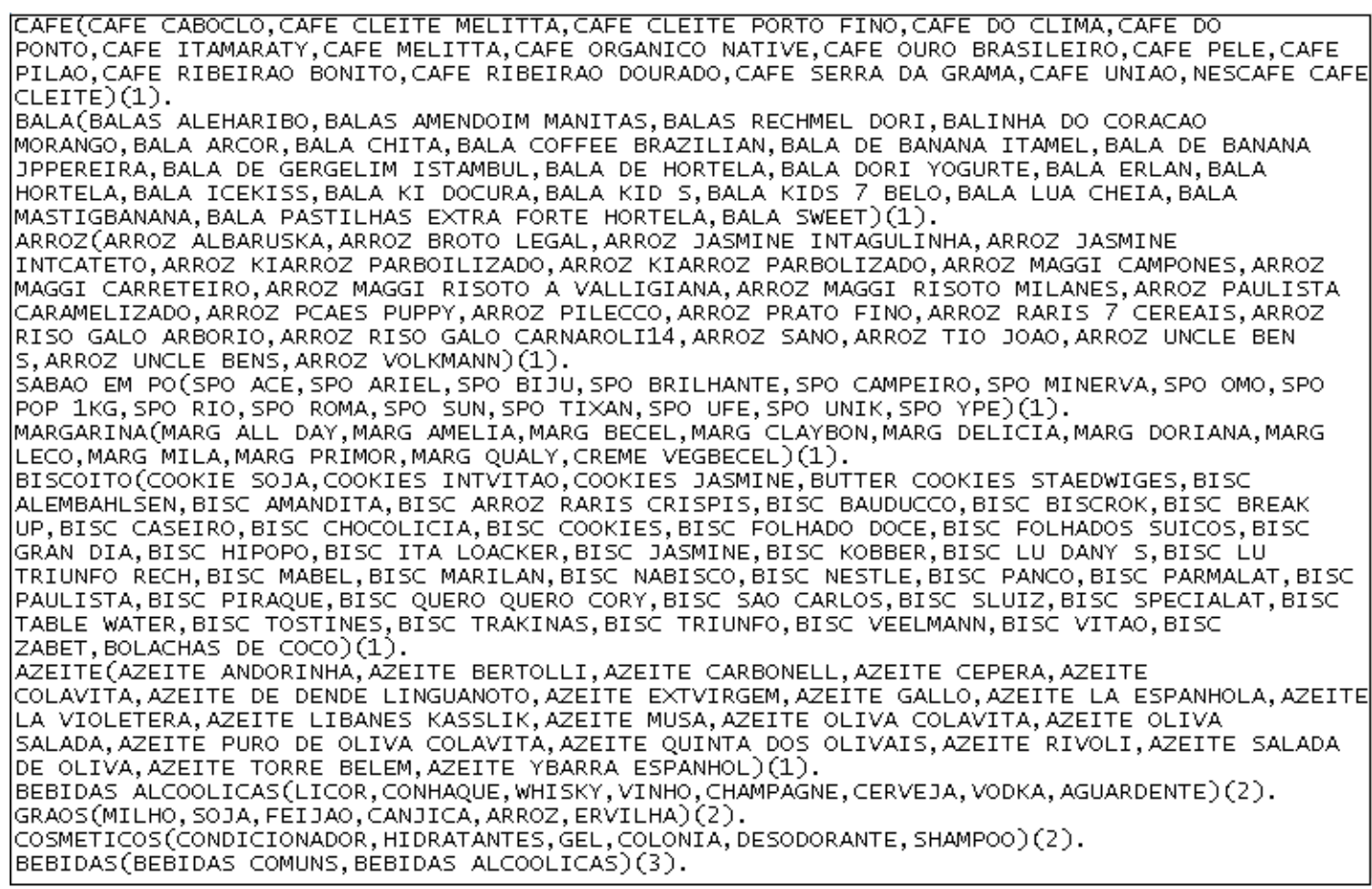

Figura 5.1: Parte da taxonomia gerada utilizando o módulo RULEE-SACT para a base de dados do supermercado

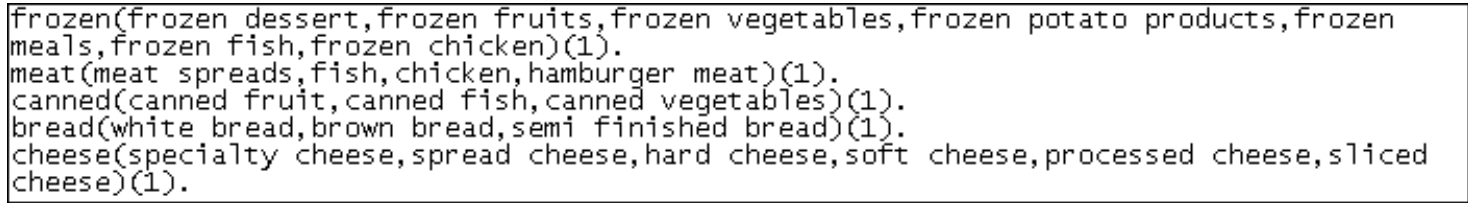

Figura 5.2: Parte da taxonomia gerada utilizando o módulo RULEE-SACT para a base de dados da mercearia

\subsection{Terceira Fase: Análise dos Resultados}

Após a construção das taxonomias utilizando o módulo RulEE-SACT, as mesmas foram utilizadas para gerar regras de associação generalizadas. Para isso, foram utilizados os algoritmos de generalização de regras de associação nas etapas de pré-processamento e de extração de padrões do processo de mineração de dados, desenvolvidos por Carvalho (2004) e descritos na Seção 3.2.3. Esses procedimentos e uma análise dos mesmos são detalhados a seguir.

No primeiro experimento foi utilizado o algoritmo de extração de padrões, para o qual foi necessário fornecer a base de transações e o arquivo de taxonomias. A única alteração necessária para colocar os arquivos no formato de entrada do algoritmo foi inserir o caractere "_" no lugar dos espaços entre as palavras.

Após a execução do algoritmo com as taxonomias apresentadas na Seção 5.2.2 e com valores de suporte e confiança iguais a 5\%, foram geradas 14413 regras das quais apenas 28 são específicas, ou seja, não possuem itens gerais. 
Analisando as regras geradas usando o Apriori normal (regras não generalizadas) e com o Apriori modificado (regras generalizadas), é possível observar um aumento do número de regras, que se deve à geração de regras com itens que estão nos níveis superiores da taxonomia. Nesse caso poderia ser utilizado um filtro (por exemplo, medidas objetivas) para selecionar as regras a serem apresentadas para um especialista. Um exemplo de regra com itens gerais é paes, produtos_de_limpeza, doces, bebidas $\Rightarrow$ papel_higienico, que indica que quem compra paes, produtos de limpeza, doces e bebidas também compra papel higienico. A regra apresenta os itens gerais de nível 2 paes, produtos_de_limpeza, doces, bebidas e o item geral de nível 1 papel_higienico.

Além disso, é possível notar a geração de regras com maior quantidade de itens, neste caso 5 itens para as regras generalizadas (geradas com o Apriori modificado) e 1 item para regras não generalizadas (geradas com o Apriori normal). Isso ocorre porque o valor do suporte dos itens gerais é maior do que o dos itens específicos e assim os itemsets por eles formados possuem suporte suficiente para gerar regras.

Vale ressaltar que os valores de suporte e confiança utilizados nesse experimento podem não ser interessantes quando são geradas apenas regras específicas, uma vez que o número de regras gerado é muito pequeno e todas elas possuem apenas um item.

O segundo experimento foi realizado com o algoritmo que utiliza taxonomias no préprocessamento. Para utilizar esse algoritmo, também foi necessário fornecer a base de transações e o arquivo de taxonomias. A única alteração necessária foi inserir o caractere "_" no lugar dos espaços entre as palavras, pois os arquivos já se encontravam no formato de entrada do algoritmo.

Após a execução do algoritmo com as taxonomias apresentadas na Seção 5.2.2 e com valores de suporte e confiança iguais a 0,5\%, foram geradas 3641 regras das quais 2170 são específicas, ou seja, não possuem itens gerais. O aumento do número de regras se deve ao aumento do suporte dos itens, que passaram a ser um grupo de diversos elementos. No caso desse experimento, poderia ser utilizado um filtro que selecione apenas as regras generalizadas. Dessa maneira restariam somente 1471 regras, o que representa uma redução de 699 regras (32\%) em relação ao total de regras específicas. Um exemplo de regra generalizada é: yogurt, rolls_buns, fruits, beverages_all $\Rightarrow$ vegetable, que indica que quem compra yogurt, rolls_buns, fruits e beverages_all também compra vegetable. A regra apresenta os itens gerais fruits e beverages_all.

É importante ressaltar que com a utilização de taxonomias para generalizar regras de associação nesse experimento também foi possível obter regras com itemsets de tamanho 5 (como a regra apresentada), ou seja, foi possível associar maior quantidade de itens. Como dito anteriormente, isso ocorre porque o valor do suporte dos itens gerais é maior do que o dos itens específicos. Ao utilizar o Apriori normal para gerar regras de associação, o número máximo de itens por regra foi 3.

Outra característica pode ser observada por meio do experimento com a base de dados 
da mercearia. Como seus itens já estavam distribuídos em 169 categorias, foi possível construir uma taxonomia com itens mais gerais. Isso porque foram gerados grupos de produtos com outras características semelhantes, além de sua descrição. Dessa maneira, nota-se que a metodologia pode ser aplicada em diversas bases de dados, mesmo quando as descrições de seus itens não representam o mesmo tipo de dado.

Por meio do estudo de caso realizado foi verificada a viabilidade da metodologia proposta. A utilização do módulo RulEE-SACT facilitou o processo de construção de taxonomias. As taxonomias foram geradas com maior rapidez em relação às construções manuais realizadas em experimentos anteriores. Além disso, a qualidade das mesmas foi validada por uma especialista do domínio.

Analisando as taxonomias geradas, é possível observar que a metodologia permite que o especialista guie sua construção a fim de gerar grupos que satisfaçam seus objetivos. A geração da taxonomia inicial fornece uma visão geral muito interessante dos itens do domínio, além de prover maior velocidade ao processo quando se deseja agrupar itens semelhantes. É importante ressaltar que o módulo RULEE-SACT também permite que diversas visões sejam representadas para um mesmo domínio, bastando para isso iniciar vários processos com o mesmo conjunto de dados e guiar o processo de acordo com a representação taxonômica desejada. Além disso, é possível notar que o módulo permite que novos grupos sejam facilmente construídos, por meio das funcionalidades desenvolvidas.

Com relação às regras generalizadas, foi possível constatar que são geradas regras com maior quantidade de itens e mais freqüentes no conjunto de dados. Essa característica disponibiliza regras que antes não apareciam e que podem ser interessantes, uma vez que relacionam maior quantidade de itens.

\subsection{Considerações Finais}

Nesse capítulo foi descrito o estudo de caso realizado com o objetivo de mostrar a viabilidade da metodologia proposta para construção semi-automática de taxonomias. Foram realizados experimentos com duas bases de dados diferentes. Inicialmente foi construída uma taxonomia para cada uma das bases de dados usando o módulo RuLEE-SACT e depois as taxonomias foram fornecidas para os algoritmos de generalização de regras de associação das etapas de pré-processamento (segundo experimento) e extração de padrões (primeiro experimento) desenvolvidos por Carvalho (2004). Durante a construção das taxonomias, foi possível notar o auxílio e a velocidade fornecidos pela metodologia em comparação com as construções manuais realizadas em outros experimentos. A taxonomia construída com a base de dados do supermercado foi avaliada e validada por uma especialista do domínio.

Como foram realizados experimentos com duas bases de dados, foi possível avaliar e 
validar a aplicação da metodologia proposta em bases de dados diferentes. Também foi possível perceber que a utilização de taxonomias para generalizar regras de associação nas etapas de pré-processamento e extração de padrões do processo de mineração de dados não proporcionou redução no volume de regras. Como dito anteriormente, isso ocorre devido à geração de regras com itens que estão nos níveis superiores da taxonomia. Dessa maneira, a redução do volume de regras ocorre especialmente na etapa de pós-processamento, na qual as regras com itens específicos são substituídas por regras com itens generalizados.

Por meio desse estudo de caso verificou-se que a metodologia proposta é viável e que a combinação de processos automáticos e interativos pode auxiliar na geração de taxonomias interessantes. Além disso, essas taxonomias podem ser aplicadas com sucesso na generalização de regras de associação. No próximo capítulo são apresentadas as conclusões deste trabalho e propostas para trabalhos futuros. 


$\overline{6}$

\section{Conclusões e Trabalhos Futuros}

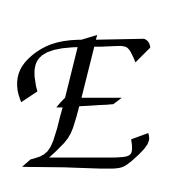

ste trabalho foi motivado pelo uso de taxonomias para generalizar regras de associação, que possibilita a geração de regras que utilizem itens contidos em qualquer nível na taxonomia, de regras que podem não ter suporte suficiente para serem geradas quando são específicas mas podem representar conhecimento interessante ao serem agrupadas e a melhora da compreensão das regras quando os itens são agrupados. Assim, inicialmente foi realizado um estudo em diversas bases de dados e sobre os conceitos de taxonomias, apresentados no Capítulo 3, com o objetivo de analisar a possibilidade de prover auxílio na construção de taxonomias. Nesse estudo foi verificado que uma combinação de métodos automáticos e interativos seria a melhor opção para obter taxonomias corretas e de boa qualidade. Além disso, foi possível concluir que uma metodologia semi-automática para construção de taxonomias seria de grande auxílio para os analistas do processo de mineração de dados.

Após a verificação da necessidade e da opção por um procedimento semi-automático, foi definida a hipótese que passou a guiar o desenvolvimento deste trabalho. Essa hipótese afirma que é possível construir taxonomias combinando métodos automáticos e interativos com o intuito de obter taxonomias novas, de boa qualidade e que possam ser utilizadas no processo de generalização de regras de associação. A hipótese também afirma que a construção semi-automática pode reduzir o tempo e a necessidade do conhecimento do especialista durante a identificação de taxonomias de um domínio, facilitando a realização dessa tarefa e a compreensão do conhecimento extraído.

Baseado na hipótese definida, foi especificada a metodologia para construção semiautomática de taxonomias, apresentada no Capítulo 4. Esta metodologia está dividida em três etapas. A primeira compreende a geração de um conjunto de itens freqüentes que devem ser analisados e selecionados pelo usuário. Na segunda é gerada a taxonomia 
inicial, baseada na comparação das descrições dos elementos do conjunto de dados com os itens freqüentes. Após a geração da taxonomia inicial, segue a etapa de exploração da taxonomia na qual é possível renomear, mover e excluir itens da taxonomia. Nesta etapa também pode-se selecionar e coordenar funcionalidades automáticas para gerar novos grupos. Uma delas realiza um reagrupamento de acordo com um atributo selecionado pelo usuário e a outra permite a criação de novos itens da taxonomia, baseada nas informações inseridas pelo usuário para os itens do nível mais alto da taxonomia.

Para viabilizar a utilização da metodologia proposta, foi desenvolvido o RuLEESACT, um módulo do ambiente RulEE para construção semi-automática de taxonomias, apresentado na Seção 4.3. Com o módulo, podem ser realizadas todas as etapas da metodologia e pode ser realizado o compartilhamento de conhecimento entre os usuários de um mesmo projeto do ambiente RulEE, por meio das opções de visualização disponíveis. Com o desenvolvimento desse módulo, foram atingidos o terceiro objetivo geral, o segundo e o quarto objetivos específicos deste trabalho, apresentados nas Seções 1.2 e Seções 1.3 respectivamente.

Com o objetivo de viabilizar e analisar a qualidade da metodologia proposta, foi realizado um estudo de caso, apresentado no Capítulo 5. Neste estudo de caso foi utilizado o módulo RULEE-SACT para construir as taxonomias e uma delas foi analisada e validada por um especialista do domínio. Após a construção das taxonomias, as mesmas foram fornecidas como entrada para algoritmos que generalizam regras de associação, visando avaliar as regras geradas. Com isso, foram atingidos o primeiro objetivo geral e o terceiro objetivo específico.

Por meio do estudo de caso realizado, foi possível concluir que a combinação de métodos automáticos e interativos proporcionados pela metodologia proposta provê rapidez ao processo de construção de taxonomias e a captação do conhecimento do especialista. A participação do especialista é importante para analisar e validar as taxonomias, além de fornecer as informações necessárias para guiar a construção das mesmas de acordo com os objetivos esperados, dos grupos e o nível de generalização desejados. Com isso foram atingidos o segundo objetivo geral e o primeiro objetivo específico deste trabalho.

Em relação à hipótese definida, além dos pontos já discutidos, é possível concluir que a utilização das taxonomias construídas para generalizar regras de associação mostra a aplicabilidade da metodologia à esse problema. Além disso, a boa qualidade de uma das taxonomias geradas foi validada por uma especialista do domínio.

Dessa maneira, todos os objetivos gerais e específicos deste trabalho foram atingidos e a hipótese foi validada.

As principais constribuições deste trabalho são:

- Proposta de uma metodologia para construção semi-automática de taxonomias para generalização de regras de associação, combinando procedimentos automáticos e in- 
terativos com o objetivo de facilitar a obtenção de taxonomias e captar o conhecimento do especialista.

- Desenvolvimento de um módulo para o ambiente RulEE, que viabiliza a construção das taxonomias e permite sua utilização por algoritmos de generalização de regras de associação.

A seguir são apresentadas algumas propostas para trabalhos futuros, que podem complementar o trabalho apresentado nesta dissertação e trazer contribuições para a construção semi-automática de taxonomias para generalização de regras de associação.

- Verificar a viabilidade da utilização de clustering para gerar novos grupos e criar novos itens da taxonomia.

- Incorporação de uma base de conhecimento de fundo, por meio da qual seria possível acessar informações sobre um domínio que auxiliariam na identificação de relacionamentos entre os itens e geração de taxonomias.

- Realização de mais experimentos utilizando a metodologia proposta, com bases de dados de domínios diferentes dos utilizados e com participação de outros especialistas. Esses experimentos devem ser realizados, principalmente, com a utilização das taxonomias para generalizar regras de associação na etapa de pós-processamento, para que seja analisada a redução do volume de regras.

- Implementação de técnicas de visualização no RuLEE-SACT, para auxiliar a avaliação das taxonomias, por exemplo, apresentando os grupos no formato de uma árvore.

- Realização de experimentos com regras de classificação, a fim de analisar a possibilidade de aplicar a metodologia proposta também para essa técnica de mineração de dados. 



\section{Referências Bibliográficas}

Adamo, J.-M. (2001). Data mining for association rules and sequential patterns: sequential and parallel algorithms (1 ed.). Springer-Verlag New York, Inc. 13, 20, 21, 22, 23, 35

Aggelis, V. (2004). Association rules model of e-banking services. In A. Zanasi, N. F. F. Ebecken, \& C. A. Brebbia (Eds.), Data Mining V, pp. 46-55. WIT Press. 5, 11

Agrawal, R., T. Imielinski, \& A. N. Swami (1993). Mining association rules between sets of items in large databases. In P. Buneman \& S. Jajodia (Eds.), Proceedings of the 1993 ACM SIGMOD International Conference on Management of Data, pp. 207-216. Disponível em: http://citeseer.nj.nec.com/agrawal93mining.html [12/04/2004]. 11, 12, $13,15,17$

Agrawal, R. \& R. Srikant (1994). Fast algorithms for mining association rules. In J. B. Bocca, M. Jarke, \& C. Zaniolo (Eds.), Proceedings of the 20th International Conference on Very Large Data Bases, VLDB'94, pp. 487-499. Disponível em: http://citeseer.nj.nec.com/agrawal94fast.html [12/04/2004]. 1, 12, 14, 15

Antonie, M. \& O. Zaane (2004). Mining positive and negative association rules: An approach for confined rules. Relatório Técnico TR04-07, Dept. of Computing Science, University of Alberta. Disponível em: citeseer.ist.psu.edu/antonie04mining.html [06/11/2004]. 5, 11

Baesens, B., S. Viaene, \& J. Vanthienen (2000). Post-processing of association rules. In Proceedings of the special workshop on post-processing, The Sixth ACM SIGKDD International Conference on Knowledge Discovery and Data Mining (KDD'2000), Boston, MA, USA, pp. 2-8. 11

Batista, G. E. A. P. A. (2003). Pré-processamento de dados em aprendizado de máquina supervisionado. Tese de Doutorado, Instituto de Ciências Matemáticas e de Computação - USP - São Carlos. 8, 29 
Batista, G. E. A. P. A., A. C. P. L. F. Carvalho, \& M. C. Monard (2000). Applying one-sided selection to unbalanced datasets. In Proceedings of the Mexican International Conference on Artificial Intelligence - MICAI'00, Lecture Notes in Artificial Intelligence, pp. 315-325. Springer-Verlag. 8

Beneditto, M. E. M. D. (2004). Descoberta de regras de classificação com hierarquias conceituais. Dissertação de Mestrado, Instituto de Matemática e Estatística - USP São Paulo. 19

Besemann, C., A. Denton, A. Yekkirala, R. Hutchison, \& M. Anderson (2004). Differential association rule mining for the study of protein-protein interaction networks. In Proceedings of 4 th Workshop on Data Mining in Bioinformatics in conjunction with The Tenth ACM SIGKDD International Conference on Knowledge Discovery and Data Mining, Seattle, WA, pp. 1-8. Disponível em: http://citeseer.ist.psu.edu/besemann04differential.html [06/11/2004]. 5, 11

Brin, S., R. Motwani, J. D. Ullman, \& S. Tsur (1997). Dynamic itemset counting and implication rules for market basket data. In J. Peckham (Ed.), Proceedings of the 1997 ACM SIGMOD International Conference on Management of Data, pp. 255-264. 15

Bruha, I. \& A. Famili (2000). Postprocessing in machine learning and data mining. ACM SIGKDD Explorations Newsletter 2(2), 110-114. Disponível em: http://portal.acm.org/citation.cfm?id=381059 [30/10/2004]. 9

Carvalho, V. O. (2004). Generalização no processo de mineração de regras de associação. Exame de Qualificação de Doutorado, Instituto de Ciências Matemáticas e de Computação - USP - São Carlos. 2, 17, 26, 32, 55, 65, 67

Carvalho, V. O., S. O. Rezende, \& M. de Castro (2006). Regras de associação generalizadas: Obtenção e avaliação. WAAMD 2006 Workshop em Algoritmos e Aplicações de Mineração de Dados, 1-8. 54

Chien, L.-F., C.-C. Huang, J.-W. Teng, \& S.-L. Chuang (2002). Automatic taxonomy generation for speech archives. In Proc. International Symposium on Chinese Spoken Language Processing ISCSLP'02, pp. 1-5. 26

Clementini, E., P. D. Felice, \& K. Koperski (2000). Mining multiple-level spatial association rules for objects with a broad boundary. Data 8 Knowledge Engineering 34 , 251-270. 11

Domingues, M. A. (2004). Generalização de regras de associação. Dissertação de Mestrado, Instituto de Ciências Matemáticas e de Computação - USP - São Carlos. 2, 17, 22, 26, $29,30,31,32,54,58$ 
Fayyad, U. M., G. Piatetsky-Shapiro, \& P. Smyth (1996). From data mining to knowledge discovery: An overview. In U. M. Fayyad, G. Piatetsky-Shapiro, P. Smyth, \& R. Uthurusamy (Eds.), Advances in Knowledge Discovery and Data Mining, Capítulo 1, pp. 1-34. AAAI Press. 6

Han, J. (1995). Mining knowledge at multiple concept levels. In Proceedings of the 4th International Conference on Information and Knowledge Management CIKM'95, pp. 19-24. 25

Han, J. \& Y. Fu (1995). Discovery of multiple-level association rules from large databases. In U. Dayal, P. M. D. Gray, \& S. Nishio (Eds.), Proceedings of 21th International Conference on Very Large Data Bases VLDB'95, pp. 420-431. Disponível em: http://citeseer.nj.nec.com/han95discovery.html [13/07/2004]. 25

Han, J. \& Y. Fu (1999). Mining multiple-level association rules in large databases. IEEE Transactions on Knowledge and Data Engineering 11(5), 798-805. 25

Han, J., J. Pei, \& Y. Yin (2000). Mining frequent patterns without candidate generation. In Proceedings of the 2000 ACM SIGMOD international conference on Management of data, pp. 1-12. ACM Press. 15

Hilderman, R. J. \& H. J. Hamilton (2001). Evaluation of interestingness measures for ranking discovered knowledge. In Proceedings of the 5th Pacific-Asia Conference on Knowledge Discovery and Data Mining PAKDD'01, pp. 247-259. 7

Hipp, J., U. Güntzer, \& G. Nakhaeizadeh (2002). Data mining of association rules and the process of knowledge discovery in databases. In Advances in Data Mining, Volume 2394 of Lecture Notes in Artificial Intelligence, pp. 15-36. Disponível em: http://citeseer.nj.nec.com/534971.html [12/04/2004]. 5, 11, 14, 15

Hipp, J., A. Myka, R. Wirth, \& U. Güntzer (1998). A new algorithm for faster mining of generalized association rules. In J. M. Zytkow \& M. Quafafou (Eds.), Proceedings of the 2nd European Symposium on Principles of Data Mining and Knowledge Discovery PKDD'98, pp. 74-82. Disponível em: http://citeseer.nj.nec.com/hipp98new.html [13/07/2004]. 25

Horrocks, I., D. Fensel, J. Broekstra, S. Decker, M. Erdmann, C. Goble, F. van Harmelen, M. Klein, S. Staab, R. Studer, \& E. Motta (2000). Oil: The ontology inference layer. Relatório Técnico IR-479, Vrije Universiteit Amsterdam, Faculty of Sciences. Disponível em: citeseer.ist.psu.edu/horrocks00ontology.html [20/11/2004]. 20

Houtsma, M. \& A. Swami (1995). Set-oriented mining for association rules in relational databases. In P. S. Yu \& A. L. P. Chen (Eds.), Proceedings of the 11th International Conference on Data Engineering, pp. 25-33. 15 
Imieliński, T. \& A. Virmani (1998). Association rules... and what's next? - towards second generation data mining systems. In W. Litwin, T. Morzy, \& G. Vossen (Eds.), Advances in Databases and Information Systems, Proceedings of the 2nd East European Symposium ADBIS'98, Volume 1475 of LNCS, pp. 6-25. 17

Jorge, A., J. Poças, \& P. Azevedo (2002). A post-processing environment for browsing large sets of association rules. In Proceedings of Second International Workshop on Integration and Collaboration Aspects of Data Mining, Decision Support and MetaLearning, pp. 53-64. 26

Kohavi, R., D. Sommerfield, \& J. Dougherty (1996). Data mining using $\mathcal{M L C + + : ~ A ~}$ machine learning library in $C++$. In Tools with Artificial Intelligence, pp. 234-245. IEEE Computer Society Press. 9

Kumar, R., P. Raghavan, S. Rajagopalan, \& A. Tomkins (2001). On semi-automated web taxonomy construction. Proceedings of the Fourth International Workshop on the Web and Databases. 26

Liu, B. \& W. Hsu (1996). Post-analysis of learned rules. In Proceedings of the 13th National Conference on Artificial Intelligence AAAI'96, pp. 828-834. 7

Liu, B., W. Hsu, S. Chen, \& Y. Ma (2000). Analyzing the subjective interestingness of association rules. IEEE Intelligent Systems \& their Applications 15(5), 47-55. 19, 22, 26

Ma, Y., B. Liu, \& C. K. Wong (2000). Web for data mining: Organizing and interpreting the discovered rules using the web. SIGKDD Explorations 2(1), 16-23. 26

Mannila, H. (1996). Data mining: Machine learning, statistics, and databases. In P. Svensson \& J. C. French (Eds.), Proceedings of the Eighth International Conference on Scientific and Statistical Database Management, Stockholm, Sweden, pp. 1-8. IEEE Computer Society. 6

Martins, C. D. \& S. O. Rezende (2006a). Construção semi-automática de taxonomias para generalização de regras de associação. WTDIA 2006 - Workshop de Teses e Dissertações em Inteligência Artificial, 1-10. 35

Martins, C. D. \& S. O. Rezende (2006b). Descrição do módulo computacional RulEESACT. Relatório Técnico em desenvolvimento, Instituto de Ciências Matemáticas e de Computação - USP - São Carlos. 42, 44, 45

Melanda, E. A. (2004). Pós-processamento de Regras de Associação. Tese de Doutorado, Instituto de Ciências Matemáticas e de Computação - USP - São Carlos. 17, 29 
Melanda, E. A. \& S. O. Rezende (2003). Sintaxe padrão para representar regras de associação. Relatório Técnico 206, Instituto de Ciências Matemáticas e de Computação - USP - São Carlos. 29, 32

Oliveira, S., O. Zaane, \& Y. Saygin (2004). Secure association rule sharing. In H. Dai, R. Srikant, \& C. Zhang (Eds.), Advances in Knowledge Discovery and Data Mining, 8th Pacific-Asia Conference, PAKDD'04, Volume 3056 of Lecture Notes in Artificial Intelligence, pp. 74-85. 5, 11

Padmanabhan, B. \& A. Tuzhilin (2000). Small is beautiful: Discovering the minimal set of unexpected patterns. In Proceedings of the International Conference in Knowledge Discover and Data Mining (KDD-00), pp. 54-63. 1

Park, J. S., M.-S. Chen, \& P. S. Yu (1997). Using a hash-based method with transaction trimming for mining association rules. IEEE Transactions on Knowledge and Data Engineering 9(5), 813-825. 15

Paula, M. F. (2003). Ambiente para exploração de regras. Dissertação de Mestrado, Instituto de Ciências Matemáticas e de Computação - USP - São Carlos. 2, 17, 26, 27, 81

Pazzani, M. J. (2000). Knowledge discovery from data? IEEE Intelligent Systems 15(2), 10-13. 1

Pei, J., J. Han, \& R. Mao (2000). CLOSET: An efficient algorithm for mining frequent closed itemsets. In D. Gunopulos \& R. Rastogi (Eds.), Proceedings of ACM SIGMOD Workshop on Research Issues in Data Mining and Knowledge Discovery, pp. 21-30. Disponível em: http://citeseer.nj.nec.com/pei00closet.html [12/04/2004]. 15

Piatetsky-Shapiro, G. \& C. J. Matheus (1994). The interestingness of deviations. In Proceedings of the Knowledge Discovery in Databases KDD'94, pp. 23-36. Disponível em: http://citeseer.nj.nec.com/piatetsky-shapiro94interestingness.html [20/03/2003]. 7

Prati, R. C. (2003). O framework de integração do sistema Discover. Dissertação de Mestrado, Instituto de Ciências Matemáticas e de Computação - USP - São Carlos. 29

Prati, R. C., J. A. Baranauskas, \& M. C. Monard (2001). Extração de informações padronizadas para a avaliação de regras induzidas por algoritmos de aprendizado de máquina simbólico. Relatório Técnico 145, Instituto de Ciências Matemáticas e de Computação - USP - São Carlos. 29

Pugliesi, J. B., D. G. Dosualdo, \& S. O. Rezende (2003). Sintaxe padrão para representar regras de regressão no Discover. Relatório Técnico 193, Instituto de Ciências Matemáticas e de Computação - USP - São Carlos. Disponível em: ftp://ftp.icmc.usp.br/pub/BIBLIOTECA/rel_tec/RT_193.zip [28/01/2004]. 29 
Rezende, S. O., J. B. Pugliesi, E. A. Melanda, \& M. F. Paula (2003). Mineração de dados. In S. O. Rezende (Ed.), Sistemas Inteligentes: Fundamentos e Aplicações (1 ed.)., Capítulo 12, pp. 307-335. Manole. 1, 6, 7

Semenova, T., M. Hegland, W. Graco, \& G. Williams (2001). Effectiveness of mining association rules for identifying trends in large health databases. In F. J. Kurfess \& M. Hilario (Eds.), Workshop on Integrating Data Mining and Knowledge Management, The 2001 IEEE International Conference on Data Mining - ICDM'01, San Jose, California, USA. Disponível em: http://cui.unige.ch/ hilario/icdm-01/DM-KMFinal/Semenova.pdf [22/10/2004]. 11

Sinoara, R. A. (2006). Identificação de regras de associação interessantes por meio de análises com medidas objetivas e subjetivas. Dissertação de Mestrado, Instituto de Ciências Matemáticas e de Computação - USP - São Carlos. 29

Srikant, R. (2001). Association rules: Past, present and future. ICCS 2001 International Workshop on Concept Lattice-based theory, methods and tools for Knowledge Discovery in Databases. Invited Talk. Disponível em: http://www.almaden.ibm.com/cs/people/srikant/talks/assoc.pdf [19/09/2003]. 22

Srikant, R. \& R. Agrawal (1995). Mining generalized association rules. In Proceedings of the 21th International Conference on Very Large Data Bases VLDB'95, pp. 407-419. 25

Srikant, R. \& R. Agrawal (1997). Mining generalized association rules. Future Generation Computer Systems 13(2/3), 161-180. 21, 23, 25

Wang, K., L. Tang, J. Han, \& J. Liu (2002). Top down fp-growth for association rule mining. In Proceedings of the 6th Pacific-Asia Conference on Advances in Knowledge Discovery and Data Mining, pp. 334-340. Springer-Verlag. 15

Webb, G. I. (1995). OPUS: An efficient admissible algorithm for unordered search. Journal of Artificial Intelligence Research 3, 431-465. Disponível em: http://citeseer.nj.nec.com/35589.html [12/04/2004]. 15

Weber, I. (1998). On pruning strategies for discovery of generalized and quantitative association rules. In I. L. Bing, W. Hsu, \& W. Ke (Eds.), Proceedings Knowledge Discovery and Data Mining Workshop Pricai'98. 8 pp. Disponível em: http://citeseer.nj.nec.com/25197.html [13/07/2004]. 25

Weiss, S. M. \& N. Indurkhya (1998). Predictive Data Mining: A Pratical Guide. Morgan Kaufmann Publishers Inc. 8

Zaki, M. \& C. Hsiao (2002). Charm: An efficient algorithm for closed itemset mining. In R. Grossman, J. Han, V. Kumar, H. Mannila, \& R. Motwani (Eds.), 2nd SIAM International Conference on Data Mining. 15 
Zeng, Z., R. Kohavi, \& L. Manson (2001). Real world performance of association rule algorithms. In Proceedings of the Seventh ACM SIGKDD International Conference on Knowledge Discovery and Data Mining, San Francisco, California, pp. 401-406. 15

Zhang, C. \& S. Zhang (2002). Association Rule Mining: Models and Algorithms, Volume 2307 of Lecture Notes in Artificial Intelligence. Springer. 16

Zheng, Z., R. Kohavi, \& L. Mason (2001). Real world performance of association rule algorithms. In F. Provost \& R. Srikant (Eds.), Proceedings of the 7th ACM SIGKDD International Conference on Knowledge Discovery and Data Mining, pp. 401-406. ACM Press. Disponível em: http://doi.acm.org/10.1145/502512.502572 [12/04/2004]. 9 



\section{Documento de Requisitos do RulEE-SACT}

\section{A.1 Introdução}

O propósito deste documento é apresentar os requisitos do módulo de de construção semi-automática de taxonomias do ambiente RulEE, denominado RulEE-SACT. O objetivo principal desse módulo é apoiar os usuários na construção de taxonomias corretas e interessantes para a generalização de regras de associação.

Assim, este documento está dividido em três seções. Na Seção A.1 é apresentada uma breve introdução sobre o conteúdo deste documento. Uma descrição geral do RuLEESACT é apresentada na Seção A.2 e na Seção A.3 são descritos os seus requisitos específicos.

\section{A.1.1 Escopo}

O RulEE-SACT, módulo de construção semi-automática de taxonomias do ambiente RulEE, possibilita a identificação de taxonomias interessantes para a generalização de regras de associação combinando métodos automáticos e interativos. A participação do especialista é muito importante para guiar o processo de acordo com os seus objetivos e os agrupamentos desejados e também para validar as taxonomias geradas.

Antes de iniciar o processo de construção semi-automática de taxonomias nesse módulo, um arquivo texto com as informações sobre o domínio em questão no formato de uma tabela deve ser inserido.

A partir da descrição dos elementos do domínio contida no arquivo fornecido pelo usuário, o RULEE-SACT gera um conjunto de itens freqüentes contando as palavras e- 
xistentes nas descrições dos registros. Esses itens freqüentes corresponderão, inicialmente, à generalização máxima e cada um deles receberá como filhos os elementos que possuirem em sua descrição o nome do próprio item freqüente. Assim é obtida a taxonomia inicial, que poderá ser explorada e modificada pelo usuário. Também é possível selecionar e coordenar outras funcionalidades para gerar novos agrupamentos. Uma delas corresponde a um reagrupamento de acordo com um atributo selecionado pelo usuário (proveniente do arquivo texto fornecido). Para isso, é realizada uma comparação entre o valor desse atributo para os itens folha (especialização máxima) selecionados e uma redistribuição dos mesmos na taxonomia. A outra funcionalidade permite que o usuário insira uma nova informação para itens da taxonomia que sejam generalização máxima a fim de agrupar os que possuam os mesmos valores para a informação e, assim, criar novos itens da taxonomia que a partir desse momento corresponderão à generalização máxima.

Após a construção da taxonomia, um arquivo no formato padrão do RuLEE-SACT pode ser obtido a fim de que a mesma seja utilizada em algoritmos de generalização de regras de associação. Uma taxonomia construída no módulo RuLEE-SACT fica disponível para os outros usuários do mesmo projeto, que não terão permissão para modificá-la mas poderão visualizar todas as informações e obter o arquivo com a taxonomia gerada. Somente o usuário que criou o processo de construção de taxonomias tem permissão para modificar a taxonomia correspondente ao mesmo.

\section{A.1.2 Definições, Acrônimos e Abreviações do Documento de Requisitos}

Algumas definições, acrônimos e abreviações de termos que devem ser considerados no módulo de construção semi-automática de taxonomias para generalização de regras de associação são:

Itens freqüentes conjunto de itens que representam as palavras que ocorrem com freqüência nas descrições dos itens da base de dados (arquivo fornecido pelo usuário).

Item da base de dados um elemento do conjunto de dados.

Generalização máxima ascendente máximo da taxonomia. Corresponde aos itens que estão no topo da taxonomia.

Especialização máxima último descendente da taxonomia. Corresponde aos itens folhas da taxonomia.

Nível representa uma generalização/especialização, sendo que o nível mais alto é a generalização máxima e o nível mais baixo é a especialização máxima.

Processo de construção semi-automática de taxonomias compreende as etapas de construção semi-automática de taxonomias. 
Projeto conjuntos de informações de um mesmo domínio ou com objetivos em comum. Cada projeto pode ter mais de um usuário cadastrado.

RulEE Rule Exploration Environment. Ambiente para exploração e disponibilização de regras de classificação, regressão e associação (Paula, 2003).

\section{A.2 Descrição Geral do RulEE-SACT}

O objetivo do módulo RulEE-SACT é auxiliar a construção de taxonomias para serem utilizadas no processo de generalização de regras de associação. O módulo realiza essa tarefa de maneira semi-automática, utilizando o conhecimento que o especialista tem sobre o domínio. Para isso, o usuário seleciona opções que auxiliam na geração dos agrupamentos.

\section{A.2.1 Funções do Módulo}

Para atingir seu objetivo de auxiliar a identificação de taxonomias corretas e interessantes, o RulEE-SACT deve possuir as seguintes funções:

- Validação dos itens freqüentes de um domínio, considerando a contagem automática e posterior seleção realizada pelo especialista;

- Distribuição dos elementos do domínio entre os itens freqüentes, criando-se a taxonomia inicial;

- Visualização e exploração (excluir, alterar ou mover) das taxonomias encontradas;

- Agrupamento ou redistribuição dos itens de acordo com algum atributo selecionado pelo especialista;

- Inserção de novos atributos identificados durante a exploração, que poderão ser utilizados para posterior criação de novos itens da taxonomia.

\section{A.2.2 Características dos Usuários}

Os usuários do módulo de construção semi-automática de taxonomias para generalização de regras de associação são os usuários do ambiente RulEE, que são classificados em:

Administrador usuário responsável pelo RulEE, capaz de realizar todas as funções do ambiente; 
Analista usuário especialista no processo de mineração de dados e responsável por sua execução;

Especialista do domínio usuário que possui amplo conhecimento do domínio da aplicação e fornece apoio para a execução do processo de mineração de dados;

Usuário final usuário que utiliza o conhecimento extraído na mineração de dados para auxiliá-lo em um processo de tomada de decisão.

Como o módulo não possui funcionalidade administrativa, todas as funcionalidades podem ser realizadas por qualquer um dos usuários do RulEE.

\section{A.2.3 Suposições e Dependências}

Para iniciar ou continuar um processo de construção semi-automática de taxonomias, o usuário deve selecionar o projeto do ambiente RulEE com o qual este está relacionado.

\section{A.3 Requisitos Específicos}

A seguir são descritos os requisitos funcionais e de desempenho do módulo RuLEESACT.

\section{A.3.1 Requisitos Funcionais}

Os requisitos funcionais do RulEE-SACT estão organizados de acordo com as funções do módulo, apresentadas na Seção A.2.

1. Requisitos para criação, manipulação e finalização de um processo de construção semi-automática de taxonomias

(a) O módulo deve permitir que qualquer usuário crie um novo processo de construção semi-automática de taxonomias vinculado a um projeto que ele é membro.

(b) No momento da criação de um novo processo de construção semi-automática de taxonomias, o módulo deve apresentar ao usuário as bases de dados do projeto selecionado que ele poderá utilizar no processo que está sendo criado.

(c) O módulo deve solicitar os seguintes dados para a criação de um novo processo de construção semi-automática de taxonomias: código do usuário, código do projeto, nome do processo, tabela com informações sobre um domínio e se o processo pode ficar visível a outros usuários do mesmo projeto. 
(d) O módulo deve armazenar para cada processo de construção semi-automática de taxonomias os dados solicitados, além do código do processo, que deve servir para identificar unicamente cada processo.

(e) O módulo deve permitir que um usuário dê continuidade a um processo que ele tenha iniciado anteriormente, sendo identificado por seu código.

(f) Caso o usuário queira dar continuidade a um processo de exploração iniciado anteriormente, o módulo deve verificar as etapas já realizadas e permitir a realização somente daquelas que não prejudiquem a consistência da taxonomia.

\section{Requisitos para a construção semi-automática de taxonomias}

(a) O módulo deve gerar automaticamente um conjunto de itens freqüentes do domínio que está sendo explorado.

(b) O módulo deve permitir que o usuário selecione quais itens freqüentes deverão ser considerados na exploração.

(c) O módulo deve distribuir automaticamente os itens da base de dados entre os itens definidos como freqüentes construindo, dessa maneira, os níveis iniciais da taxonomia.

(d) O módulo deve apresentar todos os atributos existentes na base de dados em ordem alfabética e permitir que o usuário selecione um ou mais para ser explorado. Para cada atributo selecionado, o módulo deve apresentar a opção de redistribuição.

(e) Caso o usuário selecione a opção "redistribuição", o módulo deve redistribuir os itens entre os itens da taxonomia de acordo com o atributo selecionado pelo usuário.

(f) O módulo deve permitir que o usuário insira novos atributos para serem utilizados posteriormente para criar novos itens da taxonomia.

(g) Caso o usuário selecione a opção "criar novo item da taxonomia", o módulo deve agrupar os itens com o mesmo valor para o atributo selecionado pelo usuário.

\section{Requisitos para a distribuição de itens na taxonomia}

(a) O módulo deve comparar automaticamente as três primeiras palavras de um item da base de dados com os itens freqüentes e defini-lo como filho daquele item freqüente mais a posição que corresponder a alguma dessas palavras do item da base de dados.

(b) O módulo deve definir que o nome do item freqüente mais sua posição na descrição da palavra é filho do item freqüente.

(c) O módulo deve dar prioridade à igualdade da primeira palavra do item e depois à segunda ao definir qual item freqüente será seu pai. 
(d) O módulo não deve permitir que um item da taxonomia tenha mais de um pai.

\section{Requisitos para visualização das taxonomias construídas}

(a) O módulo deve permitir que usuários de um mesmo projeto visualizem as construções das taxonomias daquele projeto, desde que essas explorações estejam visíveis a todos os membros do projeto.

(b) O módulo deve permitir que um usuário visualize e manipule todas os processos que ele criou.

(c) O módulo deve apresentar ao usuário os itens freqüentes em ordem de freqüência.

(d) O módulo deve apresentar as taxonomias num formato facilmente compreensível e de acordo com as especificações do conceito.

(e) O módulo deve permitir que o usuário exclua, mova ou altere os itens dentro da taxonomia. A exclusão não deverá ser realizada caso o item possua filhos.

(f) O módulo deve permitir que o usuário obtenha a taxonomia gerada em um processo no formato de um arquivo texto.

\section{Requisitos para a redistribuição de itens de acordo com um atributo}

(a) O módulo deve permitir que o usuário selecione o atributo que deve ser comparado e os itens que deseja redistribuir.

(b) Para cada item selecionado, o módulo deve contar a quantidade de itens correspondentes ao mesmo agrupamento com o mesmo valor para o atributo selecionado.

(c) Para cada item selecionado, o módulo deve buscar todos os itens da taxonomia que possuem o mesmo valor para o atributo selecionado. Depois, deve verificar em qual agrupamento está a maior quantidade de itens que possuem o mesmo valor para o atributo selecionado.

(d) O módulo deve realocar cada item selecionado no agrupamento que possui a maior quantidade de itens com o mesmo valor que o seu para o atributo selecionado.

\section{Requisitos para a criação de novo item da taxonomia}

(a) O módulo deve permitir que o usuário insira um atributo com diferentes valores para os itens da taxonomia.

(b) Quando um atributo e seu respectivo valor é definido para determinado item, todos os descendentes desse item deverão receber o mesmo valor para esse atributo. 
(c) O módulo deve listar os atributos criados pelo usuário, com seus respectivos valores, e permitir que ele selecione o atributo com o qual deseja realizar agrupamentos.

(d) O módulo deve criar um novo agrupamento para cada valor do atributo selecionado. O nome do agrupamento criado será o valor do atributo e nele deverão estar os itens que possuem o mesmo valor para o atributo selecionado.

\section{A.3.2 Requisitos de Desempenho}

O requisitos de desempenho do módulo RulEE-SACT são os mesmos requisitos determinados para o ambiente RulEE.

\section{A.4 Consideraçõs Finais}

Com base nesses requisitos foi implementado o módulo RuLEE-SACT, que viabiliza a utilização do algoritmo $S A C T$ para realizar a construção semi-automática de taxonomias. O módulo está disponível na Web, por meio do ambiente RulEE, e pode ser acessado por qualquer usuário do mesmo. 